\title{
THE 2007 CAPL Operating Procedure
}

\author{
CRAIG SPURN, JANA PRETE, \\ AND MELISSA ZEREBESKI*
}

This article provides an introduction and overview of the 2007 Canadian Association of Petroleum Landmen Operating Procedure and a detailed analysis of certain key provisions and changes made.

The article notes that the 2007 Procedure is responsive to significant developments in the Canadian oil and gas industry and constitutes a major update of the Procedure, including in its emphasis on a "normbased" approach rather than a "standard form" approach and articulating the need for, and cost of, deviating from the provisions of the model form.
Cet article se veut une introduction et un aperçu de la procédure opérationnelle 2007 de la Canadian Association of Petroleum Landmen ainsi qu'une analyse détaillée de certaines dispositions clés et changements effectués.

L'article fait remarquer que la procédure de 2007 réagit aux développements importants qui ont eu lieu dans le secteur gazier et pétrolier canadien et représente une importante mise à jour de la procédure, incluant l'emphase sur une approche «basée sur une norme» au lieu de l'approche du «formulaire standard» et en exprime le besoin et le coût de s'écarter du formulaire type.

\section{TABLE OF CONTENTS}

I. INTRODUCTION . . . . . . . . . . . . . . . . . . . . 429

II. APPOINTMENT AND REPLACEMENT OF OPERATOR . . . . . . . . . . . . . 431

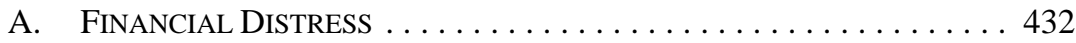

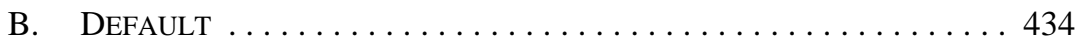

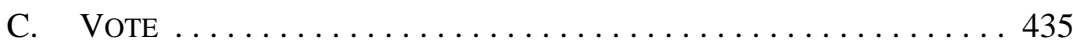

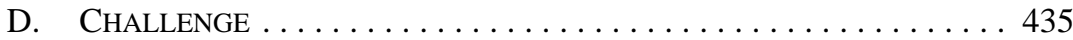

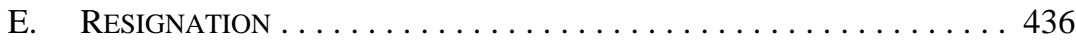

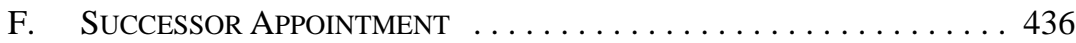

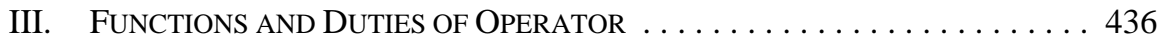

A. Delegation of Authority . . . . . . . . . . . . . . 437

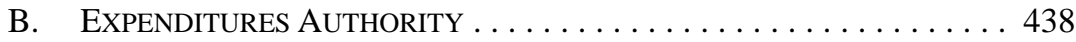

C. StANDARD OF CARE $\ldots \ldots \ldots \ldots \ldots \ldots \ldots \ldots \ldots \ldots \ldots \ldots \ldots \ldots$

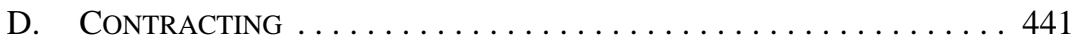

E. Health, Safety, And The Environment Compliance . . . . . 442

F. MiscellaneOus SPECIFIC Duties $\ldots \ldots \ldots \ldots \ldots \ldots \ldots \ldots$

IV. LIABILITY AND INDEMNIFICATION OBLIGATIONS . . . . . . . . . . . . . 444

A. 2007 Liability AND IndEMNificAtion Provisions . . . . . . . . . . 444

B. OPERATOR LIABILITY AND INDUSTRY EXPECTATIONS . . . . . . . . . 447

C. OPERATOR LIABILITY UNDER THE 1981

AND 1990 PROCEDURES . . . . . . . . . . . . . . . . . 448

D. UNDERSTANDING THE LEGAL LIMITS OF
OPERATOR LIABILITY $\ldots \ldots \ldots \ldots \ldots \ldots \ldots \ldots \ldots \ldots \ldots \ldots \ldots \ldots \ldots \ldots \ldots$

Blake, Cassels \& Graydon LLP, Calgary. The authors gratefully acknowledge the assistance and contributions of their colleagues Taryn Motter, Carol Hales, Kevin Kerr, and Abram Averbach in the preparation of this article and the guidance provided by Jim MacLean, Chairman of the 2007 CAPL Operating Procedure Committee. The views and positions taken herein are the authors' alone and do not represent the views and positions of Blake, Cassels \& Graydon LLP or Jim MacLean. 
V. JOINT COSTS AND EXPENSES $\ldots \ldots \ldots \ldots \ldots \ldots \ldots \ldots \ldots \ldots . \ldots \ldots 42$

A. OPERATOR TO PAY AND RECOVER . . . . . . . . . . . . 453

B. MONTHLy AdVANCES Of AFE AMOUNTS . . . . . . . . . . . 453

C. SECURITY FOR PAYMENT . . . . . . . . . . . . . . . . . . . . . . . . 454

D. OPERATOR's LiEN AND DEFAULT REMEDIES . . . . . . . . . . . . . . 454

E. CommingLing Of Funds $\ldots \ldots \ldots \ldots \ldots \ldots \ldots \ldots \ldots \ldots 47$

VI. OWNERSHIP AND DISPOSITION OF PRODUCTION . . . . . . . . . . . . . . . 457

A. Obligation to TAKe In Kind . . . . . . . . . . . . . . . . . . 457

B. OPTIONS FOR THE DiSPOSAL OF A

NON-TAKING PARTY's PRODUCTION . . . . . . . . . . . . . . . . . . . 458

C. MARKET PRICE ........................ 459

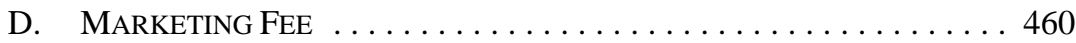

E. PAYMENTS . . . . . . . . . . . . . . . . . . . . . . . . 461

VII. OPERATOR's DUTIES IN CONDUCTING JOINT OPERATIONS . . . . . . . . . 461

VIII. HORIZONTAL WELLS $\ldots \ldots \ldots \ldots \ldots \ldots \ldots \ldots \ldots \ldots \ldots \ldots \ldots \ldots$

IX. CAsing Point Election $\ldots \ldots \ldots \ldots \ldots \ldots \ldots \ldots \ldots \ldots \ldots \ldots \ldots$

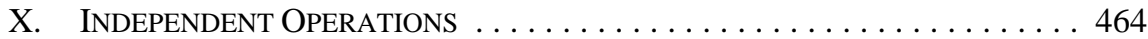

A. OPERATION Notice . . . . . . . . . . . . . . . . 465

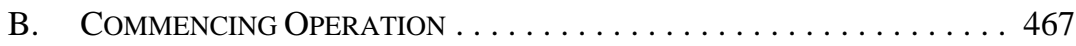

C. OPERATOR FOR INDEPENDENT OPERATION . . . . . . . . . . . . . . 467

D. Divided WELL STATUS . . . . . . . . . . . . . . . . . 468

E. WELLS SERVING JOINT LANDS AND OTHER LANDS . . . . . . . . . 468

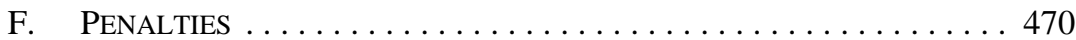

G. EXISTING WELLS . . . . . . . . . . . . . . . . . . . . . . . 471

H. Title Preserving Wells AND Forfeiture $\ldots \ldots \ldots \ldots \ldots \ldots . .472$

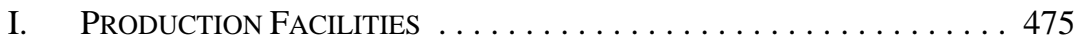

J. MisCELlANEOUS . . . . . . . . . . . . . . . . . . . . . . . 477

XI. SURRENDER OF JOINT LANDS . . . . . . . . . . . . . . . . . . . . . 477

XII. ABANDONMENT OF JoINT WELLS . . . . . . . . . . . . . . . . . 478

XIII. OPERATION OF SEgREgAted INTERESTS . . . . . . . . . . . . . . . . . . . 479

XIV. OPERATION OF JOINT PRODUCTION FACILITIES . . . . . . . . . . . . . . . . 480

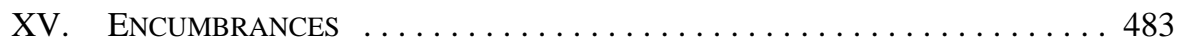

XVI. FORCE MAJEURE . . . . . . . . . . . . . . . . . . . . . . . . . . . 484

XVII. INCENTIVES . . . . . . . . . . . . . . . . . . . . . . . . . . . . . 484

XVIII. CONFIDENTIALITY AND USE OF INFORMATION . . . . . . . . . . . . 485

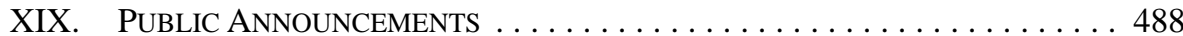

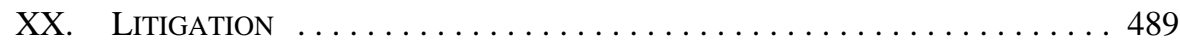

XXI. DisPUte RESOlUtion $\ldots \ldots \ldots \ldots \ldots \ldots \ldots \ldots \ldots \ldots \ldots \ldots \ldots \ldots$

XXII. NOTICE ................................ 490

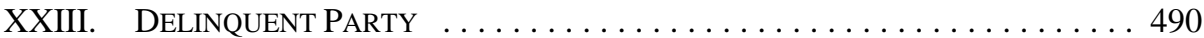

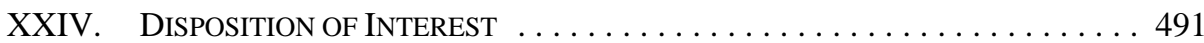

A. Treatment of Earning AgreEments . . . . . . . . . . 491

B. Consent Provisions - Subclause 24.01A . . . . . . . . . 493

C. Right OF First RefuSAL — SubClAuse 24.01B . . . . . . . . . . . 493

D. TIME LIMIT ON RIGHT OF FIRST REFUSAL -

PARAGRAPH 24.01B(A) . . . . . . . . . . . . . . . . . . . . . . . . . . 494

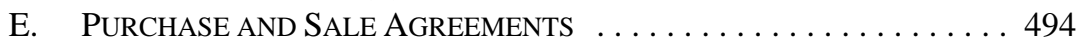


F. NON-CASH CONSIDERATION -

PARAGRAPH $24.01 B(C) \ldots \ldots \ldots \ldots \ldots \ldots \ldots \ldots \ldots \ldots$

G. VALUE OF Right OF FiRST REFUSAL -

PARAGRAPH 24.01B(D) . . . . . . . . . . . . . . . . . . . 495

H. VALUE OF Right OF FiRST REFUSAL -

PARAGRAPH $24.01 B(E) \ldots \ldots \ldots \ldots \ldots \ldots \ldots \ldots \ldots$

I. Right OF FiRST REFUSAL EXCEPTIONS TO BE BONA FidE . . . . . . . 496

J. AfFILIATE EXCEPTION — PARAGRAPH 24.02(B) . . . . . . . . . . 497

K. All or Substantially All ExCEPTION

— PARAGRAPH $24.02(\mathrm{C}) \ldots \ldots \ldots \ldots \ldots \ldots \ldots \ldots$

L. TOTAL NET HectARE EXCEPTION

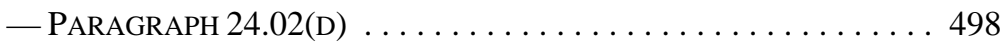

M. EARNing AgREEMENT HECTARE EXCEPTION

— PARAGRAPH 24.02(E) . . . . . . . . . . . . . . . . . . . . . 498

N. OPTIONAL EXCEPTION — EARNING AgREEMENTS

— PARAGRAPH $24.02(\mathrm{~F}) \ldots \ldots \ldots \ldots \ldots \ldots \ldots \ldots$

O. NOTICE OF EXCEPTION . . . . . . . . . . . . . . . . . . . . . . . 499

P. INCORPORATION OF CANADIAN ASSOCIATION OF PETROLEUM

LANDMEN AssignMENT PROCEDURE — Clause $24.04 \ldots \ldots$. . . . 499

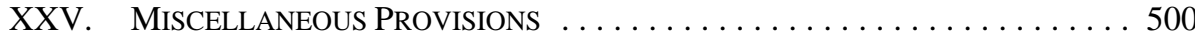

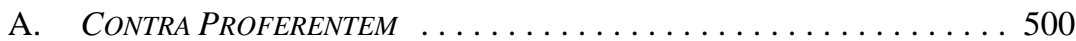

B. NO PARTNERSHIP OR FIDUCIARY RELATIONSHIP . . . . . . . . 500

C. Governing LAW . . . . . . . . . . . . . . . . . . . . . . . . . . . . . 501

D. EXTENSION OF Alberta Limitations ACT . . . . . . . . . . . 501

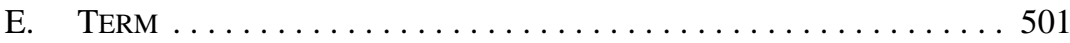

F. Modifications to Canadian Association of Petroleum

LANDMEN DOCUMENT FORM . . . . . . . . . . . . . . . . . . . . 501

G. ENUREMENT ........................ 502

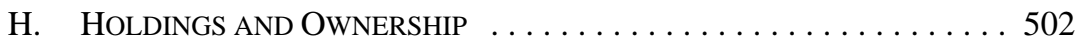

I. CONFLICT OF INTEREST $\ldots \ldots \ldots \ldots \ldots$. . . . . . . . . . . . . . . 502

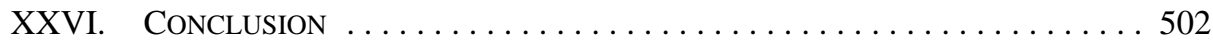

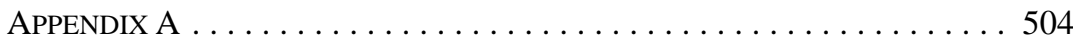

\section{INTRODUCTION}

The Canadian Association of Petroleum Landmen (CAPL) model form Operating Procedure (the Procedure) in its various versions has been an integral part of Canada's oil and gas industry for almost 40 years. Based on earlier operating agreement forms originally developed in the United States and modified for Canadian operations, the Procedure was first introduced in 1969. Subsequent versions were developed and issued in 1971, 1974, ${ }^{1} 1981,{ }^{2}$

1974 CAPL Operating Procedure (Calgary: Canadian Association of Petroleum Landmen, 1974) [1974 Procedure].

21981 CAPL Operating Procedure (Calgary: Canadian Association of Petroleum Landmen, 1981) [1981 Procedure]. 
$1990,{ }^{3}$ and most recently in $2007 .{ }^{4}$ Each version contains drafting and organizational improvements from the previous one and each has reflected and responded to legal, regulatory, commercial, and operational developments impacting the oil and gas industry in the Western Canadian Sedimentary Basin (WCSB).

The Canadian oil and gas industry has evolved significantly in the 17 years since the 1990 Procedure was approved by the CAPL. Since 1990, we have seen the benchmark West Texas Intermediate crude oil price range from a low of less than US\$11 per barrel to almost US $\$ 140$ per barrel, ${ }^{5}$ the development of a liquid energy commodities market, the maturation of conventional operations and opportunities in the WCSB, and a corresponding explosion of interest in unconventional oil and gas projects, new technologies, and innovations. The 2007 Procedure is responsive to such developments and is a significant update of the Procedure. Among other things, the drafting committee (the Drafting Committee) responsible for the 2007 Procedure emphasized a "norm-based" approach rather than a "standard form" approach articulating the occasional need for, and cost of, deviating from the provisions of the model form. Accordingly, as is the case with earlier versions of the Procedure, in some cases the 2007 Procedure will be utilized in its model form, while in other cases, users will want to modify it to address the unique aspects of the applicable project and the specific expectations of the participants.

This article attempts to provide an introduction and overview of the 2007 Procedure. Given the size and scope of the 2007 Procedure, it is not possible to provide an exhaustive review of each provision. In fact, a number of the provisions could be and have been the subject matter of one or more articles on their own. Accordingly, while the authors have provided an overview of the 2007 Procedure, they have only provided a detailed analysis of certain key provisions and changes made. Although the authors considered alternative formats, they organized their analysis based upon the layout of the 2007 Procedure primarily to assist in ease of reference, but also in recognition that the provisions of the 2007 Procedure overlap each other in multiple ways and in multiple places, and in many cases, there is no obvious way of arbitrarily allocating certain provisions to certain topic discussions to the exclusion or detriment of other discussions.

There are a number of other resources available in respect of the 2007 Procedure. The annotation to the 2007 Procedure $^{6}$ prepared by the Drafting Committee provides helpful commentary regarding various provisions, the purpose of such provisions, how they have been judicially interpreted, how they have changed over time, and in some cases, how they might be customized. In addition, there are a number of insightful articles published in

3

1990 CAPL Operating Procedure (Calgary: Canadian Association of Petroleum Landmen, 1990) [1990 Procedure].

4 Canadian Association of Petroleum Landmen(CAPL), 2007 CAPL Operating Procedure, online: CAPL $<$ http://www.landman.ca/pdf/operating_procedures/2007/final/2007\%20Operating\%20Procedure\%2 0Text\%20(Final\%20Annotated\%20Version\%202008).pdf> [2007 Procedure].

5 U.S., Energy Information Administration, "Weekly United States Spot Price FOB Weighted by Estimated Import Volume (Dollars per Barrel),” online: Energy Information Administration: Official Energy Statistics from the U.S. Government <http://tonto.eia.doe.gov/dnav/pet/hist/wtotusaw.htm>. Canadian Association of Petroleum Landmen, "2007 CAPL Operating Procedure, Annotations," online: CAPL <http://www.landman.ca/pdf/operating_procedures/2007/final/2007\%20Operating\%20 Procedure\%20Annotations\%20(Final2008).pdf $>$ [Annotations]. 
respect of different versions of the Procedure $;^{7}$ in particular, the authors recommend the series of articles prepared by Jim MacLean and published in The Negotiator ${ }^{8}$ in respect of earlier drafts and the final version of the 2007 Procedure and to which they have made repeated reference herein.

In this article, unless otherwise defined herein, capitalized terms have the meaning given to them in the 2007 Procedure. In addition, the authors sometimes refer to the 1996 Petroleum Accountants Society of Canada (PASC) Accounting Procedure ${ }^{9}$ developed by the PASC. The PASC is currently in its own process to develop a 2007 PASC Accounting Procedure, the most recent draft of which was circulated to industry in October $2007 .{ }^{10}$ The scope of this article does not allow for anything more than cursory references to the Accounting Procedure. However, the Drafting Committee cautions lawyers, landmen, negotiators, administrators, and other users of the 2007 Procedure that the Accounting Procedure is an integral and vital element of it, and the rights and obligations created thereby, and as such, should be carefully considered in negotiating, interpreting, and utilizing the 2007 Procedure and related Head Agreement.

\section{APPOINTMENT AND REPLACEMENT OF OPERATOR}

As discussed in Part III, the Operator is responsible for carrying out Operations pursuant to the Procedure as the representative of the Parties. The Operator has various degrees of control over, among other things, the pace of exploration and development, the flow of information, the manner in which field Operations are carried out, and in some cases, the gathering, processing, transportation, and sale of Petroleum Substances and the collection and distribution of revenues therefrom. Accordingly, the role of the Operator is critical and who will serve as Operator can be a contentious issue among the Working Interest owners. Factors such as Working Interests changing hands over time, the evolving nature of Operations, and the emergence of new plays on the Joint Lands, along with the backdrop of historical performance or underperformance, can contribute to tensions among Working Interest owners and lead to operatorship battles. While the Procedure has evolved such that it is now clear that the Operator carries out its duties on behalf of all Parties and not on its own behalf and that such appointment is not intended to convey any superior rights to the Party serving as the Operator, the reality is that the Operator largely controls Joint Operations, and as such, is often a coveted role.

7 See e.g. Mungo Hardwicke-Brown, “Confidentiality and Dispositions in the Oil and Gas Industry” (1997) 35 Alta. L. Rev. 356; Michael D. Josephson, "How Far Does the CAPL Travel? A Comparative Overview of the CAPL Model Form Operating Procedure and the AIPN Model Form International Operating Agreement” (2003) 41 Alta. L. Rev. 1; James A. MacLean, “The 1990 CAPL Operating Procedure: An Overview of the Revisions” (1992) 30 Alta. L. Rev. 133 [MacLean, “1990 CAPL”].

8 See The Negotiator, online: CAPL < http://www.landman.ca/publications/Negotiator/negotiator_archive. php> for the series of articles by Jim MacLean in The Negotiator on the CAPL Operating Procedure, beginning in the December 2005 issue.

91996 PASC Accounting Procedure (Calgary: Petroleum Accountants Society of Canada, 1996) [Accounting Procedure].

10 Petroleum Accountants Society of Canada (PASC), Bulletin, XX, "2007 Accounting Procedure Annotated” (22 October 2007), online: PASC < http://www.petroleumaccountants.com/resource/library/ 2007/drafts/2007FinalDraftAccountingProcedure.pdf $>$. 
Article 2.00 of the Procedure addresses the appointment and replacement of the Operator. The initial Operator is appointed by the Parties pursuant to the Head Agreement and can subsequently be replaced pursuant to the voluntary resignation by the Operator or the removal of the Operator due to financial distress, default, vote, or challenge.

\section{A. FinANCIAL Distress}

Subclause 2.02A lists the circumstances when the Operator can immediately be replaced, subject to a court's jurisdiction to override this provision as discussed below:

(a) the Operator becomes bankrupt or insolvent, commits or suffers any act of bankruptcy or insolvency, is placed in receivership or seeks debtor relief protection under applicable legislation (including the Bankruptcy and Insolvency Act (Canada) and the Companies'Creditors Arrangement Act (Canada)), and it will be deemed to be insolvent for this purpose if it is unable to pay its debts as they fall due in the usual course of business or if it does not have sufficient assets to satisfy its cumulative liabilities in full;

(b) a third party holding security over the Operator's Working Interest enforces that security;

(c) the Operator initiates shareholder or legal proceedings for its dissolution, liquidation or winding-up in circumstances in which its Working Interest is not being assigned to an Affiliate;

(d) a final judgment or order of a court is entered or rendered against the Operator's Working Interest and it remains unsatisfied for the lesser of a 30 day period or such other period as would permit that Working Interest to be sold thereunder;

(e) the Operator is in default under the Regulations or the Title Documents and: (i) the default may cause cancellation of any Title Document; (ii) the default has continued for at least one-half of the period allowed thereunder for its remedy; and (iii) the Operator is not then diligently attempting to remedy it;

(f) the Operator (or its managing partner or one of its partners if the Operator is a registered partnership or an Affiliate if the Operator is a trust) is not eligible to hold a licence or approval required under the Regulations for a well or other Joint Property; or

(g) the Operator assigns or attempts to assign its general powers and responsibilities of supervision and management as Operator hereunder, except for an assignment to an Affiliate under Clause 2.09, provided that neither of the following will be a breach of this Paragraph:

(i) a pending appointment of a new Operator under Clause 2.06 due to the Operator's disposition of a Working Interest that is not yet binding on the other Parties; or 
(ii) a contract operating agreement or a farmout or other similar agreement under which a Party, an Affiliate of a Party or a third party conducts certain specific activities as the Operator's designate. $^{11}$

Items (b) to (f) are additions to the 2007 Procedure. If an Operator is removed pursuant to subclause 2.02A, the Party with the largest Working Interest (excluding the outgoing Operator) shall serve as interim Operator until a new Operator is appointed pursuant to cl. 2.06 .

New to the 2007 Procedure is an acknowledgment in subclause 2.02A made by all Parties, including the Operator, that "the Operator's ability to fulfill its duties and obligations for the Parties' benefit is largely dependent on its ongoing financial viability and that the Operator may not seek relief at law, in equity or under the Regulations to prevent its replacement in accordance with this Subclause.”12 This addition attempts to establish three things:

(1) the purpose of the provision;

(2) an agreement that the Operator serves in such capacity for the Parties' benefit (and not its own); and

(3) an agreement that the Operator will not seek relief to prevent its replacement pursuant to this provision.

This addition is a continuation of the efforts made by the Drafting Committee of the 1990 Procedure to improve the likelihood that a court will not use its jurisdiction under s. 11 of the Companies' Creditors Arrangement $A c t^{13}$ to grant a stay of a Non-Operator's right to remove an insolvent Operator under CCAA protection and

reflects the view that insolvency will often have a significant negative impact on the Operator's ability to manage the joint property for the benefit of the working interest owners. This is due to such factors as distraction of the Operator's operational focus, the real risk of high employee turnover, the potential sacrifice of project value for near term operating performance and procurement issues with potential suppliers. ${ }^{14}$

This change addresses the judicial treatment given to an earlier version of this provision by the courts. Although the 1990 version of subclause 2.02A has not been considered, the 1981 version has been considered. Subparagraph 202(a)(i) of the 1981 Procedure provides that the Operator shall be replaced immediately and a new operator appointed "[i]f the Operator becomes bankrupt or insolvent or commits or suffers any act of bankruptcy or insolvency, or makes any assignment for the benefit of creditors, or causes any judgment to be registered against its participating interest." 15 This provision was first considered in Tri-

R.S.C. 1985 , c. C-36 [CCAA].

Jim MacLean, "2006 CAPL Operating Procedure: Balancing the Needs of Operators and NonOperators," The Negotiator (February 2006) 10 at 12, online: CAPL <http://www.landman.ca/ publications/Negotiator/2006/february/2006_february.pdf> [MacLean, “February 2006 CAPL”].

15

2007 Procedure, supra note 4, subclause 2.02A. Supra note 2 at para. 202(a)(I). 
Star Resources Ltd. v. J.C. International Petroleum Ltd. ${ }^{16}$ In that case, Tri-Star Resources Ltd. was seeking to be declared operator pursuant to $\mathrm{cl}$. 202 of the 1981 Procedure due to the insolvency of the operator and related proceedings under the Bankruptcy Act ${ }^{17}$ as it then existed. In its decision, the Court of Queen's Bench gave effect to the plain meaning of cl. 202, granted the motion, and issued the requested declaration.

The Alberta Court of Queen's Bench decision in Norcen Energy Resources Ltd. v. Oakwood Petroleums Ltd. ${ }^{18}$ also considered cl. 202 of the 1981 Procedure, but in circumstances of an insolvent Operator under the protection of a stay order issued pursuant to s. 11 of the CCAA. Norcen was not a creditor but a party to the operating agreement and made a motion to enforce the 1981 Procedure's provisions for immediate replacement of Oakwood Petroleums Ltd. (Oakwood) as Operator due to its insolvency. The Court did not grant Norcen's motion. The Court gave a broad interpretation to s. 11 of the CCAA with a view to achieving its legislative purposes and held that it had the authority thereunder to affect rights between the parties by staying the provisions of cl. 202 of the 1981 Procedure. Tri-Star was distinguished on the basis that the stay power under the Bankruptcy Act, 1970 was limited to a stay of claims provable in bankruptcy while s. 11 of the CCAA supported a broader interpretation of the relations that can be interfered with under that Act. The case was not appealed, although this may simply be because the Oakwood CCAA process was nearing its conclusion in any event.

\section{B. DEFAULT}

Paragraphs 2.02B(b) and (c) of the 2007 Procedure contemplate the replacement of the Operator where:

(b) the Operator defaults in performance of any of its duties or obligations hereunder (other than as contemplated in Paragraph 2.02A(e)) and does not begin to remedy diligently that default within 30 days after receiving a bona fide notice from Parties holding a majority of the Working Interests (excluding those of the Operator and any of its Affiliates that are Parties), specifying the default in sufficient detail to enable the Operator to understand its nature and requiring the Operator to remedy it, provided that the Operator will be replaced immediately by an interim Operator under Subclause $2.06 \mathrm{D}$ if those duties or obligations must be fulfilled sooner to protect life, property or the environment; or

(c) it receives a bona fide notice from Parties holding a majority of the Working Interests (excluding those of the Operator and any of its Affiliates that are Parties) that it has failed to remedy diligently a default it began to remedy under Paragraph 2.02B(b) and the basis for that determination in reasonable detail. ${ }^{19}$

While default provisions remain largely the same as those used in the 1990 Procedure, it is now expressly required that notices be bona fide and provide sufficient detail to allow the 
Operator to understand the nature of the default. Parties negotiating an operating agreement that incorporates the 2007 Procedure may wish to consider customizing this provision by abridging the time period allotted for the Operator to commence remedying a default for certain breaches. For example, Non-Operators may want to insist on a shorter cure period where the Operator is only liable for a breach constituting Gross Negligence or Wilful Misconduct (cl. 3.04, subclause 3.05A, and subclause 3.10A), or where the consequences of such breach could have significant negative consequences and ultimately threaten the safety or protection of life, property, or the environment (cl. 3.05), but falls short of grounds for immediate removal of the Operator pursuant to the provision in para. 2.02B(b). In the latter case, the Parties may wish to modify para. 2.02B(b) to defer to an earlier date to commence a remedy and an outside date for completion of the remedy under para. 2.02B(c), if, for example, called for under a Health, Safety And The Environment (HSE) audit or incident report, provided that the proviso for immediate replacement of Operator is preserved for breach of duties involving emergent circumstances requiring immediate steps to protect life, property, or the environment.

\section{Vote}

Pursuant to para. 2.02B(a) of the 2007 Procedure, two or more Parties holding at least 60 percent (as compared to more than 50 percent in the 1990 Procedure $^{20}$ ) of the Working Interests can vote to remove and replace the Operator. A single Party holding at least a 60 percent (as compared to more than 66 percent in the 1990 Procedure) ${ }^{21}$ Working Interest, who is not in default or otherwise not disentitled from becoming an Operator, may on notice, replace the Operator. This voting mechanism is the simplest and most effective means of replacing the Operator should the circumstances allow it. However, it has been noted that, given the costs and disruption inherent in changing Operators at critical junctures, the provision should not be used lightly and may be an effective check and balance on the Operator's conduct without having to be resorted to. ${ }^{22}$

\section{Challenge}

Provided the Operator has already served for a continuous period of two years, cl. 2.03 allows a Non-Operator to issue a challenge notice to the Parties containing the terms by which it would be prepared to assume operatorship, which must be more favourable than the terms under which the Operator is currently operating. If a Party does issue a challenge notice, the Operator must elect within 60 days to accept the notice and continue to operate in accordance with the terms of the challenge notice or decline to operate, and the Party issuing the notice shall be obligated to assume operatorship in accordance with the terms it proposed. The 2007 Procedure reduces the Operator's resignation period from 90 days to 45 days if it is not prepared to operate on the conditions set out in the challenge notice.

Unfortunately, from the Non-Operator's perspective, this provision is of limited value, as evidenced by the infrequent usage it receives in practice. This is likely because the basis of

Supra note 3 at subclause 202(b)(i).

Ibid.

Annotations, supra note 6 at 9-10. 
a challenge is practically limited to reducing stipulated overhead rates and amounts set out in the Accounting Procedure, turning on standing wells, and other simple criteria that could easily be met by the current Operator, particularly given that qualitative measures of operatorship are such that they cannot easily be quantifiable and are difficult to commit to. In addition, the access of Non-Operators to the Independent Operations provisions and the ability to remove an Operator by vote are both effective provisions in the right circumstances and may also explain the relative lack of usage of this provision historically.

\section{E. RESIGNATION}

An Operator who wishes to resign from its role as Operator does so pursuant to cl. 2.04. The minimum notice period has been reduced from 90 days in the 1990 Procedure $^{23}$ to 45 days in the 2007 Procedure. As most resignations occur in the context of a disposition, this new notice period is more consistent with the timing of the 1993 CAPL Assignment Procedure. $^{24}$

\section{F. SUCCESSOR APPOINTMENT}

Clause 2.06 contains the process to appoint a new Operator where the old Operator has resigned or was removed (other than by way of challenge notice), and the latest revisions are a significant step forward in ensuring the replacement and succession process is clearly understood in the 2007 Procedure. The successor Operator will be appointed upon the affirmative vote of at least two Parties that are not Affiliates and collectively hold greater than 50 percent of the Working Interest. ${ }^{25}$ The outgoing Operator is eligible to vote and may vote its Working Interest in favour of its proposed assignee, even though that assignee is not yet recognized as a Party for that Working Interest. ${ }^{26}$ A Party that holds at least a 60 percent Working Interest may, by notice to the Parties, become the Operator. This threshold has been lowered from the 1990 Procedure's threshold of more than 66 percent. ${ }^{27}$ In addition, the two Party scenario has also been modified in the 2007 Procedure. If there are only two Parties, the Non-Operator may, by notice, become the Operator; however, if the appointment is because of the Operator's disposition of its Working Interest, the Non-Operator must have at least a 40 percent Working Interest to assert such a right. ${ }^{28}$ If, notwithstanding the foregoing provisions, a successor Operator has not immediately been appointed, the Party (excluding the outgoing Operator) with the largest percentage Working Interest will act as interim Operator until a successor Operator is appointed.

\section{FUNCTIONS AND DUTIES OF OPERATOR}

Article 3.00 addresses the following: (1) the general delegation of authority to the Operator; (2) the specific authority of the Operator to make expenditures for the Joint

$23 \quad$ Supra note 3, cl. 204.

24 Assignment Procedure (Calgary: Canadian Association of Petroleum Landmen, 1993).

252007 Procedure, supra note 4, subclause 2.06C.

26 Ibid. at para. 2.06C(b).

$27 \quad$ Supra note 3 at para. 206(a).

28 Supra note 4, subclause 2.06C. 
Account; (3) the standard of care expected of the Operator; and (4) certain specific duties of the Operator.

\title{
A. Delegation of Authority
}

The Procedure has seen an important evolution in the delegation of authority and description of the role of the Operator. Earlier versions of subclause 3.01A of the Procedure granted the Operator “exclusive control and management” of Joint Operations. Concerns that "this provision literally tended to equate the position of operator with a greater form of ownership" led to its tempering in the 1981 Procedure by "eliminating the reference to 'exclusive control' and by adding a general duty to consult."29 The Drafting Committee for the 1990 Procedure further reworked the provision to emphasize the duties associated with the delegation of authority to the Operator and this approach was continued in the 2007 Procedure.

Subclause 3.01A of the 2007 Procedure provides:

\begin{abstract}
The Operator will consult with the Parties periodically about the exploration, development and operation of the Joint Lands, the construction, installation and operation of any Production Facility and management of the Joint Property. It will keep them informed in a timely manner about Joint Operations planned or conducted by it. Subject to this Agreement, the Parties delegate to the Operator, on their behalf, management of the exploration, development and operation of the Joint Lands and management of the other Joint Property. However, the Operator does not have any obligation to initiate or optimize the exploration and development of the Joint Lands, except insofar as this Agreement includes specific obligations to the contrary. $^{30}$
\end{abstract}

This provision makes it clear that the delegation of authority to the Operator in the 2007 Procedure is:

(1) subject to a duty to consult with the Parties;

(2) subject to a duty to keep the Parties informed in a timely manner;

(3) subject to all other terms of the Procedure and Head Agreement; and

(4) made on the basis that such management function is performed on behalf of the Parties.

The imposition of duties and parameters on the delegation of authority to the Operator is understandable given the absence of an operating committee by which Non-Operators could participate in the supervision and direction of Joint Operations. As noted in the Annotations, the incorporation of an operating committee is not feasible in the circumstances in which the Procedure is typically used. ${ }^{31}$ Generally in the WCSB, industry customs and conventions, the 
number of parties, efficiency requirements, scale of operations, profitability margins, and other factors will mitigate the need or desire for an operating committee and the processes and inefficiencies that are inherent in their operation. Although in some circumstances involving large-scale operations, it may be appropriate to provide for an effective operating committee to provide decision-making, supervision, and direction.

Pursuant to subclause 3.03A, the Operator is deemed an independent contractor with respect to its activities under the Agreement. Notwithstanding this designation, in the 2007 Procedure, the Operator's status as an independent contractor is expressly stated to not alter its responsibility for liability and indemnification which is governed by art. $4.00,{ }^{32}$ to ensure that this status will not result in the imposition of a standard of negligence against the Operator, other than the contemplated Gross Negligence or Wilful Misconduct standard.

\section{B. EXPENDITURES AUTHORITY}

Absent an AFE, subclause 3.01B gives the Operator the authority to make expenditures on behalf of the Joint Account, provided the total amount or bona fide estimated cost does not exceed the applicable expenditure threshold prescribed by the Accounting Procedure or CDN\$50,000 if the Accounting Procedure does not prescribe any such amount. There are two exceptions to this limitation:

(a) [if] an emergency exists (or is imminent) and the expenditure is then required: (i) for safety or the protection of life or property; or (ii) to prevent or mitigate pollution or other Environmental Liabilities; or

(b) the expenditure is required by the Regulations ... where failure to make that expenditure at that time could result in prosecution of the Operator or the imposition of enforcement actions, penalties or any other material adverse formal consequence on the Operator under the Regulations. ${ }^{33}$

Subclause 3.01C expressly provides that the approval by a Party of an AFE constitutes its approval of all expenditures by the Operator necessary to conduct the Operation described therein provided. However, the Operator shall promptly notify the Non-Operators if such expenditure will exceed the AFE amount by the greater of $\$ 50,000$ or 10 percent, explain why such over-expenditure occurred, and provide a new estimate in respect thereof. This provision has evolved over time with the different versions of the Procedure. Whether or not the Non-Operator is liable for cost overruns on AFEs is largely dependent on which version of the Procedure governs the subject operation as discussed below.

Clause 301 of the 1974 Procedure provides:

The Operator shall not make an expenditure for any single undertaking the total estimated cost of which is in excess of Ten Thousand Dollars $(\$ 10,000)$ without a written authority for expenditure from JointOperators, unless the expenditure is considered by Operator to be necessary by reason of an event

Supra note 4, subclause 3.03A.

Ibid., subclause 3.01B. 
endangering life or property. Particulars of each such event shall be reported promptly to the JointOperators. $^{34}$

In Renaissance Resources Ltd. v. Metalore Resources Ltd., ${ }^{35}$ the Alberta Court of Queen's Bench considered this provision in the 1974 Procedure and held that " $[\mathrm{t}] \mathrm{he}$ AFE is a written manifestation of consent to participate in an undertaking. Once consent is given the joint operator becomes liable for its share of the total costs of that undertaking." 36 The defendants claimed that this interpretation was unreasonable because any estimate given would result in them paying the cost overrun, regardless of the lack of care that might have been involved in its preparation. To address this criticism, the Court stated that under the proper circumstances the joint operator could allege negligence in the preparation of the AFE or carrying out the work under the AFE as a defence for not paying the cost overrun. ${ }^{37}$ However, these defences were not included in the pleadings and therefore not considered.

The relevant portion of cl. 301 of the 1981 Procedure is:

if the Operator while conducting any single operation for the joint account, which operation is covered by a written Authority for Expenditure, incurs or expects to incur expenditures for the joint account in excess of the total amount authorized in writing by the Joint-Operators for that operation plus ten (10\%) percent thereof, the Operator shall forthwith so advise the Joint-Operators and submit for their approval a written supplementary authority for such excess expenditures. ${ }^{38}$

In a 1994 Court of Queen’s Bench decision, Novalta Resources Ltd. v. Ortynsky Exploration Ltd., ${ }^{39}$ the Court's interpretation of the 1981 Procedure provided an exception for AFEs involving exploration and drilling. As a result, the requirement for a supplemental AFE for cost overruns above the 10-percent threshold was limited in its application. The Court concluded that cl. 301 excluded drilling and completion operations from the Operator's duty to forthwith notify the joint operators and submit a supplemental AFE. The Court found that this was consistent with industry practice as operators were not known to stop drilling or completion activities to wait for supplemental AFEs to be signed. ${ }^{40}$

A different interpretation was taken in the more recent decisions of Morrison Petroleums Ltd. v. Phoenix Canada Oil Co. ${ }^{41}$ and Powermax Energy Inc. v. Argonauts Group Ltd. ${ }^{42}$ These cases are the current authority in Alberta relating to the interpretation of cl. 301 of the 1981 Procedure. The Alberta Court of Queen's Bench held that parties were only liable for up to 10 percent over the estimate provided on the AFE unless they expressly authorized the additional expenditures in supplemental AFEs. The Court concluded that the wording used in the 1981 Procedure created a contractual obligation on an operator to issue supplemental

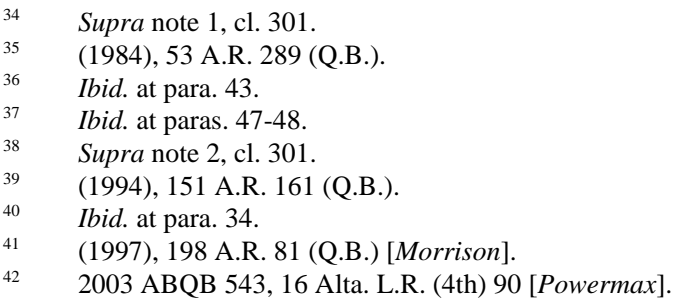


AFEs to joint operators for cost overruns of operations that exceeded the original estimate by more than 10 percent. ${ }^{43}$ The liability for the cost overruns were attributed to the party who had incurred the additional cost by their own volition and without any approval, either express or implied, from the joint operator. ${ }^{44}$

The relevant portion of cl. 301 of the 1990 Procedure is:

\begin{abstract}
Approval of an Authority for Expenditure by a party shall constitute that party's approval of all expenditures necessary to conduct the operation described therein, subject to the provisions of Article IX. However, if the Operator incurs or expects to incur expenditures with respect to a joint operation which would exceed by more than ten percent (10\%) the total amount estimated in the AFE therefor, the Operator thereupon shall, for informational purposes only, forthwith advise the Joint-Operators of such overexpenditure, the Operator's explanation therefor and the Operator's revised estimate of the cost of such operation. The Operator thereafter shall provide estimates of current and cumulative costs incurred for the joint account with respect to such operation. Such estimates shall be provided on a daily basis where practical, but in any event at intervals of not greater than ten (10) days until the operation is completed. ${ }^{45}$
\end{abstract}

\title{
Subclause 3.01C of the 2007 Procedure states:
}

A Party's approval of an AFE constitutes its approval of all expenditures necessary to conduct the Operation described therein, subject to the limitations on charges prescribed by the Accounting Procedure and Articles 8.00 and 9.00 for Horizontal Wells and a Casing Point election respectively. However, the Operator will, for informational purposes only, promptly notify the Non-Operators if it incurs or expects to incur expenditures for a Joint Operation that exceed the total amount estimated in the applicable AFE by more than the greater of $\$ 50,000$ or $10 \%$. It will include in that notice its explanation for that overexpenditure and its revised cost estimate for that Joint Operation. If that Joint Operation relates to a well, the Operator will then provide estimates of current and cumulative costs incurred therefor on a daily basis where practicable and weekly estimates of forecast costs until that Joint Operation is completed. ${ }^{46}$

While there has been no judicial consideration of liability for cost overruns under these later Procedures, it is clear that the wording of the 1990 Procedure and 2007 Procedure are substantially different from the wording in the 1981 Procedure. Even though the Court was not dealing with the 1990 Procedure in Morrison, the defendants raised the argument that the marked changes in the wording of the 1990 Procedure indicated that under the 1981 Procedure, an operator was required to obtain authorization prior to incurring expenditures in excess of the AFE estimate. ${ }^{47}$ The Court commented on the difference between the two versions:

It will be seen that Clause 301(c) in CAPL 1990, unlike CAPL 1981, contains an express statement that an AFE constituted the approval of the parties to all expenditures necessary to conduct the drilling operations, including any cost overruns. The operator, although still required to provide advice to the joint operators of

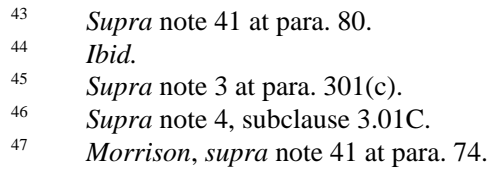


any over-expenditures, does so only for "informational purposes.” In addition the operator is no longer required to submit a written supplementary authority for cost overruns nor is the operator required any longer to obtain approval for such authority. It is clear therefore that the language of Clause 301(c) of CAPL 1990 is fundamentally different from the language employed in paragraph three of Clause 301 of CAPL $1981 .{ }^{48}$

Therefore, absent evidence of bad faith or gross negligence or wilful misconduct on the part of the Operator, under both the 1990 Procedure and the 2007 Procedure, parties should be liable for their pro rata share of cost overruns even if they substantially exceed the AFE estimate, provided that the Operation conducted is within the scope of the original approval.

\section{STANDARD OF CARE}

Clause 3.04 contains the Operator's standard of care and states:

The Operator will manage all Joint Property and conduct all Joint Operations diligently, in a good and workmanlike manner, in compliance with the Title Documents and the Regulations and in accordance with good oilfield practice, including prudent reservoir management and conservation principles. Insofar as the Operator hires contractors hereunder, it will supervise them as is reasonable. Notwithstanding the preceding portion of this Clause, a breach of the obligations contained in this Clause will not result in any form of liability (whether in tort, contract or otherwise) of the Operator to the Parties, except insofar as the conduct to which the breach pertains constitutes Gross Negligence or Wilful Misconduct for which the Operator is solely responsible under Article 4.00. ${ }^{49}$

The words “including prudent reservoir management and conservation principles” are new to the 2007 Procedure. The Annotations explain the perceived need for such additional wording to protect against an Operator using its position to its advantage and inconsistent with good oilfield practices. The example referenced in the Annotations is of an Operator that uses its position to reduce production volumes below productive capacity to produce higher interest equity wells in competitive drainage situations. ${ }^{50}$

Given the exculpation of any liability of Operator for any breach of this provision that does not constitute Gross Negligence or Wilful Misconduct, the effect of this provision is somewhat limited. However, in the authors' view, such limitations on an Operator's liability are consistent with the historical expectations of most industry participants. A more fulsome discussion of the liability and indemnification of an Operator are contained in Part IV of this article.

\section{Contracting}

Subclause 3.03B was added to the 2007 Procedure to expressly address an Operator's general duty to award goods and services supply contracts in accordance with good contracting practices in the oil and gas industry. It also provides certain commercially reasonable exceptions, including awarding contracts pursuant to terms and processes

\footnotetext{
$48 \quad$ Ibid. at para. 75.

Supra note 4, cl. 3.04.

Annotations, supra note 6 at 13.
} 
otherwise authorized by the Parties, under preferred supply arrangements, and under bona fide arm’s-length contracts having a total value of less than CDN\$50,000.

\section{E. HeAlth, SAFETy AND The ENVIRONMENT CoMPliance}

Clause 3.05 is a new provision in the 2007 Procedure. It addresses HSE and reflects the increased emphasis and importance of HSE compliance. The provisions of cl. 3.05 are designed to ensure compliance with the Regulations. It also entitles Non-Operators to timely information in respect of HSE issues and to conduct their own HSE reviews or audits. It should be noted that cl. 3.05 is in addition to cl. 3.08 (Non-Operator's Rights of Access), which exists in earlier versions of the Procedure and could be used by Non-Operators under those Procedures to make similar investigations. While a Non-Operator may utilize its right to review or audit Joint Property or any other Joint Operation with respect to HSE matters, subclause 3.05F attempts to mitigate the legal risk assumed by the Non-Operator as a result of choosing or not choosing to exercise such rights, by providing that nothing therein shall be interpreted as imposing on a Non-Operator any duty to take action in circumstances in which an Operator's HSE performance is deficient.

While the 2007 Procedure establishes duties, rights, and obligations between the Parties to it, the Procedure, and specifically subclause 3.05F, cannot limit a Party's common law and statutory duties and liabilities to third parties. Accordingly, Non-Operators should be aware of such duties and liabilities and utilize the provisions of the Procedure to ensure the Operator is in compliance with HSE legal requirements. If the Non-Operator suspects something is wrong and chooses not to conduct an audit or inspection, if an audit or inspection is conducted that uncovers a deficiency, or if the Non-Operator is advised by the Operator of a deficiency and the Non-Operator does little or nothing about it, the NonOperator may become subject to common law as well as statutory liability. ${ }^{51}$

The exercise of audit rights pursuant to subclause 3.05E (and cl. 3.08) could lead to additional responsibilities on the Non-Operator to ensure the Operator's compliance with HSE Regulations, and may create additional liabilities as noted above. On the other hand, these responsibilities and liabilities may exist at law regardless of subclause 3.05E and cl. 3.08 - in fact, the authors suggest that the increased emphasis on HSE compliance is at least in part because of this very concern. While a Party could, when negotiating, remove their access and audit rights from the Procedure in an attempt to limit this liability, a Non-Operator should be aware that a court may view contracting out of rights to review and ensure compliance as an indication of lack of due diligence, thereby removing this defence. It should also be noted that if there is an HSE concern, simply not exercising the right to audit under subclause 3.05E would likely not be enough to protect a Non-Operator from common law and statutory liability. As contracting out or choosing not to act will likely not protect a NonOperator if there are HSE issues, the authors suggest that a Non-Operator would be better off utilizing the provisions of subclause 3.05E and cl. 3.08 and be diligent in ensuring that all necessary steps are taken by the Operator to comply with all HSE Regulations and if they are not complied with, Non-Operators should take the necessary steps to have the Operator

51 For further discussion of common law and statutory liability regarding HSE compliance, see Appendix A. 
removed. As noted in the discussion of para. 2.02B(b), a Non-Operator may wish to abridge the time period for removal of the Operator for a strict breach of this nature in circumstances where such breach may not otherwise permit immediate removal of the Operator to ensure that it can act, and be seen to be acting, diligently in enforcing the Operator's HSE compliance obligations.

\section{F. Miscellaneous Specific DUTIES}

With some modifications, improvements, and expansions over the 1990 Procedure, the 2007 Procedure contains provisions requiring the Operator to protect the Joint Property from liens and encumbrances, keep and maintain true and correct records and accounts, provide Non-Operators with rights of access to the Joint Operations and Joint Property, and maintain all necessary surface rights and all licences, approvals, and other rights of the Joint Account that are required by the Regulations for Joint Operations. New to the 2007 Procedure is the imposition of a duty to conduct such community and stakeholder consultation as required by the Regulations and any additional consultation the Operator reasonably determines is appropriate. ${ }^{52}$ Also new is $\mathrm{cl}$. 3.09, which specifies that if the Operator must post a letter of credit or other financial security in order to hold any licences or approvals under the Regulations as the result of its own unique corporate or organization attributes, it will do so at its own cost. This provision is designed to address orphan well and facility regulatory requirements (such as Alberta's licensee liability rating deposit requirements) that have been imposed since 1990 .

Clause 3.10 addresses the maintenance of Title Documents. Unlike earlier versions of the Procedure, the 2007 Procedure recognizes that in some circumstances the Party responsible for paying royalties under and maintaining Title Documents may not be the Operator in all cases. Accordingly, the concept of a Title Administrator was introduced to address this issue. Though the Title Administrator is not otherwise compensated (except for reimbursement of rentals and other land maintenance charges), the Title Administrator is largely protected from liability except to the extent that their conduct constitutes Gross Negligence or Wilful Misconduct.

Clause 3.11 requires the Operator to maintain certain minimum levels and types of insurance. First, pursuant to subclause 3.11A, the Operator must comply with requirements in respect of “all Employment Insurance, Canada Pension, Workers' Compensation and Occupational Health and Safety legislation and all similar Regulations applicable to personnel conducting Joint Operations." 53 Second, pursuant to subclause 3.11B, the Joint Account Operator will "obtain and maintain all insurance policies, indemnities and other forms of financial responsibility required by the Regulations for Joint Operations insofar as those requirements cannot otherwise be satisfied by the Parties collectively or on an individual basis." ${ }^{54}$ In addition to the foregoing mandated minimum insurance requirements, subclause 3.11C allows the Parties to elect to cause the Operator to obtain and maintain additional automobile liability insurance to a limit of CDN\$5 million, commercial liability 
insurance to a limit of \$5 million, and aircraft liability insurance to a limit of \$10 million per occurrence. These limits of insurance have been increased from the now out-of-date 1990 levels of $\$ 1$ million, $\$ 1$ million, and $\$ 5$ million respectively, ${ }^{55}$ but can be increased or reduced to suit the project and the requirements of participants.

Consistent with the 1990 Procedure, cl. 3.12 of the 2007 Procedure mandates that the Operator shall provide each Non-Operator with production statements and reports for each month within 25 days of the end of such month showing production volumes, inventories, volumes available for sale, and deliveries in kind. The Operator is obligated to submit "all reports for Joint Operations and the production of Petroleum Substances as required by the Regulations, and will provide a Non-Operator with a copy of any such report upon request."56 In addition, the Operator will pay for the Joint Account all taxes (excluding income taxes) levied against Joint Property including freehold mineral taxes unless the Operator is not the lessee in respect thereof, in which event the Operator may decline to pay these taxes.

New to the 2007 Procedure is cl. 3.14, which imposes on the Operator the responsibility of testing the accuracy of any metering equipment held as Joint Property and operated by the Operator and used to measure Petroleum Substances or related emissions. The Operator must conduct such tests as frequently as is required by the Regulations or as is otherwise reasonable. Testing must be done using Regulation-compliant or better engineering methods.

\section{LIABILITY AND INDEMNIFICATION OBLIGATIONS}

Article 4.00 of the 2007 Procedure addresses the extent to which an Operator will be indemnified against, or be held liable for and indemnify Non-Operators against Losses and Liabilities $^{57}$ resulting from, attributable to, or arising from the performance of Operator's duties under the Agreement. While the indemnification and liability provisions contained in the 2007 Procedure remain in a similar format to those in previous versions, several substantive changes have been made. In addition to streamlining the provisions, the changes are intended to clarify the standard of care to which an Operator will be held accountable and to address interpretation issues that exist in previous versions of the Procedure.

\section{A. 2007 LiABILITY AND INDEMNIFICATION PROVISIONS}

Subject to two exceptions, cl. 4.01 of the 2007 Procedure sets out the general rule that applies to Operator liability:

This Clause applies except insofar as the Operator: (i) is solely responsible for any Losses and Liabilities under Clause 4.02; or (ii) may otherwise be liable to any Party for breach of any of its contractual obligations as Operator under this Agreement, other than for its duties under Clause 3.04, Subclause 3.05A or Subclause 3.10A. The Parties will indemnify and save harmless the Operator, its Affiliates and their respective directors, officers and employees from and against all Losses and Liabilities arising directly out of the

See e.g. Hardwicke-Brown, supra note 7; Josephson, supra note 7; MacLean, “1990 CAPL,” supra note 7. 
Operator's performance of its duties under this Agreement, including those of such Losses and Liabilities arising by reason of, or which may be attributable to, any act, omission or failure to act of the Operator or its Affiliates and their respective directors, officers, agents, contractors or employees in planning or conducting any Joint Operation. All such Losses and Liabilities for which that indemnification applies will be for the Joint Account, and will be borne by the Parties (including the Operator) in proportion to their respective Working Interests. ${ }^{58}$

In the first exception, an Operator will be liable to Non-Operators under cl. 4.02 for any Losses and Liabilities that result from, or are attributable to, its performance of duties under the Agreement if:

(1) the loss or liability occurs as a result of the Gross Negligence or Wilful Misconduct of the Operator;

(2) the Operator would otherwise be liable to the Non-Operator for the breach of its contractual obligations as Operator, other than its duties imposed under cl. 3.04, subclause 3.05A, or subclause 3.10A; or

(3) it relates to a risk that the Operator was required to carry insurance for, and the loss or liability is within the required insurance limit.

If an Operator is found to be responsible for a loss or liability in one of these three circumstances, the Operator will be solely liable and is required to indemnify each of the Non-Operators from and against any such loss or liability. The second exception set out in cl. 4.01 is a reiteration of the second item listed in cl. 4.02, which states that an Operator may be liable to a Non-Operator for any breach of its contractual obligations under the Procedure, as long as that obligation does not arise from its duties under cl. 3.04, subclause 3.05A, or subclause 3.10A.

In considering the words now used in cls. 4.01 and 4.02 of the 2007 Procedure, the main difference from the 1990 Procedure is the inclusion of the two specific exceptions to Operator indemnification in cl. 4.01, rather than relying on a simple "notwithstanding" reference at the beginning of $\mathrm{cl}$. 401 of the 1990 Procedure to restrict Operator liability. The most notable of the 2007 exceptions is the express reference to an Operator being liable to Non-Operators for breaches of its contractual duties for the performance of any duty or obligation that is not included as a part of cl. 3.04 (proper practices in Joint Operations), subclause 3.05A (management of HSE risks), or subclause 3.10A (maintenance of Title Documents, as it relates to payments). Corresponding amendments were also made to each of the foregoing to state that an Operator will not be liable for any breach of the obligations owed to Non-Operators in these provisions, except insofar as the breach constitutes Gross Negligence or Wilful Misconduct for which the Operator is solely responsible under art. 4.00. In addition, "planning or conducting” Joint Operations has replaced "conducting or carrying out" 59 Joint Operations in cls. 4.01 and 4.02. This revision was made to clarify that 
liability for planning the Joint Operations as well as the actual Operations themselves, would be indemnified. ${ }^{60}$

Along with providing a clearer articulation on the limits of Operator liability and indemnification in cls. 4.01 and 4.02, the 2007 revisions extend these provisions to NonOperators in certain circumstances. As the wording used in these clauses relate specifically to Operator liability and indemnification, cl. 4.03 has been added in the 2007 Procedure to extend the same level of protection and limits on liability under art. 4.00 to each NonOperator by allowing cls. 4.01 and 4.02 to apply, mutatis mutandis, for any authorized activity that a Non-Operator conducts for the benefit of the Joint Account or any Joint Account judgment enforced against a Non-Operator. Previous versions of the Procedure did not expressly indicate that a Non-Operator would be placed in a similar position to the Operator and be indemnified for Losses and Liabilities incurred for the benefit of the Joint Account.

The 2007 Procedure also provides broader protection against additional damages that can be claimed by a Party. Clause 4.04 has been added to restrict the types of damages that can be recovered by stating that no Party is responsible for Extraordinary Damages suffered as a result of Losses and Liabilities except to the extent another Party is entitled to be indemnified against any such damages suffered by a third party. This creates a distinction precluding a Party from claiming Extraordinary Damages relating to its own interest, but will not require an innocent injured Party to compound its loss by having to pay Extraordinary Damages awarded to a third party by the courts where it is entitled to be indemnified for losses suffered. ${ }^{61}$ Previously, the only restriction placed on the type of damages that could be claimed was for loss of profit or other indirect losses arising from the delay of production. In the definition provided in the 2007 Procedure, the exclusion of Extraordinary Damages encompasses:

[A]ny Losses and Liabilities howsoever arising or occurring that: (i) are in the nature of consequential, indirect, punitive or exemplary damages (including compensation for business interruption, loss of profits, loss of opportunity, opportunity costs, reservoir or formation damage, the inability to produce Petroleum Substances or a delay in their production); or (ii) pertain to loss of well control during drilling or other well Operations, including, for this item (ii), associated Environmental Liabilities. ${ }^{62}$

In addition to these specific provisions, the 2007 Procedure also provides definitions for two key terms used throughout art. 4.00 that were previously undefined. The key term "Losses and Liabilities" is now included and has been defined as

all claims, liabilities, actions, proceedings, demands, losses, costs, expenses, penalties, fines and damages, whether statutory, regulatory, contractual, tortious or otherwise, which may be sustained or incurred by a Party, its Affiliates and their respective directors, officers, and employees respecting any person (including 
that Party or any other Party), including reasonable legal fees and disbursements on a solicitor and its own client basis. $^{63}$

By including this as a definition, art. 4.00 has been simplified by not requiring each provision to articulate what constitutes Losses and Liabilities. Also, the definition itself makes reference to "whether ... contractual, tortious or otherwise" and "including that Party or any other Party" to ensure the Losses and Liabilities will not be limited to purely tortious liability for third party losses, but also extend to contractual losses suffered by Parties to the Agreement. ${ }^{64}$ The inclusion of legal fees on a solicitor and own client basis within the definition better addresses legal costs than previous versions of the Procedure. As set out in the Annotations, without this reference, Parties would be restricted to recovering costs on a party-party basis, as prescribed by the Alberta Rules of Court ${ }^{65}$ which would allow Parties to recover only a small portion of the actual legal costs incurred. ${ }^{66}$

The second key term added is that of "Gross Negligence or Wilful Misconduct." This has been defined as:

\begin{abstract}
any act, omission or failure to act (whether sole, joint or concurrent) by a person that was intended to cause, or was in reckless disregard of, or wanton indifference to, the harmful consequences to the safety or property of another person or to the environment which the person acting or failing to act knew (or should have known) would result from such act, omission or failure to act. However, Gross Negligence or Wilful Misconduct does not include any act, omission or failure to act insofar as it: (i) constituted mere ordinary negligence; or (ii) was done or omitted in accordance with the express instructions or approval of all Parties, insofar as the act, omission or failure to act otherwise constituting Gross Negligence or Wilful Misconduct was inherent in those instructions or that approval. ${ }^{67}$
\end{abstract}

The inclusion of this definition has eliminated the potential issue that exists under previous Procedures to determine what common law articulation of "Gross Negligence or Wilful Misconduct" would apply in the oil and gas context. ${ }^{68}$ The traditional qualification used to provide an exception for losses that result from authorized acts or omissions has been incorporated in the 2007 Procedure to make it clear that if prudent instructions authorized by the Parties are implemented in a manner that is grossly negligent, the Operator will not be able to avoid liability unless the act or omission of Gross Negligence or Wilful Misconduct was inherent in the instructions provided.

\title{
B. OPERATOR LIABILITY AND INDUSTRY EXPECTATIONS
}

In considering the effect that the new indemnification and liability provisions of the 2007 Procedure will have, there is a concern that such provisions may not be consistent with the

\footnotetext{
63 Ibid.

64 Ibid.

$65 \quad$ Alta. Reg. 390/1968.

66 Annotations, supra note 6 at 4.

$67 \quad$ Supra note 4, cl. 1.01 .

68 Jim MacLean, "2006 CAPL Operating Procedure: Liability and Indemnification Obligations” The Negotiator (December 2006) 4 at 9, online: CAPL < http://www.landman.ca/publications/Negotiator/ 2006/december/dec06_layout.pdf> [MacLean, “December 2006 CAPL”].
} 
expectations of some industry participants. Generally speaking, as a result of the Operator assuming the responsibility for undertaking Joint Operations and managing Joint Property on behalf of all Working Interest owners, the Operator is not expected to realize any gains or suffer any losses relative to the Non-Operators while fulfilling that role. ${ }^{69}$ As an extension of this principle, some industry participants may feel that an Operator's liability for the performance of its duties under a joint operating agreement should be, and historically has been, limited to only those losses and liabilities that are incurred as a result of the operator's gross negligence or wilful misconduct.

When the 2007 amendments for art. 4.00 were proposed, the Drafting Committee's intention was to provide Operators with a greater scope of protection from potential liability than previously provided in the 1990 Procedure with respect to the conduct of Operations because of the changes to $\mathrm{cl}$. 3.04 and the related qualification in subclause $3.05 \mathrm{~A}^{70}$ Commentary received from industry participants regarding the proposed changes included a concern that the amendments would in fact broaden the scope of Operator liability, rather than reduce it. ${ }^{71}$ In particular, the proposed reference within art. 4.00 to Operators being otherwise liable to Non-Operators for breaching contractual obligations under the operating agreement had companies concerned that they would become more susceptible to liability. ${ }^{72}$ In considering industry concerns, it is apparent that there are misconceptions held regarding Operator liability, with a disconnect between what the industry perceives Operator liability to be and what Operator liability actually is under previous versions of the Procedure as interpreted by the courts.

\section{OPERATOR LiabiLity Under THE 1981 AND 1990 Procedures}

When the 1990 and 2007 Procedures were revised, changes had to be made without having the benefit of any judicial interpretations of the indemnification and liability provisions from the previous version. This lack of judicial treatment required the 1990 and 2007 Drafting Committees to identify and address potential issues that might result from the wording used previously.

In identifying the potential issues with the 1981 Procedure language, the 1990 Drafting Committee considered judicial rulings made in reference to other indemnification and liability provisions. ${ }^{73}$ As a result of these decisions, the 1990 Procedure changes were aimed at reducing the extent to which an Operator would be liable to Non-Operators for negligence by extending indemnification of the Operator in certain instances beyond third party losses. To achieve this result, one of the most notable changes in the 1990 Procedure was the insertion of "notwithstanding Clauses 303 and 304" at the beginning of cl. 401, which was intended to prevent the overall standard prescribed by these clauses, which includes the

Ibid. at 5 .

Ibid. at 8 .

Ibid. at 5 .

Ibid. at 7-8.

MacLean, “1990 CAPL,” supra note 7 at 147-48. See e.g. Mobil Oil Canada Ltd. v. Beta Well Service Ltd. (1974), 50 D.L.R. (3d) 158 (S.C.C.) [Mobil], where the interpretation given to an indemnification and liability clause was that it related specifically to third party losses and did not extend to losses that were directly incurred by parties to the contract. 
standard of "good oilfield practice,” from overriding the limitation placed on an Operator's general liability in art. 4.00 to require gross negligence or wilful misconduct. ${ }^{74}$

It was not until after the revisions were made in 1990 that the liability and indemnification clauses in the 1981 Procedure were first litigated in Erehwon Exploration Ltd. v. Northstar Energy. ${ }^{75}$ In Erehwon, an allegation was made by the plaintiff non-operator of specific instances where the operator had acted inappropriately or levied inappropriate charges relating to accounting matters for joint operations. ${ }^{76}$ In addressing this dispute, two clauses of the 1981 Procedure were considered to determine the appropriate standard of care to which an operator should be held accountable. In reaching its decision, the Court addressed the interrelationship between the duty of "good oilfield practice" imposed on an operator under cl. 304 and limitations placed on the extent of Operator liability under cl. 401. In reconciling these two provisions, Hunt J. stated:

I reject the suggestion that Article IV was meant to relate to the standard of care applicable to the relations between the CAPL parties themselves, and in particular to the Operator's duty to the Non-Operators in carrying out the joint operations. In my opinion, Article IV is most likely intended to deal with third party losses. $^{77}$

In reaching this decision, the Court did not rely on the interpretation given in Mobil as being conclusive that indemnification clauses are intended to relate only to third party losses, stating that specific wording of the governing contract must be considered. ${ }^{78}$ In looking at the specific wording, the Court held that by imposing the obligation of "good oilfield practice" in cl. 304, it would then be difficult to conclude that the parties intended cl. 401 to mean that an operator would only be liable if it were to carry out its duties in a grossly negligent fashion. ${ }^{79}$

In 1997, the courts revisited operator liability under the 1981 Procedure in Morrison. ${ }^{80}$ In this case, the plaintiff was suing the defendant non-operators to recover their proportionate share of cost overruns incurred for joint operations. The defendants counterclaimed for damages, alleging that the plaintiff failed to observe good oilfield practices in planning operations, issuing the AFE, and drilling the well. ${ }^{81}$ In determining the standard of care owed, Moshansky J. relied on the precedent set in Erehwon and stated that

Although the Erehwon Exploration case dealt with “accounting matters” I am of the view that the reasoning of Hunt J.'s therein applies equally to the question of the standard of care imposed upon an operator by the

See generally MacLean, “1990 CAPL,” ibid., for a detailed description of all changes made. (1993), 147 A.R. 1 (Q.B.) [Erehwon].

Ibid. at para. 57.

Ibid. at para. 62.

Ibid. at para. 65. Subsequent cases such as TransCanada Pipelines Ltd. v. Potter Station Power Limited Partnership (2003), 172 O.A.C. 379, aff'g (2002), 22 B.L.R. (3d) 210 (Ont. Sup. Ct. J.) and Alberta v. Western Irrigation District, 2002 ABCA 200, 312 A.R. 358, have established that courts are willing to consider the wording of each contract in its context and not assume that it extends only to third party liability.

Erehwon, ibid.

Supra note 41.

Ibid. at para. 85 . 
requirement in Clause 304 of CAPL 1981 to employ "good oilfield practices" with respect to "all operations., $^{82}$

Clearly, if the plaintiff had intended that the defendants were to relieve it from liability for losses caused by its own negligence, other than third party claims, that could have been accomplished by requiring from the defendants an undertaking in the participation agreement not to sue for anything except gross negligence or wilful misconduct. ${ }^{83}$

These decisions establish that gross negligence or wilful misconduct is not required before an operator is liable to a non-operator acting under the 1981 Procedure for breaches of contractual duties while conducting operations. This places significant risk on an operator, given the nature of potential losses that are inherent in the planning and conducting of joint operations. ${ }^{84}$ This interpretation, which allows an operator to assume all the risk for breaches of contract without gross negligence or wilful misconduct, was not consistent with the general expectation that owners share equally in all losses and gains that relate to the joint operations. ${ }^{85}$ Without receiving compensation for assuming the risk of conducting operations, they should not be financially responsible to non-operators for those risks.

Subsequent to the 2007 Procedure being issued, the indemnification and liability provisions of the 1990 Procedure were subject to judicial interpretation by the Alberta Court of Appeal in Adeco Exploration Company Ltd. v. Hunt Oil Company of Canada Inc. ${ }^{86}$ In this case, the Court had to determine what standard an operator would be liable to non-operators for a contractual breach under the 1990 Procedure for failing to continue certain Crown leases. The operator's position was that the non-operators must prove gross negligence, pursuant to cl. 401 of the 1990 Procedure, in order for them to be accountable for failing to continue the leases, either on the basis of contract or negligence. The non-operators argued that cl. 401 only provided the operator with protection from third party claims and claims by non-operators arising from cls. 303 and 304 of the 1990 Procedure and that their claim was based on cl. 309 (maintenance of title documents), which is not subject to the gross negligence exclusion contained in cl. $401{ }^{87}$

In reaching a decision, Ritter J.A. stated:

I conclude that the notwithstanding provisions, which does not mention clause 309, does not affect the issue of whether lease renewal is an activity subject to the gross negligence standard imposed by clause 401 of the 1990 CAPL. However, even if the notwithstanding provision is excised from clause 401, what remains is this:

Ibid. at para. 91 .

Ibid. at para. 92.

MacLean, “December 2006 CAPL,” supra note 68 at 7-8.

Ibid.

2008 ABCA 214, 437 A.R. 33 [Adeco Exploration].

Ibid. at para. 29. 
"The operator ... shall not be liable to the [non-operators] ... for any loss ... whether contractual or tortuous ... arising out of any act or omission, whether negligent or otherwise, of the operator ... in conducting or carrying out the joint operations, except:

(a) [the Insurance exception]

(b) when $\ldots$ such loss $\ldots$ is attributable ... to the gross negligence ... of the operator...” [Emphasis added.]

This language is clear and unambiguous. The concepts of liability and indemnification are no longer mixed since the indemnification of the operator is isolated to clause 402 of the 1990 CAPL. Here, what Hunt Oil failed to do in continuing the lease, constitutes an omission in conjunction with Hunt Oil carrying out the joint operation. Pursuant to the plain and ordinary meaning of the words in clause 401 of the 1990 CAPL, Hunt Oil is only responsible to the non-operators, Adeco and Shaman, if its omission amounted to gross negligence. $^{88}$

In reaching this conclusion, the Court focused on the wording of cl. 401, which refers to the defined term "Joint Operation,” being an operation for the joint account. Clause 309 states that renewal obligations of the Operator are for the joint account. Therefore, "failure to renew is an omission relating to a Joint Operation, and that omission is caught by clause 401 of the CAPL." ${ }^{89}$ Through this decision, the courts have effectively required nonoperators to establish that an operator was grossly negligent prior to being able to recover against the operator for breaches of specific contractual obligations in the Procedure, if such obligation relates to the joint account or joint operations, regardless if they exist outside of cls. 303 and 304. In light of the Adeco Exploration decision, the provisions of the 1990 Procedure would in fact provide greater protection to operators than was previously anticipated pursuant to the Erehwon decision by extending the gross negligence requirement beyond the scope of cls. 303 and 304.

\section{UNDERSTANDING THE LEGAL LIMITS OF OPERATOR LIABILITY}

Given the industry expectation that an operator should not be liable for losses and liabilities for Operations unless they are incurred as a result of gross negligence or wilful misconduct, the impact that Erehwon and Morrison have had on Operator liability for Operations conducted under the 1981 Procedure may not be commonly understood. In light of these decisions, the 1981 Procedure provides no limitations on the liability of the operator vis-à-vis a non-operator, and at the time the revisions were made, it was not clear what limitations the 1990 Procedure placed on the scope of Operator liability. Given that this was the starting point of operator liability for the 2007 Drafting Committee, it is clear that the cumulative effect of the changes made to the 2007 Procedure were expected to provide greater protection to Operators than the 1981 and 1990 Procedures. In actuality, the 2007 Procedure may not provide greater protection as a result of the subsequent decision made in Adeco Exploration in 2008, which has indicated that Operator protection under the 1990 Procedure is broader than it was originally anticipated to be. 
Although historically the Procedure has tended to favour operators, in recent years the focus has shifted to providing industry with a more balanced document that recognizes the competing needs of all Parties. As a result, the changes made in 2007 have clearly set the limitations on Operator liability with respect to Non-Operators and have allowed an Operator to remain liable for any simple breach of contract that does not relate to planning or conducting operations for the Joint Account, managing HSE aspects of Operations, or maintenance of Title Documents. The 2007 Procedure attempts to establish that an Operator should not be exposed to the undue risk of Losses and Liabilities that are associated with certain aspects of Operations that have the potential for significant unknown losses, but that in other lesser matters, Operators should be responsible for such breaches of contract to minimize the potential for abuse. Unfortunately, the 2007 Drafting Committee only had the benefit of the Court's interpretation of the 1981 Procedure in Erehwon, and in that light, the 2007 Procedure would be viewed not only as bringing clarity and certainty to the issue, but also as imposing a narrower scope of liability for the Operator compared to the 1981 Procedure. We can only speculate whether the Drafting Committee would have taken a different approach if they had the benefit of the Adeco Exploration decision in respect of the 1990 Procedure and industry reaction to it.

Regardless, if Parties do not agree with the division that has been made to maintain a balanced approach to Operator indemnification, when negotiating the joint operating agreement, they are free to alter what duties and obligations will attract the higher standard before they will be liable under art. 4.00. Alternatively, if Operators only want to be liable as a result of Gross Negligence or Wilful Misconduct for all duties and functions under the contract as some thought they were under previous Procedures, a general provision to that effect could be made in the Head Agreement overriding the applicable limitations in art. 4.00 of the Procedure.

\section{JOINT COSTS AND EXPENSES}

Article 5.00 addresses the manner in which the Joint Account (being the notional account maintained by the Operator tracking capital and operating advances and contributions and the sharing of benefits, risks, costs, expenses, and obligations by the Parties in proportion to their respective Working Interests) is administered, the manner in which the Operator pays and recovers expenditures and the remedies in the event of failure by a Party to make any required payments. Clause 5.01 provides that the Accounting Procedure is the basis for all charges and credits for the Joint Account, except to the extent that it is in conflict with the 2007 Procedure or the Head Agreement. The Operator must maintain an accounting of financial records for the Joint Account in accordance with established accounting practices in the oil and gas industry and in a manner in which charges and credits can be accessed separately from those kept by it for operations not conducted thereunder. As noted elsewhere, in emphasizing that the Operator is acting in such capacity on behalf of all Parties and not to its own advantage, the 2007 Drafting Committee added a statement of general intention in cl. 5.01 that the Operator not gain a profit or suffer a loss because it is the Operator, subject to:

(1) the Accounting Procedure; 
(2) the supply of goods and services by the Operator as permitted by the Procedure;

(3) management of a Non-Taking Party’s production under art. 6.00; and

(4) Operator's sole liability or indemnity obligations under the Procedure..$^{90}$

Users of earlier versions of the Procedure will appreciate improvements to the organization of this Article in the 2007 Procedure.

\section{A. Operator to PAy AND Recover}

Clause 5.02 sets forth the general rule that the Operator will initially pay all costs and expenses incurred for the Joint Account and will charge each Party its Working Interest share of those costs and expenses as required by the Accounting Procedure.

The Accounting Procedure provides that each Non-Operator shall pay all bills rendered by the Operator within 30 days of receipt thereof. The Accounting Procedure also requires that a Non-Operator not withhold payment of any portion of a bill due to protest or question related to such bill, unless there is a significant item under dispute and Operator agrees to the withholding. ${ }^{91}$ The Operator "shall not unreasonably deny the Non-Operator's request to withhold payment for significant disputed charges which require adjustment and for which written notice has been received." 92 Absent such Operator agreement, the Non-Operator must pay the Operator's bill and has 26 months to take written exception to it. ${ }^{93}$ The Non-Operator has 24 months from calendar year end to access and audit the Operator's books and records in respect of such calendar year. ${ }^{94}$

\section{B. Monthly Advances of AFE Amounts}

Clause 5.02 is expressly subject to cl. 5.03, which provides the basis by which the Operator may require an advance of expenditures from the Non-Operators. Pursuant to subclause 5.03A, the Operator may do this by notice to the Non-Operators requiring each of them to advance their Working Interest share of the costs that the Operator reasonably expects to pay for the Joint Account under an approved AFE provided, however, such advances may only be required for the anticipated costs to be paid in an upcoming calendar month and not the entire AFE amount. A Non-Operator will pay its share on or before the later of 20 days after receipt of the Operator's itemized written estimate of such costs and request for a payment and the fifteenth day of the month to which such estimate relates. The Operator will adjust each monthly billing to reflect advances received and any costs exceeding requested advances will be billed by the Operator and paid by the Non-Operators under the Accounting Procedure. Any amounts advanced by Non-Operators that are in excess of its Working Interest share of the actual cost paid for a month will either be refunded by

902007 Procedure, supra note 4, cl. 5.01.

91 Accounting Procedure, supra note 9 at para. 107(a).

92 Ibid.

$93 \quad$ Ibid. at para. $107(\mathrm{~b})$.

$94 \quad$ Ibid. at para. 107 (c). 
the Operator or retained by the Operator to reduce such Non-Operator's share of the following month's advance proportionately.

The Accounting Procedure contains a similar provision at cl. 104 addressing the mechanics of capital advances as contemplated in cl. 5.02 of the Procedure. In addition, cl. 105 of the Accounting Procedure contains a mechanism whereby the Operator can require Non-Operators to advance funds toward a percentage of the approved forecast for expenditures for Operations and maintenance for a year. The operating fund is used to address operating expense items, rather than items to which the capital advance process applies. The Procedure does not address the operating fund concept for operating expenses. An Operator may be inclined to attempt to use this mechanism in circumstances where net billing and recovery from monthly revenues is not available or practicable.

\section{SECURITY FOR PAYMENT}

The 2007 Drafting Committee added clarity to the 2007 Procedure simply by moving the provision respecting entitlement of the Operator to secure a payment of the AFE costs from Non-Operators from para. 503(a) in the 1990 Procedure to subclause 5.03C in the 2007 Procedure. Pursuant to subclause 5.03C, the Operator may require a Non-Operator to secure payment of its Working Interest share of costs for an approved Joint Operation in a manner satisfactory to the Operator acting reasonably, if it reasonably believes that the Non-Operator might be unable to pay those costs as and when they become due. The relocation of this provision to the end of cl. 5.03 should clarify that this security for payment provision is in addition to the Operator's entitlement under subclause 5.03B to require monthly advances of estimated capital expenditures from the Joint Account and is not an alternative to such provision.

The 2007 Procedure also contains new protective provisions for Non-Operators concerned with abuse of this provision by the Operator. First, para. 5.03C(a) of the 2007 Procedure, unlike the 1990 provision, imposes an objective standard that the Operator "reasonably believes" that the Non-Operator may be unable to pay. Second, in establishing the required satisfactory security for payment, the Operator must act reasonably in doing so. Third, unlike the 1990 Procedure, a Non-Operator subject to such notice from the Operator may notify the Operator of its objection and refer the matter to dispute resolution pursuant to art. 21.00. ${ }^{95}$ However, a Non-Operator will be disentitled from objecting if that Non-Operator: "(i) has been placed into bankruptcy or receivership; (ii) is then subject to debtor relief protection under the Bankruptcy and Insolvency Act (Canada), the Companies' Creditors Arrangement Act (Canada), or similar Regulations; or (iii) has been served a bona fide notice of default under Subclause 5.05B during the preceding 6 months." 96

\section{OPERATOR'S LIEN AND DEFAULT REMEDIES}

Pursuant to cl. 5.05, the Operator is granted certain rights and remedies in the event of non-payment by a Non-Operator of its Working Interest share of approved expenditures.

$95 \quad$ Supra note 4, subclause 5.03C.

$96 \quad$ Ibid. at para. $5.03 \mathrm{C}(\mathrm{d})$. 
Pursuant to subclause 5.05A, the Operator is granted "a lien and charge with respect to the interest of each Party in the Joint Lands, the wells and equipment thereon.... Subject to the Regulations, that lien and charge has priority over any other lien, charge, mortgage or other security interest applicable to those interests."97

In addition, subclause 5.05B provides a list of remedies that the Operator may impose including charges and interest on outstanding amounts, ${ }^{98}$ withholding further information and rights with respect to Operations, ${ }^{99}$ set-off against the unpaid amount of any amounts payable to that Non-Operator from the Operator, ${ }^{100}$ maintaining an action for such unpaid amounts and interest thereon, ${ }^{101}$ and treating the default as an immediate and automatic assignment to the Operator of that Non-Operator's share of Petroleum Substances and the right to dispose of them on its behalf. ${ }^{102}$

The assignment of the defaulting Party's share of Petroleum Substances replaces the remedy in subparagraph 505(b)(v) of the 1990 Procedure to "treat the default as an immediate and automatic assignment to the Operator of the proceeds of the sale of such Joint-Operator's share of petroleum substances produced hereunder."103 Under the 2007 Procedure, an Operator can take possession of Petroleum Substances and sell them directly. Unlike the 1990 version, it does not have to serve notice to a third party to whom such substances have been sold by the defaulting Non-Operator and merely hope that such third party complies with such notice. Attempts to enforce this provision in the 1990 Procedure often led to third party purchasers simply paying such monies into court rather than risking being held liable by the Non-Operator or the Operator for such amounts by paying the wrong party. Under the 2007 Procedure, Operators can instead take those substances into possession at the wellhead and sell them after having given five Business Days prior notice to the NonOperator. The notice requirement, however, may reduce the efficiency of this provision in that the Non-Operator may seek interim relief from the courts against imposition of this remedy. As noted below, the Operator should carefully consider the usage of this remedy if there is any doubt as to its appropriateness in the circumstances.

New to the 2007 Procedure is an additional remedy whereby the Operator may, by specific notice to the defaulting Non-Operator and the other Non-Operators, assume the defaulting Non-Operator's share of unpaid and remaining costs pertaining to a Joint Operation and deem the defaulting Non-Operator to be a Non-Participating Party with respect to the unpaid and future costs of that Joint Operation and apply art. 10.00 respecting Independent Operations thereto. ${ }^{104}$

In addition, as is the case in the 1990 Procedure, the Operator may also enforce its Operator's lien by taking possession of and selling the defaulting party's Working Interest

$\begin{array}{ll}97 & \text { Ibid., subclause 5.05A. } \\ 98 & \text { Ibid. at para. 5.05B(a). } \\ 99 & \text { Ibid. at para. 5.05B(b). } \\ 100 & \text { Ibid. at para. 5.05B(c). } \\ 101 & \text { Ibid. at para. 5.05B(d). } \\ 102 & \text { Ibid. at para. 5.05B(e). } \\ 103 & \text { Supra note } 3 \text { at para. 505(b)(v). } \\ 104 & \text { 2007 Procedure, supra note 4 at para. 5.05B(f). }\end{array}$


and Working Interest share of Joint Property. ${ }^{105}$ The 2007 Procedure does expressly specify, unlike the 1990 Procedure, that any such proposed disposition must not occur unless the Operator has obtained any required court order confirming such disposition before it is completed, although this is likely required at law anyway in the exercise of this seizure and sale remedy under other versions of the Procedure. As noted in the Annotations, this is an exceptional remedy that would only be used in extreme circumstances. ${ }^{106}$ Given that those circumstances almost certainly would not include the co-operation of the defaulting Party, the Operator is granted authority to execute, on behalf of the defaulting Party, any transfers and assignments required to complete such seizure and sale.

Pursuant to cl. 5.06, Non-Operators that contribute to payment of a delinquent Party's share of costs are subrogated to the Operator's rights and remedies with respect to the unpaid portion of such contribution and interest thereon.

Operators and Non-Operators that are considering taking steps to enforce the Operator's lien or assert remedies should do so with caution. As stated in the Annotations:

Default rights are premised on the existence of a default, and are only as good as the validity of the charges under Clause 5.02. An Operator should not resort to these remedies if Parties are disputing an approval, an accounting practice or the adequacy of invoice information.

An Operator that purports to apply the default remedies for amounts that are not owing is in breach of the Agreement. It potentially could be removed as Operator under Subclause 2.02B if its default were to persist, and could also face a claim for damages. ${ }^{107}$

In a number of cases, the Operator under earlier Procedures was found to be a fiduciary. ${ }^{108}$ Accordingly, the exercise of certain remedies such as set-off and taking possession of and selling a Non-Operator's share of production without authority or legal right to do so can lead to liability for damages for breach of contract and potentially punitive damages for breach of trust. ${ }^{109}$ Such exposure may be somewhat more limited, though, under the 2007 Procedure by virtue of cl. 1.05 (formerly cl. 1501 of the 1990 Procedure). In addition to the statement that the Parties hold their interests as tenants in common, that their obligations and liabilities are separate and not joint or collective or joint and several, and that no partnership, association, partnership duty, obligation, or liability exists or is created thereby, all of which is included in the 1990 Procedure, cl. 1.05 provides that there is not any trust, trust duty, or fiduciary relationship between them except as provided for (1) the commingling of funds; (2) the distribution of proceeds of sale of Petroleum Substances; and (3) the obligation to keep information confidential. ${ }^{110}$ 


\section{E. CoMmingLing OF FUNDS}

Pursuant to subclause 5.07A, the Operator is permitted to commingle with its own funds any monies held for the Joint Account or otherwise on behalf of other Parties. Such funds are deemed to be held in trust on behalf of such Parties and shall only be used for their intended purpose and will not be deemed to belong to the Operator. ${ }^{111}$ The right to commingle is terminated if Parties holding a majority of the Working Interest serve notice to such effect in circumstances where the Operator cannot be replaced immediately under subclause 2.02A (financial distress) after notice that any of paras. 2.02A(a), (b), (c), or (d) apply.

\section{OWNERSHIP AND DisPosition OF PRODUCTION}

The marketing provisions contained in art. 6.00 address situations where a Party fails to take its proportionate share of production in kind. As with the revisions made in 1990, the rationale for changing art. 6.00 in the 2007 Procedure was to have the marketing provisions reflect the current nature of the marketing environment in the oil and gas industry. In particular, the focus was on preventing any notional or discretionary allocations by a disposing Party of the least favourable marketing arrangements to production it is disposing on behalf of a Non-Taking Party. ${ }^{112}$

\section{A. Obligation to TAKE In KIND}

Each Party owns its Working Interest share of production and, pursuant to subclause 6.01A, each Party also has the right and obligation to take its production in kind and separately dispose of it at its own expense. This differs from the approach used in the 1990 Procedure, which gave Parties the right to take production, but did not state it to be an obligation. This change reflects the industry expectation that Parties will take in kind and is consistent with commonly used international model joint operating agreements, which require parties to take production in kind. ${ }^{113}$ Although this change may seem significant, making this an obligation has no legal impact on Non-Taking Parties, as failure to take production will not make such a Party liable for damages as a result of breach of contract. ${ }^{114}$ Clause 6.01 clarifies that the only consequence a Non-Taking Party has for failure to take production in kind is the payment of the marketing fee to the disposing Party. ${ }^{115}$

For those Parties taking in kind, the point at which the Operator will deliver production is the First Point of Measurement or the first practical delivery point thereafter, if delivery at the First Point of Measurement is not possible. First Point of Measurement is a newly defined term in the 2007 Procedure and has been added to provide clarity to users as to when each Party is entitled to take possession of its proportionate share of production. First Point

111 Ibid., subclause 5.07B.

112 MacLean, “February 2006 CAPL,” supra note 14 at 10.

113 See art. 9 of the 2002 Model International Operating Agreement developed by the Association of International Petroleum Negotiators for international operators outside of North American and art. 9 of Form 610 Model Form Operating Agreement (Fortworth: American Association of Petroleum Landmen, 1989) for onshore operations in the United States.

114 Annotations, supra note 6 at 22.

115 MacLean, “February 2006 CAPL,” supra note 14 at 11. 
of Measurement is defined as "the first point at which Petroleum Substances are metered, measured, or allocated downstream of the wellhead" after basic processing (that is, removal of sediment and water from liquids and dehydration of gas) at the well site; in essence it is the point at which applicable royalties will typically be calculated under Title Documents and Regulations, making this the first feasible point when production can be taken. ${ }^{116}$

\section{B. OPTIONS For the Disposal OF A Non-TAKing PARTY’s Production}

The 2007 Procedure introduces the term Non-Taking Party to refer to a Party that fails to take in kind and separately dispose of its production to simplify the language used in art. 6.00. Insofar as a Non-Operator is a Non-Taking Party, cl. 6.02 provides the Operator with the authority, but not obligation, to dispose of that Non-Taking Party's share of production under a marketing arrangement that does not exceed 31 days, unless that arrangement can be terminated at any time with 31 days notice. Subclause 6.02A gives the Operator two options to dispose of a Non-Taking Party's production. It can choose to:

(1) sell production at a Market Price to a third party in a bona fide arm's-length transaction; or

(2) purchase production at the First Point of Measurement for the account of the Operator at a Market Price. ${ }^{117}$

The Operator will account to Non-Taking Parties for sale proceeds after deduction of Facility Fees for direct processing, transportation, and enhancement and the applicable marketing fee prescribed by cl. 6.04. These options provided to an Operator for the disposal of a NonTaking Party's proportionate share of production have changed from the 1990 Procedure. The disposing Party is no longer given the option to sell a Non-Taking Party's production for the same price it receives under a third party sales contract under which it sells its own production, as was provided under the 1990 Procedure. This reflects the market shift from dedicated land sales contracts to gas supply arrangements. ${ }^{118}$ In addition, by not providing the option of allowing a disposing Party to sell production for the same price it receives under a third party sales contract, it should limit the potential for abuse by the Operator in using a Non-Taking Party's production to fulfill its own out-of-the-money marketing commitments.

Subclause 6.02B addresses situations where the Operator proposes to dispose of production under a sales contract that exceeds the 31 day restriction included in cl. 6.01. In order to do so, the Operator must provide the Non-Taking Party with a detailed summary of the proposed sales contract. ${ }^{119}$ Non-Taking Parties are provided with a minimum of five Business Days to consent to such arrangement. ${ }^{120}$ The time frame for providing consent has

2007 Procedure, supra, note 4, cl. 1.01; Annotations, supra note 6 at 3.

Ibid., subclause 6.02A.

Jim MacLean, “2007 CAPL Operating Procedure: Marketing” The Negotiator (February 2008) 7 at 9, online: CAPL < http://www.landman.ca/publications/Negotiator/2008/feb/feb08_layout.pdf> [MacLean, “2007 CAPL”].

Supra note 4 at para. 6.02B(a).

Ibid. at para. 6.02B(b). 
been reduced from the ten days used in the 1990 Procedure to reflect the fact that short-term natural gas contracts are often available for limited periods of time. ${ }^{121}$ In addition, the 2007 Procedure has also deemed the failure to respond to an Operator's request to constitute a refusal of that proposal. ${ }^{122}$ By no longer deeming consent, there is a benefit for an Operator to extend the election period where possible, to allow a Non-Taking Party proper time to evaluate the marketing proposal. ${ }^{123}$ An additional contracting restraint is placed on Operators in the 2007 Procedure with the inclusion of a new provision, subclause 6.01B. This provision restricts the Operator from contracting for gathering, processing, and transportation capacity for the Joint Account without approval from all Parties unless the contracted service: "(i) is on terms that are not unreasonable; (ii) may be terminated on notice without any use or pay obligations, termination fee or other penalty; and (iii) does not provide for any dedication of reserves." ${ }^{24}$ In the event that a Party does not consent to the sale proposed under subclause 6.02B and does not proceed to take its production in kind, the Operator will continue to dispose of such production under subclause 6.02A.

If a Non-Taking Party does elect to commence to take production in kind, subclause 6.02C requires that Party to provide notice, which will be effective at the end of any sales contract to which the production is being handled or at the date such sales contract is terminated, if terminable by the Operator at an earlier date. ${ }^{125}$ In the latter case, the Non-Taking Party must provide seven Business Days' notice prior to the date upon which the Operator is required to serve notice of its termination.

Clause 6.03 addresses the situation where the Operator is the Non-Taking Party or it elects not to dispose of a Non-Taking Party's production to provide Non-Operators with the same rights as the Operator to dispose of such production, in accordance with cl. 6.02. If more than one Non-Operator chooses to exercise this right, they will do so in proportion to their Working Interests or in other proportions to which the Parties may agree.

\section{MARKET PRICE}

The definition of "Market Price" has been amended in the 2007 Procedure and is as follows:

[T] he price at which Petroleum Substances are disposed of for purposes of this Operating Procedure, which price is not unreasonable, having regard to market conditions applicable to similar production in bona fide arm's length sales agreements at the time of that disposition. A Party making a determination of a Market Price will use a bona fide methodology that is reasonably consistent for the period to which the disposition pertains, and will consider such factors as: (i) the kind, quality and volume of Petroleum Substances disposed; (ii) the timing and duration of the disposition; (iii) whether the disposition is required under a preexisting bona fide arm's length agreement that applies specifically to the Joint Lands and those disposed Petroleum Substances; (iv) the point of sale; and (v) the type of, and costs for using, transportation service 
(including any applicable demand and variable charges, measurement variance and any other volumetric deductions forming part of the consideration for the transportation service, including fuel) to deliver those Petroleum Substances to the nearest point of sale. Except as provided in item (iii) above and, if applicable, in the optional last sentence of this definition, structured prices for terms exceeding 31 days, whether transacted or referenced, are not relevant to the determination of Market Price hereunder. For this purpose, a structured price includes any fixed price, price swap, forward or futures contract, put or call option, either physical or financial, entered into by a Party for the sale of production volumes.

This optional sentence will _____will not ___ (Specify) apply: Notwithstanding the preceding portion of this definition, a Party making a determination of Market Price for a particular type of Petroleum Substance may, for ease of administration, use as a basis for that calculation the weighted average sale price received by it in the applicable period for physical deliveries of substantially all of its own production sale volumes produced in the applicable jurisdiction, including deliveries under arm's length sales agreements with terms exceeding 31 days. ${ }^{126}$

The restriction placed on calculating Market Price to exclude structured pricing, such as fixed prices, price swaps, forward or futures contracts, or put options or call options for contracts with terms that exceed 31 days, provides Non-Taking Parties with security against a disposing Party incorporating out-of-the-money hedging contracts into the calculation of Market Price. For added flexibility and ease of administration, the optional sentence allows for structured prices to be included. However, if Parties elect to include the optional sentence, a Non-Taking Party would receive the same weighted average price the disposing Party receives for its own sale of production, preventing any potential notional allocations by the taking Party of unfavourable marketing contracts. Thus, the optional sentence is based on the assumption that a Party's entire marketing portfolio, consisting of short-term arrangements, in-the-money longer term contracts, and out-of-the-money longer term contracts, will balance out with a corporate average price that is in a reasonable range. If the optional sentence is included, the only difference of payment received would be the payment of the marketing fee by a Non-Taking Party to compensate for marketing efforts.

Given the potential for abuse under the 1990 Procedure's definition of Market Price, Parties entering into new joint ventures that incorporate the 1990 Procedure should consider modifying the definition of Market Price to something similar in the 2007 Procedure definition to mitigate against any potential for abuse, particularly with respect to gas.

\section{MARKETING FEE}

Clause 6.04 has reduced the marketing fee that may be charged from 2.5 percent to 1.25 percent. In addition, cl. 6.02 makes this fee payable by the Non-Taking Party for all production sold, whether under an arm's-length contract or not. This provides administrative simplicity for Operators when calculating fees owed for marketing activities. ${ }^{127}$ The point at which the marketing fee is calculated was also changed to be on the value as calculated at either the wellhead or at the applicable gas plant through an adjustment to the Market Price and not the end sales price, to prevent the Operator from receiving a larger fee depending on 
the extent that the natural gas was gathered, processed, and transported. ${ }^{128}$ While these changes reduce the overall marketing fee a disposing Party will receive, cl. 6.04 requires that a minimum marketing fee for natural gas and sulphur be paid to ensure adequate compensation for the taking Party. In addition, “Alternate B” in cl. 604 of the 1990 Procedure, which was rarely used, has been omitted. The changes made to the marketing fee provision highlight the importance of Parties tailoring a marketing arrangement amongst themselves and entering into a specific marketing agreement if the payment of 1.25 percent is considered insufficient. ${ }^{129}$

\section{E. Payments}

Clause 6.05 allows a disposing Party to pay the royalties owed on the production it is disposing of on behalf of the Non-Taking Party. The corresponding obligations placed on a Non-Taking Party in cl. 6.05 have been expanded in the 2007 Procedure to require NonTaking Parties to provide any information that is reasonably required to enable the taking party to pay these amounts. ${ }^{130}$ This change reflects the fact that a disposing Party would otherwise not have access to company-specific information to properly make payments. ${ }^{131}$ To reduce the risk of liability for the disposing Party, subclause 6.05B has been added to require the Non-Taking Party to indemnify the disposing Party for payments that are made on the Non-Taking Party's behalf for royalties, if payments made are consistent with the information that has been provided. Despite providing the Operator with the ability to pay royalties on behalf of the other Parties, this is an exceptional provision and would only be used if the Operator had a real concern about the ability or willingness of the Non-Taking Party to pay its lessor royalties. ${ }^{132}$

Pursuant to cl. 6.06, funds held by an Operator for the Non-Taking Party's account are to be held in trust. All proceeds received from marketing activities must be paid to Non-Taking Parties no later than the 25th day of the second month after the production month. ${ }^{133}$ This better reflects the accounting practices within the industry, rather than requiring that proceeds be distributed within ten days of receipt, as was required by the 1990 Procedure. Finally, the marketing provisions clarify that the taking Party assumes the risk that a purchaser of a NonTaking Party’s gas will not make payment.

\section{OPERATOR's DUTIES IN CONDUCTING JOINT OPERATIONS}

Article 7.00 addresses the manner in which Joint Operations shall be proposed, conducted, and reported. A Joint Operation is an Operation authorized and conducted under the 2007 Procedure for the Joint Account and will necessarily involve participation by all Parties with a Working Interest in the relevant Joint Property. Joint Operations are distinguished from 
Independent Operations, which are governed by art. 10.00 (and art. 9.00, if applicable) and do not involve full participation by all Working Interest owners.

Clause 7.01 addresses the pre-commencement requirements in circumstances where the Operator proposes to conduct a Joint Operation. The Operator, pursuant to para. 7.01(a), will submit an AFE to each Non-Operator for approval and unless each Non-Operator has returned an approved copy to the Operator within 30 days (compared to 45 days under the 1990 Procedure), that AFE is void. Further, the Operator may not commence a Joint Operation described in an approved AFE more than 120 days after that AFE was received by the Non-Operators (150 days in the case of a Production Facility). If the Operation is not commenced within the applicable period, the AFE is void. ${ }^{134}$

It is interesting to note that approval of an AFE for a Joint Operation by a Party does not prevent that Party from serving an Operation Notice pursuant to art. 10.00 in respect of the same Operation as described in the approved AFE. If the initial AFE is approved by all Parties, such Operation Notice would be nullified, but if the initial AFE is not approved, the Independent Operation under the Operation Notice can proceed. If all Parties elect to participate in the Independent Operation proposed in the Operation Notice, the Operation will be conducted as a Joint Operation under that Operation Notice. ${ }^{135}$ An Operator will likely serve an Operation Notice in addition to or in place of circulating an AFE to ensure that the Operation will proceed if there is some risk that all Parties will not approve the AFE.

Article 7.00 imposes a number of specific duties on the Operator to keep the NonOperators fully informed of the progress of Joint Operations and provide specific information and data at various intervals. With respect to the drilling of a well for the Joint Account, the Operator is required to submit to each Non-Operator, at least 48 hours before Spudding such well, certain information including a copy of the plan and the well location survey, a copy of the well licence, and the proposed program for drilling, coring, logging, testing, and casing that well. ${ }^{136}$ During the drilling of a well for the Joint Account, the Operator must provide certain information including daily drilling and geological reports, ${ }^{137}$ access to cores taken, and copies of any core analysis conducted for the Joint Account, ${ }^{138}$ prompt advice of any porous formations with showings of Petroleum Substances encountered, ${ }^{139}$ and estimates of the current cumulative costs incurred for the Joint Account. ${ }^{140}$ After a well has been drilled, certain logging and testing information is required to be delivered by the Operator to the Non-Operators. ${ }^{141}$ Clause 7.04 states that "[d]uring any Completion connected with the Joint Account, the Operator will Complete that well in accordance with the approved program. It will supply each Non-Operator with current reports on all Completion activities."142 Subsequent to the Completion of any well for the Joint Account, the Operator is required to

$\begin{array}{ll}134 & \text { 2007 Procedure, supra note } 4 \text { at para. 7.01(b). } \\ 135 & \text { Ibid. at para. 7.01(c). } \\ 136 & \text { Ibid. at para. 7.01(d). } \\ 137 & \text { Ibid. at para. 7.02(c). } \\ 138 & \text { Ibid. at para. 7.02(e). } \\ 139 & \text { Ibid. at para. 7.02(f). } \\ 140 & \text { Ibid. at para. 7.02(i). } \\ 141 & \text { Ibid., cl. 7.03. } \\ 142 & \text { Ibid., cl. 7.04. }\end{array}$


supply the Non-Operators with additional information including a complete summary of the drilling and Completion of that well. ${ }^{143}$

\section{HoRIZONTAL WELLS}

At the time the 1990 Procedure was adopted by the CAPL, horizontal wells were not being utilized in the WCSB in a significant way. Accordingly, the 1990 Procedure does not address the unique aspects of horizontal wells and related operations. The interceding 17 years have seen extensive developments in horizontal well technology, knowledge, and usage in Western Canada such that the 2007 Drafting Committee has incorporated art. 8.00 to address Horizontal Wells.

In the 2007 Procedure, a Horizontal Well includes both a Horizontal Wellbore and a Horizontal Leg. ${ }^{144}$ A Horizontal Wellbore is a "single wellbore ... where a portion of that wellbore is drilled with an inclination of at least 80 degrees into a formation"145 (that is, a single wellbore drilled vertically at first, and then gradually varying at an increased angle from the vertical until the wellbore is continuing horizontally into or within a particular formation ${ }^{146}$ ). A Horizontal Leg is "any single wellbore downhole from the point of kickoff from a Vertical Stratigraphic Wellbore if a portion of that wellbore is drilled with an inclination of at least 80 degrees into a formation" ${ }^{\text {"147 }}$ (that is, a horizontal kick off from a vertical wellbore; there can be several Horizontal Legs for each vertical wellbore).

Clause 8.02 recognizes the potential for variation that is inherent in the drilling of a Horizontal Well. Accordingly, latitude is built into the approval of an AFE for a Horizontal Well to allow for operational deviation within reasonable parameters. Notwithstanding this latitude, subclause $8.02 \mathrm{~B}$ specifies that

\footnotetext{
the Operator of an Horizontal Well may not vary it from the description in the associated AFE or Operation

Notice by: (i) drilling a different number of Horizontal Wellbores or Horizontal Legs than the number identified therein; (ii) intentionally varying (other than as required to address drilling difficulties) the length or direction of any single Horizontal Wellbore or Horizontal Leg so that the bottom hole coordinates thereof are not within a radius of 75 metres of the bottom hole coordinates presented therefor in the associated AFE or Operation Notice (or such greater radius as may be agreed). ${ }^{148}$
}

\section{Casing Point Election}

Unlike the 1990 Procedure, which applied to all wells, cl. 9.01 now provides that, subject to a few specific exceptions such as Horizontal Wells and shallow wells where the Parties agree to the setting production casing as part of the drilling approval, the approval by a Party of a drilling AFE does not constitute its agreement to participate in: 
(i) the setting of casing for production; (ii) the further attempted Completion of that well; or (iii) any Completion program described in the drilling AFE. All such additional expenditures for setting casing and the Completion of that well are subject to approval on the basis prescribed by [art. 9.00]. ${ }^{149}$

Pursuant to cl. 9.02, the Operator must notify Non-Operators when a well has been drilled to its authorized total depth and the authorized logs and wireline or drillstem tests have been conducted. The Operator must also "notify the Non-Operators ... [when] it proposes to set casing for production and to Complete that well, and ... promptly provide an AFE for that program." ${ }^{\text {} 50}$ Each Non-Operator will have a period of 24 hours after its receipt of required information to notify the Operator if it will participate in setting casing for production and any associated additional Completion program for that well. A Party will be deemed to have elected to participate if it fails to reply to that notice within the 24-hour period.

Clause 9.03 no longer provides Parties with an election, as Alternate B has been omitted from the 2007 Procedure. Pursuant to cl. 9.03, "if fewer than all Parties set casing for production and further attempt to Complete a well that is Completed for production of Petroleum Substances ... [t]hat Operation will be considered an Independent Operation under Article 10.00 as if it were for a Development Well or an Exploratory Well, as applicable,” subject to the penalty prescribed therein (excluding Drilling Costs), including the application of the title forfeiture provisions of cl. 10.10. Pursuant to cl. 9.04, if fewer than all Parties participated in the casing Operation and those Parties that did participate wish to later abandon that well, the Parties will abandon that well for the Joint Account. However, the Parties participating in the Completion attempt will assume all extra costs of that Abandonment incurred because of that Completion attempt and shall be entitled to priority cost recovery from any income from the sale of Petroleum Substances produced from such well and amounts received from the sale of salvageable material and equipment related thereto.

\section{INDEPENDENT OPERATIONS}

An Independent Operation is an Operation proposed to be conducted pursuant to an Operation Notice issued in accordance with art. 10.00 (and art. 9.00 if applicable) and can be carried out by less than all of the Parties with a Working Interest in the subject matter of the Independent Operation. Article 10.00 is a critical component of the Procedure and ensures that the Joint Lands are not sterilized from development merely because not all Parties agree upon a proposed Operation or the manner in which it will be carried out. The Annotations describe the issue and how it is addressed in the Procedure as follows:

The paramount policy objective of an Operating Procedure is to encourage the joint evaluation of the Joint Lands. It is important to place it in a practical perspective, though. The investment strategies of the Parties will often differ with respect to the nature or timing of a work program and internal budget thresholds. In practice, those differences will often (but not always) be resolved through negotiation. An Operating Procedure, therefore, must include some mechanism for resolution of these differences - an Independent Operations provision. 
The fact that the strategies of the Parties may differ is not inconsistent with the underlying objective of encouraging Joint Operations. The Independent Operations provision, therefore, should not include consequences for non-participation that are chosen so that an Independent Operation will not be a practical alternative. The Parties will probably have different business strategies from time to time. The Parties must structure an Agreement accordingly, to neither encourage nor discourage an Independent Operation if differences cannot be resolved through negotiation. The attempt to balance the recognition of risk and reward is the foundation of this Article. ${ }^{151}$

\section{A. OpERATION Notice}

Subclause 10.02A provides that any Party may, at any time, issue an Operation Notice to the other Parties for an Operation on or in respect of the Joint Lands or for the construction, acquisition, installation, modification, or expansion of a Production Facility. The definition of Operation Notice in cl. 10.01 sets out the information required in such a notice. A notice that does not contain this information or is insufficient runs the risk of being challenged as being invalid. ${ }^{152}$ An Operation Notice must contain all non-proprietary information that would be expected to be material to a Party's decision to participate. In addition, the Operation Notice must identify not only if cl. 10.10 (Wells that Preserve Title) is expected to apply, but also a description of the Joint Lands to which it is expected to apply. ${ }^{153}$

Generally, the Receiving Party has 30 days from receipt of the Operation Notice to elect to participate in the described Operation, failing which it will be deemed to have elected not to participate. ${ }^{154}$ Subclause $10.02 \mathrm{~A}$ in the 2007 Procedure clarifies that this normal response time will apply to a well to reflect the assumption that applications will be approved in due course, even if there is an outstanding application for a holding or other modifications to the Spacing Unit under the Regulation. ${ }^{155}$ Subclause 10.02B of the 2007 Procedure provides exceptions to when the 30-day period can be abridged to 15 days, ${ }^{156} 48$ hours, ${ }^{157}$ or seven Business Days. ${ }^{158}$ Similar to the 1990 Procedure, the 15-day response time relates to Operation Notices that state the proposed Operation is being conducted to evaluate Crown lands being offered for public tender and the 48-hour response period is for Operations on an existing well for Deepening, Sidetracking, re-entry, and completion, provided that the rig to be used is then on site for other Operations on that well. The seven Business Days response time in para. $10.02 \mathrm{~B}$ (c) is new and addresses situations where a rig is on location and a well is being brought into the Agreement after being used for another purpose. The length of such response time reinforces the benefits of prior communication between Parties with a view to abridging the decision process. reference materials and precedents for different situations.

Supra note 4 at para. 10.01(v).

Ibid., cl. 10.02B.

Annotations, supra note 6 at 28-29.

Supra note 4 at para. 10.02B(a).

Ibid. at para. $10.02 \mathrm{~B}(\mathrm{~b})$.

Ibid. at para. $10.02 \mathrm{~B}(\mathrm{c})$. 
A Party that wishes to participate in an Independent Operation may elect to participate only to the extent of its Working Interest ${ }^{159}$ or to the extent of its Working Interest plus its proportionate share of any unassumed percentage of participation until the Participating Parties have fully assumed the total Participating Interest therein. ${ }^{160}$ A Participating Party may also specify a maximum total Participating Interest it is prepared to accept for that Independent Operation, which shall not be less than its Working Interest. ${ }^{161}$ If the Participating Parties have not fully assumed the Participating Interests in an Independent Operation within five Business Days (12 hours in the case of a 48-hour notice) of being notified by the Proposing Party that there remain unassumed Participating Interests, the Operation Notice will be deemed to be withdrawn. ${ }^{162}$

Pursuant to subclause 10.02F, an Operation Notice may not relate to more than one well or more than one Production Facility or any combination thereof. A Party may propose more than one Operation Notice at any given time; however, if it does so, it must "state the order in which they are deemed to be received by the Receiving Parties." 163 The Receiving Parties will be deemed not to have received an Operation Notice served by a Proposing Party for a drilling or Completion Operation respecting a well if any well on the Joint Lands located within 3.2 kilometres of the well to which the new Operation pertains: “(a) has then been approved to be drilled or Completed for the Joint Account under an earlier AFE or Operation Notice; or (b) is then the subject of any other Operation Notice issued by that Proposing Party for a drilling or Completion Operation which has not then been approved for the Joint Account." ${ }^{164}$ Exception (a) is new to the 2007 Procedure and reflects the importance that the results of an approved Operation will have on the decision to participate in the proposed Operation. ${ }^{165}$ If either (a) or (b) applies, the Receiving Parties will be deemed to have received that Operation Notice at: "(i) completion of that other Operation on that other well and the provision to them of the information prescribed ... [under] Article 7.00 ...; or (ii) that earlier date at which that pre-existing AFE or Operation Notice is withdrawn or expires.”166

New to the 2007 Procedure is an optional provision, subclause 10.02G, which provides that the foregoing may not be used to defer a response to an Operation Notice for the drilling or completion of a well if the well's bona fide projected total vertical depth is less than a certain depth specified therein as agreed upon by the Parties at the time of negotiation and execution of the Agreement. As noted in the Annotations:

The restrictions in Subclause 10.02F are sometimes overly restrictive. Large sequential infill drilling programs are common for low risk shallow gas/tight gas and heavy oil projects if the variation in results between wells is expected to be minor. The Operators of those programs usually prefer to treat those wells as a single project to optimize project efficiency, the construction of associated project infrastructure and the 
program cost. They will often be reluctant to sacrifice the program waiting for elections on a well by well basis from a Receiving Party.

This optional Subclause substantially addresses the issues relating to shallow programs, and may often enable an Operator to obtain agreement to handle a program under a single AFE in practice. The Parties should elect that this Subclause will apply if this type of program is expected. (An amendment should be considered if it was not selected and the issue arises after execution.) While Receiving Parties may still elect on a well by well basis (rather than on an entire program), they cannot defer their elections until they see results from other wells in the program. Although a Receiving Party may elect not to participate in a particular well, this is likely to be the exception because of the nature of shallow infill programs. ${ }^{167}$

\section{B. COMMENCING OPERATION}

Pursuant to subclause 10.03A, the Proposing Party may commence the Operation subject to an Operation Notice without waiting for the response period prescribed by $\mathrm{cl}$. 10.02 to lapse, but it cannot commence an Operation with respect to a well without serving an Operation Notice for it; if it does so, it is liable for any damages suffered by the Parties as a result thereof. If a Proposing Party has commenced such Operation prior to expiry of the response period, it is not required to provide any other information pertaining to that Independent Operation to any Receiving Party before the Receiving Party elects to participate therein. According to subclause 10.03B, “[a] Proposing Party may not Commence an Operation more than 120 days [for a well (150 days for a Production Facility)] after the Receiving Parties are deemed to have received the associated Operation Notice.”168 If the Operation has not been commenced in such time, the Receiving Parties are no longer bound by their elections. ${ }^{169}$ New to the 2007 Procedure is a definition of Commenced (the Spud or re-entry date for a well, and in other circumstances, the initiation of the Operation, beyond surveying if applicable) which brings additional certainty to determining whether or not an Operation has been initiated as required.

\section{OPERATOR FOR INDEPENDENT OPERATION}

Notwithstanding the provisions of art. 2.00, subclause 10.04A provides alternative provisions with respect to the options regarding the Operator of an Independent Operation. This differs from both the 1981 and the 1990 Procedures, which did not provide the Parties with an election. In that regard, the 2007 Procedure gives users greater flexibility. In the 2007 Procedure, Alternate (a) provides that the Proposing Party will be the Operator of the Independent Operation and Alternate (b) provides that the Proposing Party will be the Operator of an Independent Operation; however, if the Operator is a Participating Party, it shall have the right to conduct such Operation. In both cases, the Proposing Party cannot be Operator if it is in default under cl. 5.05 or is disqualified from being an Operator under subclause 2.02A. 
Pursuant to subclause 10.04B, if the Operator is a Participating Party in an Independent Operation and it has not already elected to be the Operator of the Independent Operation pursuant to the provisions of Alternate (b) above (if applicable), it may elect to succeed the Proposing Party as Operator thereof at the completion of such Independent Operation or at the conclusion of an agreed upon phase of such Operation.

\section{Divided Well Status}

Clause 10.05 has been broadened in the 2007 Procedure. If a well proposed to be drilled under an Operation Notice would be in part a Development Well and in part an Exploratory Well, the Proposing Party must identify in reasonable detail an allocation of the costs for each portion of the well, ${ }^{170}$ and pursuant to subclause $10.05 \mathrm{~B}$, a Party may elect to participate in the entire Operation or just in the Development Well portion only. ${ }^{171}$ In the event that not all Parties elect to participate in the entire Operation and testing demonstrates that the well is capable of producing Petroleum Substances in Paying Quantities from at least one formation in each such portion of the well: (1) if the Petroleum Substances can be produced simultaneously from each portion of the well, the Operator of the deepest producing formation shall operate the well and will produce and apportion the substances on an equitable basis; ${ }^{172}$ and (2) if the Petroleum Substances cannot be produced simultaneously from both the Development Well and the Exploratory Well portions, the Participating Parties in the Exploratory Well will have a pre-emptive right to produce their portion and will notify the Participating Parties in the Development Well if they exercise their right within 30 days of obtaining production data from the Exploratory Well. ${ }^{173}$ In such event, the Participating Parties in the Exploratory Well will reimburse the Participating Parties in the Development Well all of their Drilling Costs and Completion Costs and such well will be deemed a single Operation conducted in respect of the Exploratory Well portion of the well only. ${ }^{174}$

\section{E. WELLS SERVING JOINT LANDS AND OTHER LANDS}

Clause 10.06 is new to the 2007 Procedure. It addresses circumstances involving the use of a wellbore for activities in both the Joint Lands and in other formations, as well as the acquisition of a wellbore from a third party for potential use with respect to the Joint Lands. The Annotations describe the general rationale behind this Clause as follows:

This Clause has been included to address the issues associated with use of a well for multiple purposes when P\&NG ownership varies. One of the major issues associated with the Operating Procedure since the mid 1990s has been the handling of a well used for multiple purposes-Operations under the Agreement and other activities. The most common example has been the cost equalization when a Party owning a $100 \%$ well abandoned in its own deeper rights then proposes to use it for an uphole Completion in the Joint Lands. Parties holding such a well have typically requested a cost equalization for that use, often based on $100 \%$ of the costs of a new well to that formation. ${ }^{175}$

\footnotetext{
$170 \quad$ Ibid., subclause $10.05 B$.

171 Ibid.

172 Ibid. at para. $10.05 \mathrm{C}(\mathrm{a})$.

173 Ibid. at para. $10.05 \mathrm{C}(\mathrm{b})$.

174 Ibid.

175 Annotations, supra note 6 at 31.
} 
Subclause 10.06A provides that a Party may not use a wellbore held for the Joint Account to either drill more than 15 metres deeper than formations included in the Joint Lands, or conduct a test in any formation not included in the Joint Lands, without the consent of the other Parties. As noted in the Annotations:

\begin{abstract}
A Party may not use a Joint Account well for its own purposes in formations not included in the Joint Lands, unless that other use has been authorized by the other Parties. This reflects the principle that a Party should not be able to use Joint Property for its own gain. This Subclause could see a negotiated transfer of an unsuccessful Joint Account well for assumption of the Abandonment responsibility, perhaps contingent on the initial evaluation of the other formation. However, it could also result in a negotiated cost equalization if its value is high to the Party that wishes to acquire it.
\end{abstract}

This Subclause, Subclause 10.06B and Subparagraph 10.06C(b)(i) contemplate permitted drilling for an additional 15 metres. These references were included to accommodate a logging tool. This incremental depth may change over time because of changes to technology or the Regulations. Insofar as any such change requires some minor incremental depth, Parties are encouraged to administer the $15 \mathrm{~m}$ qualification accordingly. $^{176}$

Subclause 10.06B contains the same prohibition with respect to an Independent Well, although such consent is only required from Participating Parties in such well. However,

(1) "that Participating Party must provide prior notice of that intended use to each NonParticipating Party";

(2) the Participating Party must obtain the consent of all such Non-Participating Parties if such Independent Well is producing or is reasonably anticipated to be capable of producing Petroleum Substances in Paying Quantities from the Joint Lands; ${ }^{178}$

(3) the Drilling Costs and Completion Costs included in the penalty provisions of cl. 10.07 and the cost recovery for that Independent Well shall be reduced in accordance with subclause $10.06 \mathrm{C}$, regardless of whether the well is ultimately successfully completed in any other formation; ${ }^{179}$

(4) if hydrocarbon production is obtained from such well from such other formation for more than 30 total days, "the Participating Parties will be deemed to waive entirely any cost recovery otherwise applicable to that Independent Well ... (and the NonParticipating Parties will have no residual interest in the well) ... unless ... that well will be produced simultaneously from both the Joint Lands” and such other formation and the Non-Participating Parties have agreed to this per item (2) above; ${ }^{180}$ and

$\begin{array}{ll}176 & \text { Ibid. } \\ 177 & \text { Supra note 4 at para. 10.06B(a). } \\ 178 & \text { Ibid. at para. 10.06B(b). } \\ 179 & \text { Ibid. at para. 10.06B(c). } \\ 180 & \text { Ibid. at para. 10.06B(d). }\end{array}$


(5) the Non-Participating Parties are indemnified from liability by the Participating Parties in accordance with cl. 10.18. Subject to any required consents noted above, subclause 10.06B additionally provides that the Operator of any such well producing simultaneously from both the Joint Lands and another formation will manage production from the respective portions of the well separately for measurement purposes while allocating costs on a reasonable basis between the respective portions of the wells. ${ }^{181}$

Subclause 10.06C addresses the proposed usage and importation into the Agreement of an existing well that is owned by a Party (but is not Joint Property) for the conduct of Operations on the Joint Lands. A Party that wishes to propose by way of Operation Notice the usage of such well only for further Operations in the Joint Lands shall propose its bona fide equalization of Drilling Costs between the respective portions of the well on the basis set out, including reasonable details as specified in the 2007 Procedure. The Receiving Parties can object to such equalization figure, and if the Parties cannot agree, the matter shall be referred to arbitration. The response period will be suspended while the matter is arbitrated.

Similar to subclause $10.06 \mathrm{C}$, subclause $10.06 \mathrm{~F}$ addresses the circumstances of a Party acquiring an existing well from a third party, which it then proposes by Operation Notice to use for the Joint Lands. The Receiving Parties shall have a right to equalize into such well based on the Proposing Party's acquisition costs.

\section{F. Penalties}

Clause 10.07 addresses the manner in which penalties are applied and recovered in the event an Independent Well results in production. The 2007 Procedure changes the terminology to replace references to production penalties with cost recovery references. Although this results in the same outcome, it provides a more transparent description of the relationship between Participating and Non-Participating Parties if there is no forfeiture of Working Interest. Subclause 10.07A provides that

[t]he Participating Parties will retain possession of an Independent Well Completed or Recompleted for the production of Petroleum Substances ... until the gross proceeds from sale of that production equal the total of:

(a) $100 \%$ of the lessor's royalty and $100 \%$ of any overriding royalties, freehold mineral taxes or other encumbrances borne for the Joint Account that are paid with respect to that production...;

(b) $100 \%$ of the Operating Costs respecting that well...;

(c) $100 \%$ of the Facility Fees incurred for use of a facility in the production, processing, treatment, storage, transportation or other handling of that production...;

(d) $200 \%$ of the Equipping Costs of that well; 
(e) [some specified percentage (set by the Parties at the time of negotiation and execution of the Agreement) of the Drilling Costs and Completion Costs of the well.. ${ }^{182}$

The percentage in item (e) is typically lower for a Development Well than for an Exploratory Well. Industry standard is typically 300 percent for a Development Well and 500 percent for an Exploratory Well in most areas within the WCSB.

Notification of cost recovery has been modified in the 2007 Procedure. Now, the Operator of an Independent Well must notify the Non-Participating Parties upon payout of the applicable penalty and not later than 30 days after the end of the calendar month in which payout occurred and not 30 days after the event, to correspond with the fact that accounting is typically done on a monthly basis. ${ }^{183}$ Upon payout, each Non-Participating Party shall have the right to elect to become a Participating Party in such well and thereafter share in production and revenues from it and assume a share of the Abandonment and reclamation liability related to it. If a Non-Participating Party elects not to accept participation in such well, it will "forfeit to the Participating Parties its right ... to Petroleum Substances produced from [the well's] Spacing Unit, insofar only as that Spacing Unit relates to production through that wellbore from the formations of the Joint Lands in which that well is then Completed or Recompleted." ${ }^{\prime 84}$ The Party does not otherwise forfeit its Working Interest in the Joint Lands or its right to recover Petroleum Substances from that Spacing Unit from that formation in a different location through a different wellbore. ${ }^{185}$

Subclause 10.07F provides that if a Non-Participating Party's Working Interest is subject to an encumbrance not borne by the Joint Account, the Participating Parties will make any required payments with respect to such encumbrance's share of production or revenues from production from the Independent Well. Participating Parties must post 150 percent of the amount for cost recovery pursuant to subclause 10.07A with respect to such NonParticipating Party. ${ }^{186}$

\section{G. EXISTING WeLlS}

Clause 10.08 addresses Operations on an existing well. The 2007 Procedure places additional limitations on the ability to propose such Operations. Prohibited circumstances where an Operation Notice may not be served include the following: (1) where the condition of the wellbore is "not reasonably appropriate for the purposes of the proposed Operation", ${ }^{187}$ (2) where the proposed Operation "would damage the wellbore or pose material HSE risks"; ${ }^{188}$ (3) where the Operation involves "Deepening, Sidetracking, Recompletion, Reworking or other downhole Operation for a well ... that is producing or capable of producing Petroleum Substances in Paying Quantities” (unless authorized by all Parties

Ibid., subclause 10.07A.

Ibid., subclause $10.07 \mathrm{C}$.

Ibid., subclause 10.07E.

Ibid.

Ibid. at para. $10.07 \mathrm{~F}(\mathrm{~b})$.

Ibid., subclause 10.08A.

Ibid. 
having a Participating Interest in such well); ${ }^{189}$ and (4) where it involves "the Deepening or Sidetracking of a well below its authorized total depth if at least one Party has proposed to Complete or Recomplete that well in a formation at or above that depth ... [pursuant to] Article 9.00 or this Clause 10.08.”190 Further, a Non-Participating Party may not propose or participate in an Operation in respect of a well until after it has regained the right to share the production of Petroleum Substances therefrom except in certain specified circumstances. ${ }^{191}$

Pursuant to para. 10.08C(b), with respect to the Deepening or Sidetracking of an Independent Well for which there is at least one Non-Participating Party, "each such NonParticipating Party may participate in that Deepening or Sidetracking, provided that ... it [generally] reimburses the applicable participating Parties $100 \%$ of its Working Interest share of the estimated Drilling Costs and Completion Costs already accrued for that well” as set out therein. ${ }^{192}$

Pursuant to subclause 10.08F, the Receiving Party in respect of an Operation Notice for an Equipping may elect to: (1) participate in that Equipping; ${ }^{193}$ (2) not participate in that Equipping but take in kind its share of Petroleum Substances at a point prior to the use of equipment to which the Equipping pertains provided that the nature of the proposed Equipping allows that Party to take in kind without using such equipment; ${ }^{194}$ or (3) not participate in that Equipping and be subject to a cost recovery pursuant to cl. 10.07, mutatis mutandis. ${ }^{195}$

\section{H. Title Preserving Wells ANd Forfeiture}

Clause 10.10 addresses the forfeiture of rights when an Independent Well is also a Title Preserving Well or Subsequent Title Preserving Well. If a Party does not participate in an Operation in respect of a well that has the effect of preventing the reversion of areal and stratigraphic rights to the grantor under a Title Document (that is, it continues the Title Document with respect to such rights), rather than being subject to the penalties contemplated in cl. 10.07, the Parties that do not participate in such well are deemed to have forfeited their interests in such areal and stratigraphic rights to the Parties who did participate in such well. The Participating Parties entitled to the forfeited interest are only those that participated beyond their initial Working Interests and assumed a share of the forfeiting Parties' interest in the well.

The provisions of cl. 10.10, and the practical application of such clause in multiple scenarios, are significantly more complex than the above simple explanation. Accordingly, while this discussion attempts to provide a useful overview of such provisions, the scope of this article does not allow a complete analysis of these provisions. With the maturity of the 
WCSB and the related increasing usage of downspacing and infill drilling along with the proliferation of areal and stratigraphic (deep and shallow rights), and in some cases, substance (natural gas or petroleum) reversion mechanisms in freehold and Crown Title Documents, the authors anticipate that this mechanism, in its various iterations under the 2007 and earlier Procedures, will be increasingly referred to and relied upon. Accordingly, the authors caution users of the Procedure to take the time to appreciate the differences between the various Procedures. In that regard, the Annotations to the 2007 Procedure and those provided with the 1990 Procedure will be particularly helpful.

In order to develop an understanding of cl. 10.10 of the 2007 Procedure, it is important to understand the concepts of the Title Preserving Well and Subsequent Title Preserving Well, which have been modified in the 2007 Procedure to provide greater clarity. A Title Preserving Well

\begin{abstract}
means a well that is drilled (in whole or in part), Completed, Recompleted or placed on production hereunder, insofar as failure to conduct that Operation would result in the reversion of any Joint Lands to the grantor of the applicable Title Document(s), provided that: (i) such Operation is to be Commenced not earlier than _ days before the date that reversion would occur; and (ii) the reversion date for a Title Document that may be extended for another year, without approval of its grantor, by paying either or both of a prescribed rental or fee will be the last day of that extension period. ${ }^{196}$
\end{abstract}

For the purposes of art. 10.00, a well drilled early in the term of a Title Document will not be a Title Preserving Well even though ultimately, it may be the basis on which certain areal and stratigraphic rights under the Title Document are continued. In this case, a NonParticipating Party is only subject to the production penalties contemplated in cl. 10.07. Accordingly, a Title Preserving Well must be drilled late in the term of a Title Document and have the effect of continuing rights therein. The Parties can customize the provision to accommodate the time frame of when an Independent Well can be a Title Preserving Well, taking into account the unique provisions of the Title Document and the operational logistics and other relevant factors of the area of Operations.

\title{
A Subsequent Title Preserving Well is defined in the 2007 Procedure as
}

\begin{abstract}
a well that is drilled (in whole or in part), Completed, Recompleted or placed on production hereunder at such time and in such manner that it also would have been a Title Preserving Well for any Preserved Lands, provided that a well that is a Subsequent Title Preserving Well for certain Preserved Lands may also simultaneously be a Title Preserving Well for other areal and stratigraphic rights included in the Joint Lands. $^{197}$
\end{abstract}

Assuming traditional spacing of one section for a gas well and one quarter-section for an oil well, and that two wells are drilled in the same section of land, one being a Viking gas well and the other being an Ostracod oil well, both within the required time frame to constitute a Title Preserving Well, then the first well will be the Title Preserving Well and the second well will be the Subsequent Title Preserving Well. 
The circumstances of having both a Title Preserving Well and Subsequent Title Preserving Well are expected to be rare. Where there is only a Title Preserving Well, a NonParticipating Party will forfeit 100 percent of its Working Interest to the Participating Parties in: (1) that well and its Spacing Unit at completion of that Operation insofar only as that Spacing Unit pertains to Preserved Lands; ${ }^{198}$ and (2) "the balance of the Preserved Lands at the date they would otherwise have reverted under the applicable Title Document(s)."199 Preserved Lands are defined as "any areal and stratigraphic rights included in the Joint Lands that would have reverted to the grantor of the applicable Title Document(s) if there were no Title Preserving Well, subject to any designation of Preserved Lands under Subclause 3.10D." 200

Under some tenure regimes, the Parties may have some ability to select which stratigraphic and areal rights shall be continued under a Title Document based upon the work undertaken prior to a specified land selection point. Subclauses 3.10C and 3.10D provide a process by which that designation occurs and a mechanism to resolve disagreement arising in connection therewith. The definition of Preserved Lands is expressly subject to this designation.

The purpose of subclause $10.10 \mathrm{C}$ with respect to the unlikely scenario of a Subsequent Title Preserving Well has been described by MacLean (in a commentary on the similar provisions of the 1990 Procedure) as addressing three potential situations:

The first is the situation in which a non-participating party with respect to the title preserving well participates in the subsequent title preserving well. It will not be required to forfeit its working interest in any common preserved lands.

The second is the situation in which a non-participating party with respect to the subsequent title preserving well was also a non-participating party with respect to the title preserving well. It generally shall forfeit its working interest in the spacing unit of the subsequent title preserving well to the participating parties therein, rather than to the participating parties in the title preserving well.

The third is the situation in which a non-participating party in the subsequent title preserving well was a participating party in the title preserving well. It would generally only be subject to a production penalty respecting the subsequent title preserving well. However, it would be subject to the forfeiture ... if the well preserved lands in addition to those preserved by the initial title preserving well, since a subsequent title preserving well can also be a title preserving well with respect to another portion of the joint lands. ${ }^{201}$ 
Subclause 10.10C contains provisions respecting the above scenarios and consequences which are as described above. Subclause 10.10D contains additional provisions respecting the consequences of the temporary retention of Common Preserved Lands with a requirement that the applicable Participating Parties would redetermine the Preserved Lands and Common Preserved Lands as of the expiry of that temporary retention,

based on the principle that the benefits of continued retention of the applicable Joint Lands should accrue to the Participating Parties in the work conducted hereunder that allows those lands to continue to be retained. The Parties will apply Subclauses 10.10B and C, mutatis mutandis, to adjust their Working Interests in the former Common Preserved Lands accordingly to reflect any redetermination under this Subclause. ${ }^{202}$

Subclauses $10.10 \mathrm{~B}$ and $10.10 \mathrm{~F}$ address circumstances where a Non-Participating Party in a Title Preserving Well or Subsequent Title Preserving Well may be subject to cost recovery under cls. 9.03, 10.07, or 10.08, insofar as the areal and stratigraphic rights of the Spacing Unit do not contain Preserved Lands.

\section{Production FAcilities}

Clauses 10.13 and 10.14 address non-participation in the installation or expansion of Production Facilities. Production Facility provisions were first introduced in the 1990 Procedure and have been expanded in the 2007 Procedure to provide more options for Parties that do not wish to participate in the proposed facility. Pursuant to subclause 10.13A, "a Party may, at any time, issue an Operation Notice for a Production Facility."203 As set out in subclause 10.13B, a Party receiving such Operation Notice may elect to: (1) participate in the Operation; ${ }^{204}(2)$ take its share of Petroleum Substances in kind after the First Point of Measurement and before the inlet to the proposed Production Facility (assuming the nature of the proposed Production Facility allows a Party to take in kind without using that Production Facility); ${ }^{205}$ (3) not participate in the Operation and be subject to cost recovery under subclause $10.13 \mathrm{D} ;{ }^{206}$ or (4) use that Production Facility for a fee to be determined in accordance with cl. 14.04. ${ }^{207} \mathrm{~A}$ Party that fails to make an election will be deemed to elect to take in kind pursuant to para. $10.13 \mathrm{~B}$ (b) unless such taking in kind is not possible, in which event, such Party will be deemed to have elected to pay a fee to use such Production Facility pursuant to para. $10.13 \mathrm{~B}(\mathrm{~d})$. A Party receiving notice can object on the grounds that the Production Facility in such Operation Notice does not satisfy the requirements of the definition of Production Facility, in which event the matter will be referred for resolution pursuant to art. 21.00. The authors note that the definition of Non-Participating Party in cl. 10.01 clarifies that a Non-Participating Party does not include a Party making an election in respect of a Production Facility under para. 10.13B(b) to take its share of production in kind or under para. $10.13 \mathrm{~B}(\mathrm{~d})$ to pay a usage fee. 
A Party that elects not to participate pursuant to para. 10.13B(c) will be subject to the specified cost recovery set out in subclause 10.13D. In such circumstances, the NonParticipating Party's share of production from those wells governed by the Operating Procedure that use the Production Facility shall be retained by the Participating Parties until the gross proceeds from the sale of that production equal the total of: (1) " $100 \%$ of the lessor's royalty and any overriding royalties, freehold mineral taxes or other encumbrances”; ${ }^{208}$ (2) “100\% of the Operating Costs incurred for those wells and ... for that use of the Production Facility"; ${ }^{209}$ (3) 100\% of the Facility Fees [excluding the Production Facility] incurred for use of any additional facility for the production, processing, treatment, storage, transportation or other handling of Petroleum Substances; ${ }^{210}$ or (4) " $200 \%$ of the cost of the construction, acquisition and installation of that Production Facility.”211

Pursuant to subclause 10.13E, a Non-Participating Party may, at any time, become a Participating Party with respect to the Production Facility by paying the total amount of the cost recovery outstanding, as calculated in accordance with subclause $10.13 \mathrm{D}$.

The Operator for the Participating Parties in the Production Facility will notify the NonParticipating Parties within 30 days after the end of the calendar month in which cost recovery occurs. Within 30 days of receipt of such notice, each Non-Participating Party will notify the Operator if it accepts or refuses participation in that Production Facility. Failure to respond will be deemed an election to accept participation. ${ }^{212}$

Whether a Non-Participating Party becomes a Participating Party pursuant to subclause 10.13E by paying a lump sum cash payment or after election upon notice pursuant to subclause 10.13G of cost recovery, on acceptance of participation, the Non-Participating Party will become a Participating Party and will acquire an interest in the Production Facility equal to its Working Interest, effective as of the date of that payment or cost recovery. ${ }^{213}$

If a Non-Participating Party refuses participation in a Production Facility pursuant to subclause 10.13G, it "will forfeit its right to participation therein" and may only use such Production Facility for a "fee as may be agreed upon with the Parties that own it." such agreement, the Participating Parties may impose a fee on the same basis as provided in cl. 14.04, including a reasonable rate of return on capital investment. Such fee shall be in addition to any marketing fee under cl. 6.04. ${ }^{215}$

Clause 10.14 deals with non-participation in the expansion of the Production Facility and incorporates the provisions of $\mathrm{cl}$. 10.13, mutatis mutandis, subject to certain exceptions including that the cost recovery prescribed under para. $10.13 \mathrm{D}(\mathrm{d})$ shall be 150 percent rather than 200 percent $^{216}$ and that "a Party that holds a Working Interest in that Production Facility 
that is a Non-Participating Party for that expansion ... will acquire its Working Interest” in expansion upon cost recovery. ${ }^{217}$

\section{J. MiscellaneOUS}

Clause 10.16 expressly provides that, subject to the terms of art. 10.00, "the provisions of this Operating Procedure will apply, mutatis mutandis, to an Independent Operation, as if it otherwise were a Joint Operation of the Participating Parties." 218 Clause 10.17 specifies that the Participating Parties will share, in the same proportions as their participation in the relevant Independent Operation, the allocation of any production, any forfeiture of interest, any cash payment by a Non-Participating Party pursuant to cls. 10.13 or 10.14 , any right of a Non-Participating Party to resume participation under art. 10.00, and any other benefits and obligations related to the Independent Operation.

Clause 10.18 addresses the indemnification by Participating Parties of Non-Participating Parties and a Receiving Party that has made an election under subclause $10.08 \mathrm{~F}$ or subclause $10.13 \mathrm{~B}$ to take its share of production in kind or pay any applicable usage fee.

Clause 10.19 provides that a Non-Participating Party with respect to an Independent Well will not initially be entitled to access to a well site or any information therefrom until it becomes a Participating Party therein subject to earlier access in certain circumstances. Numerous changes were made to this provision in the 2007 Procedure, including increasing the time for distribution of drilling information to 150 days after rig release ${ }^{219}$ compared to 90 days under the 1990 Procedure, ${ }^{220}$ applying the provision to Deepenings and Sidetrackings, and clarifying the information to be provided for Completions and production data.

\section{SURRENDER OF JOINT LANDS}

Article 11.00 addresses the process for surrender of Joint Lands.

[Any] Party may notify the other Parties that all or some of the Joint Lands held thereunder are proposed for surrender to their grantor. That Party may only propose for surrender Joint Lands of dimensions that such grantor would be required to accept the surrender... Each other Party will notify the other Parties within 30 days after receipt of the notice if it elects to join in the surrender ... [and] ... will be deemed to elect not to join in the surrender. 221

This occurs if it fails to respond to the notice within the required period.

Pursuant to cl. 11.02, if all Parties elect to surrender Joint Lands,

$\begin{array}{ll}217 & \text { Ibid. at para. 10.14(d). } \\ 218 & \text { Ibid. at para. 10.16. } \\ 219 & \text { Ibid. at para. 10.19(a). } \\ 220 & \text { Supra note 3 at para. 1018(a). } \\ 221 & \text { Supra note 4, cl. 11.01. }\end{array}$


the Operator will promptly salvage all salvable Joint Property serving only the Joint Lands ... including any Production Facilities serving only wells located on those Joint Lands.... [T] he Parties will hold the applicable Joint Lands and other associated Joint Property for the Joint Account until the surrender has been irrevocably effected. Each Party will accrue its Working Interest share of all benefits and obligations pertaining to those Joint Lands and that Joint Property ... until the surrender is complete.,222

Further, the 2007 Procedure has added a new provision, which states that "Parties will remain responsible ... for accrued liabilities pertaining to the Joint Lands surrendered under [art. 11.00], including any Abandonment obligations or other Environmental Liabilities for associated surface rights." ${ }^{223}$

Pursuant to cl. 11.03, if fewer than all of the Parties elect to join in the surrender, ${ }^{224}$ "each Party that elected to surrender its Working Interest ... will be deemed to have assigned those interests to the non-surrendering Parties in proportion to their respective Working Interests therein, or in such other proportions as they may agree.”225 This assignment is effective immediately prior to the next anniversary date or other date on which an obligation must be fulfilled to maintain a Title Document in good standing. "[A] surrendering Party will be released from all obligations thereafter accruing for the surrendered Joint Lands and the associated Joint Property,"226 however, such release will not apply to obligations and liabilities accrued prior to the effective date of such assignment, including any Environmental Liabilities, capital costs for approved Operations, and any required adjustments of accounts under the Accounting Procedure. ${ }^{227}$

\section{Abandonment of Joint Wells}

Pursuant to cl. 12.01, any Party may notify the other Parties of its intention to initiate Abandonment of a well held for the Joint Account. Within 30 days after receipt of the notice, each other Party will notify the other Parties if it wishes to take over that well. A failure to respond to the notice will be deemed to be an election to retain the well. Any Party may, by notice to the other Parties, revoke its election to abandon a well if at least one Party elected (or was deemed to elect) to retain the well and not join in the Abandonment. It is the Operator's responsibility to abandon the well for the Joint Account if all Parties elect to join in the Abandonment.

If fewer than all Parties elect to abandon a well, the abandoning Parties will, effective as of the expiry of the 30-day notice period and without consideration or warranty, be deemed to have assigned to the Parties electing to retain the well, on an "as is, where is" basis, the abandoning Parties' Working Interests in: “(i) that well; (ii) the surface rights and other Joint Property serving only that well; and (iii) the right to produce Petroleum Substances from the Spacing Unit of that well, insofar only as it relates to the formation in which that well has

\footnotetext{
222 Ibid., subclauses 11.02A-B.

223 Ibid., subclause $11.02 \mathrm{C}$.

224 Ibid., subclause 11.03A.

225 Ibid., subclause 11.03B.

226 Ibid., subclause 11.03C.

227 Ibid.
} 
been Completed and the exploitation thereof through that wellbore.”228 Subclause 12.02A specifies, however, that this assignment does not apply to the abandoning Parties' Working Interest right to recover Petroleum Substances from that formation or that Spacing Unit through the use, in whole or in part, of a different wellbore. The authors note that cl. 1201 of the 1990 Procedure provided that the assignment of the Working Interest related to the "producing zone of the well."229 This has caused some confusion among parties in cases where the well proposed for abandonment did not produce. This has been interpreted by a few parties as resulting in the assignment of the wellbore and if there is a subsequent completion to another formation, the deemed surrender and assignment of such formation on the basis of the Abandonment notice. Accordingly, the Drafting Committee responded to this concern and clarified that only the existing completed formation is subject to this assignment.

Also new for the 2007 Procedure is cl. 12.03, which provides that the abandoning Parties (including their successors in interest) then holding Working Interests in the applicable Joint Lands have the opportunity to reacquire for little incremental consideration (salvage value less Abandonment costs) a Working Interest in the well equal to their Working Interest in the Joint Lands, if the well is subsequently plugged back or Deepened in order to conduct additional Operations on the Joint Lands.

\section{OPERATION OF SEGREgATED INTERESTS}

Article 13.00 is designed to accommodate changes in ownership and rights that are a natural evolution of joint venture contracting in the oil and gas industry. While Working Interest ownership at the time of initially entering into the Head Agreement will be consistent across the Joint Property, over time, with partial Working Interest dispositions, partial Joint Land dispositions and forfeitures (geographic and stratigraphic), and dispositions of rights to only some of the Petroleum Substances (that is, natural gas rights or petroleum rights), the ownership of all of the initial Joint Property may no longer be held by the same Parties in the same interests. Accordingly, art. 13.00 has been developed to address these circumstances and to create parallel agreements and operating procedures among the different ownership groups and their assets.

In effect, cl. 13.01 provides that an identical agreement is deemed to have been created upon creation of these heterogeneous ownership situations and the parallel agreements govern the segregated assets and parties. The following example is used in the Annotations to explain how this mechanism works:

To illustrate the impact of this provision, assume that the Parties' Working Interests in sections 1 and 2 were initially held by A, B and C, and that A and B later acquired all of C's interest in section 1 because of a forfeiture. $\mathrm{B}$ is now proposing to dispose of its entire interest in both sections when there is a ROFR obligation. B would serve one ROFR notice to A for section 1 and a separate ROFR notice to A and C for section 2, as each section is treated as being subject to its own Agreement. ${ }^{230}$ 
Parties should be mindful of this provision both when negotiating the Head Agreement and when completing a transaction resulting in such segregation. For example, the Parties should consider whether an area of mutual interest provision in the Head Agreement is intended to be carried forward and duplicated in the parallel agreement or excluded and bind only the original parties. The handling of existing Production Facilities and wellbores may also require additional consideration in a transfer situation. While the segregation mechanism has proven to be a valuable contracting and administration tool, its application in certain circumstances can have unintended consequences, and accordingly, the Parties should give careful consideration to this provision's potential impact at the time of negotiating the Head Agreement and Procedure.

\title{
XIV. Operation of Joint Production Facilities
}

The 1990 Procedure was the first Procedure to include provisions relating to the construction, ownership, and operation (CO\&O) of certain minor production facilities initially constructed exclusively for the Joint Lands. Such provisions are intended to accommodate these activities without the need for a comprehensive CO\&O agreement. The 2007 Procedure has benefited from the development since the 1990 Procedure comprehensively and widely utilized forms of CO\&O agreements developed by the Petroleum Joint Venture Association (PJVA).

Clause 1.01 of the 2007 Procedure contains a new and narrower definition of Production Facility:

\begin{abstract}
"Production Facility" means, subject to any application of: (i) Article 13.00 to create a separate agreement due to inconsistent Working Interests; (ii) Clauses 10.13 and 10.14 for Independent Operations; and (iii) Clause 14.02 to require a separate agreement, any personal property and fixtures beyond wellhead connections serving (or intended to serve) more than one well, including any battery, separator, disposal well, injection well approved by all Parties, compressor station, gathering system, pipeline, production storage facility or warehouse, which is:
\end{abstract}

(a) constructed or installed for the Joint Account;

(b) owned exclusively by the Parties;

(c) initially designed and intended exclusively for the production, treatment, storage, transportation or other handling of Petroleum Substances or associated sediment, water or other impurities;

(d) not a gas plant, being a facility (other than a dehydration unit) that changes the quality of natural gas, including such activities as fractionation of Petroleum Substances, sulphur extraction or separation of liquids by refrigeration;

(e) not subject to a separate agreement governing the construction, ownership and operation of that facility; and

(f) This optional Paragraph will /will not (Specify) apply: 
A Production Facility includes all directly associated real and personal property of every kind, nature and description, excluding Petroleum Substances, the Joint Lands and the Operator's owned or leased equipment, unless leased for the Joint Account for use as or with respect to a Production Facility. ${ }^{231}$

Consistent with the approach in the 1990 Procedure, the concept of Production Facility in the 2007 Procedure is distinguished from equipment installed pursuant to an Equipping Operation on the basis that such equipment serves only one well and a Production Facility is intended to serve more than one well. The definition of Production Facility gained some clarification in this version with a view to ensuring that for a facility to qualify, it must not be initially designated and intended to process Outside Substances and expressly excludes all gas plants, rather than only more complex gas plants as in the 1990 Procedure. $^{232}$ In addition, an optional qualification is included at para. (f) to exclude facilities with initial construction and installation capital costs of more than a specified amount (to be specified by the Parties at the time of entering into the Procedure). The intention is for the Procedure to apply to small facilities only; if any of the Parties are contemplating a large facility, they should negotiate a separate CO\&O agreement.

One notable difference between the 1990 Procedure and the 2007 Procedure is that the commitment to deliver contained in cl. 1402 of the 1990 Procedure was not carried forward to the 2007 Procedure. The explanation from the 2007 Drafting Committee for the removal of the provision is that such a covenant could limit the Parties' ability to manage their production cost effectively. Given the minor nature of the facilities intended to be covered by this Agreement and the associated capital spending in respect of same, one expects this added flexibility to be helpful in most situations.

Clause 14.02 provides that a Production Facility will no longer be operated under the Operating Procedure if:

(a) surplus capacity therein will be used to handle Outside Substances of a Party or third party and any Party requests, by notice, that the Production Facility be governed by a separate agreement...;

(b) any proposed expansion of or addition to a Production Facility would result in it thereupon being used to handle Outside Substances...; or

(c) the Parties so agree, in which case it will cease to be a Production Facility as of the time they designate.

If a Production Facility ceases to be a Production Facility under this Clause, the Parties will negotiate a separate agreement for its operation with due diligence and in good faith, using as a basis the 1999 PJVA CO\&O Agreement (or the most current replacement therefore then endorsed for use by the Petroleum Joint Venture Association) and the Accounting Procedure. ${ }^{233}$

Clause 14.03 provides that each Production Facility will initially be designed and used exclusively for Petroleum Substances (that is, petroleum and natural gas for which the Title 
Documents, insofar as they pertain to the Joint Lands, grant the right to explore, develop, or produce). A Party with a Working Interest in a Production Facility may "use all or a portion of any surplus capacity therein on an interruptible basis for Outside Substances owned by it, provided that the Outside Substances are compatible with the design and operation of that Production Facility”234 and with other Petroleum Substances. Petroleum Substances will always have priority in the use of the Production Facility. ${ }^{235}$ "The Operator will prorate any additional surplus capacity to the Parties wishing to use it in the ratio that each of their Working Interests therein bears to their total Working Interests therein."236 The 1990 and 2007 Procedures do not provide for a capital fee to be paid by Working Interest owners using surplus capacity for their own Outside Substances. The Annotations helpfully suggest an alternative to the absence of a capital fee for usage by a Party of surplus capacity for such Party's Outside Substances by suggesting the drafters incorporate in cl. 14.03 a customized provision reflecting the payment of a capital fee on the same basic terms as that established pursuant to subclause $14.04 \mathrm{~B}$. $^{237}$ In addition, users should not overlook the right that all Parties have, pursuant to cl. 14.02, to force the Production Facility to be governed by a separate agreement.

Clause 14.04 provides that "a Production Facility may only be used for Outside Substances owned by a third party with the approval of all Parties with Working Interests therein. The Operator will notify the other Parties of the material terms of any such proposed third party arrangement"238 and any Party that does not object to such a proposed arrangement within ten Business Days of receipt of such notice will be deemed to have approved it. "[T]he fee charged to a third party for use of a Production Facility ... will include (a) a capital recovery component ... Jumping Pound-05 methodology ...; and (b) an operating cost component calculated and assessed on the basis of facility throughput costs." "239 “The Operator will credit the Parties on a monthly basis the capital recovery component of all fees received from a third party in proportion to their Working Interests in the Production Facility."240 The treatment of sharing of capital fees earned on Outside Substances is handled differently than is typical under major facility CO\&O agreements, including the PJVA model form. Capital fees for major facilities are typically allocated on the basis of the contribution to surplus capacity that an owner has made; however, under the 1990 Procedure $^{241}$ and 2007 Procedure, capital fees are allocated based on the Party's Working Interest in the Production Facility, which creates some potential for unfairness. To the extent this potential for unfairness is not sufficiently justified by the additional administrative burden associated with allocating capital fees differently, the likelihood that the ownership in the Production Facility will be roughly equivalent to the ownership of Petroleum Substances serviced by the Production Facility, and by the fact that Outside Substances should represent a very small percentage of total throughput at the facility, Parties 
negotiating using the 2007 Procedure may wish to customize this provision to accommodate a difference method of fee allocation.

Clause 14.05 provides: “[t]he Operator will allocate Operating Costs of a Production Facility on a throughput basis, proportionate to the volumes of Petroleum Substances and Outside Substances delivered to the Production Facility for handling."242 Clauses 14.06 and 14.07 address the allocation of products and the allocation of losses and shrinkage on a basis consistent with industry standards.

\section{ENCUMBRANCES}

A provision addressing the treatment of additional royalties encumbering a Party's Working Interest was first introduced in art. VIII of the 1990 Procedure and has been retained in substantially the same form in art. 15.00 of the 2007 Procedure. This Article has been included to discourage a Party from creating or recognizing any encumbrances on its Working Interest that are not lessor royalties or charges borne by the Joint Account. Pursuant to cl. 15.01, each Party is solely responsible for any such additional encumbrances that become attached to its Working Interest. As a result of this responsibility, in the event that the encumbered Working Interest is subject to an assignment because of: (1) enforcement of default remedies in cl. 5.05; (2) "non-participation in an Operation under a Casing Point election in Article 9.00 or the Independent Operation processes in Article 10.00"; (3) "surrender or proposed Abandonment by fewer than all Parties under Article 11.00 or 12.00"; or (4) any other provision of the Procedure, other than disposition made under art. 24.00, that Party will remain liable for the additional encumbrance on such Working Interest, notwithstanding that it no longer holds the Working Interest. ${ }^{243}$ In addition, cl. 15.01 imposes indemnification obligations from any resulting Losses and Liabilities that another Party may suffer "because of the encumbered Party's failure to fulfill its responsibilities for that additional encumbrance." 244 By placing liability and indemnification obligations on the Parties in such circumstances, it is anticipated that this will encourage Parties to structure contracts that create additional encumbrances, such as overriding royalties granted to employees or consultants, in a way that is not adverse to the interest of the other Parties upon the surrender, forfeiture, or cost recovery of such Working Interests.

Clause 15.02 provides an exception to $\mathrm{cl}$. 15.01 by stating that insofar as the additional encumbrance is created under the Agreement or is acknowledged by the Parties as being an encumbrance that applies to the Working Interest, an encumbering Party will not be held solely responsible for that encumbrance pursuant to $\mathrm{cl}$. 14.01 in the referenced circumstances. As a result of this exception, Parties should always review the Head Agreement to determine if there is any special treatment of encumbrances that will apply. The Head Agreement itself may create additional encumbrances or override the provisions contained in art. 15.00 . 


\section{FORCE MAJEURE}

The purpose of including a Force Majeure clause is to excuse a Party from the performance of contractual obligations upon the happening of some specified event, if that event is beyond its control and prevents performance of the applicable obligation. Clause 16.01 states that "[n]otwithstanding any provision ... requiring performance of a particular obligation or its performance by a particular time (including that prescribed for Commencement of an Operation ....)"245 any obligation that a Party is prevented from fulfilling, either in whole or in part, as a result of Force Majeure, will be suspended with the period for performance extended. Any Party relying on Force Majeure for non-performance is required to notify the other Parties and provide in reasonable detail the suspended obligations, the date and extent of the suspension, and its anticipated duration. Clause 16.02 places an obligation on any Party relying on Force Majeure to "promptly remedy its cause and effect, insofar as it is reasonably able to do so."246 For the duration of the suspension, the Party claiming Force Majeure must also update the other Parties regarding the status and efforts taken to remedy the situation at a reasonable frequency.

Although the changes made to art. 16.00 in the 2007 Procedure are relatively minor, the Drafting Committee has clarified that Force Majeure applies not only to the performance of obligations, but also includes the time for Commencing Operations. Additionally, the obligation to update other Parties regarding the status and efforts taken to remedy the event of Force Majeure have been added, replacing the previous requirement that notice merely be provided to the other Parties when the Force Majeure ends. The definition of Force Majeure has been moved to $\mathrm{cl}$. 1.01 to streamline the document. The financial restrictions stating that lack of financing or changes in a party's economic circumstances or changes that affect the economic attributes of investments will not be considered an event of Force Majeure have been included as part of the definition, rather than as a separate "notwithstanding” clause.

\section{INCENTIVES}

Article 17.00 addresses the sharing of incentives and benefits among Parties. Subclause 17.01A states: "Parties participating in an Operation will share any resultant drilling incentives, geophysical incentive credits, royalty exemptions or other incentives that accrue collectively to them under the Regulations.”247 The 2007 Procedure places a restriction on this obligation by stating that notwithstanding the foregoing, in the event that any benefit or incentive accrues to an individual Party due to its unique corporate or organization attributes, that Party does not share these types of incentives among all Working Interest owners. This recognizes that some benefits, such as a different cost base in Joint Property, may entitle a Party to a lower royalty rate than other Parties. 
Subclause 17.01B has been added in the 2007 Procedure, bringing clarity to the allocation of grouping entitlements. It states that "[i]f an Operation enables the Parties to apply entitlements under the Regulations to retain portions of the Joint Lands for a further period under the Title Documents, the Parties will first apply them to the Joint Lands." ${ }^{448}$ If there are additional entitlements left over after this is done that would allow for the retention of other petroleum and natural gas rights, the Parties that participated in that Operation must consult about the use of those additional benefits. If Parties are unable to agree on their use, each shares those additional entitlements in proportion to their Participating Interest in the Operation that generated the entitlement. Essentially, subclause 17.01B has created an obligation to apply any entitlements to eligible Joint Lands first, before any Party can use its proportionate share as it wishes for its own benefit. The following example has been included in the Annotations to explain how this allocation would work:

To illustrate, assume that: (a) A and B have participated on a 50-50 basis in a well that would entitle them to the retention of 12 sections under the Regulations when there are only 6 sections of Joint Lands that could use those entitlements; (b) A (50\%) and B (15\%) hold 6 sections of other P\&NG rights that could use those entitlements under another agreement; and (c) B holds 2 other sections of $100 \%$ lands that could also use those entitlements. Unless otherwise agreed by A and B, the first 6 sections of entitlement would be applied to the Joint Lands, such that each has an entitlement to 3 sections remaining. Assuming that B's greater priority was the retention of its $100 \%$ P\&NG rights, B could apply 2 sections of its entitlement to its $100 \%$ P\&NG rights and the remaining section to its minor interest J.V. section. ${ }^{249}$

\section{CONFIDENTIALITY AND USE OF INFORMATION}

Protecting and disclosing confidential information is a highly sensitive issue in the oil and gas industry. In trying to achieve an appropriate balance between protecting confidential information and allowing Parties to use it to facilitate legitimate business transactions, cl. 18.01 of the 2007 Procedure entitles each Party to use information obtained pursuant to the Agreement for its own benefit and account, provided that, subject to certain exceptions, each Party is required to take appropriate measures to keep information confidential from third parties or other Parties to the Agreement that are not entitled to such information. As noted below, such wording should help to mitigate the risk of a constructive trust being imposed in certain circumstances.

In the 2007 Procedure, the obligation to maintain confidentiality will apply except insofar as the Parties have agreed to release such information, the information has become part of the public domain, or disclosure occurs as a result of:

(1) it being required under a Title Document or to a regulatory authority, whether required by Regulations or regarded as appropriate for optimization of the retention of Joint Lands or other lands, provided it does not disclose that information to any third party it holds the other lands with and will request confidentiality protection permitted by the Regulations; ${ }^{250}$ 
(2) it being required by securities laws; ${ }^{251}$

(3) it being provided to employees, officers, directors, and Affiliates; ${ }^{252}$

(4) it being given "to a third party that is a bona fide prospective assignee of any of that Party’s Working Interest ... or a third party with which it is conducting bona fide negotiations directed towards a merger, amalgamation, or sale of shares representing a majority ownership interest of that Party";253

(5) it being provided to "its lenders, legal counsel, auditors, underwriters, financial and other professional advisors"; 254 or

(6) it being required by any legal or administrative proceeding. ${ }^{255}$

Clause 18.01 imposes a further requirement on disclosures made under para. 18.01(d), by stating that they cannot be made unless there is a prior agreement with the applicable third party, which at a minimum provides that the third party will take the appropriate measures to ensure the information is not disclosed by it to any other third party. In addition, new cl. 18 has been added in 2007 and imposes a further restriction on the third party exception by recognizing that a Party who holds proprietary information is not required to disclose that information to other participating parties. Given that such disclosure will often be in the best interest of Operations, cl. 18.02 attempts to encourage the sharing of proprietary information by requiring receiving Parties to agree that it will keep the information confidential in accordance with $\mathrm{cl}$. 18.01, without the benefit of disclosing such proprietary information under paras. 18.01(a) or (d). To emphasize the importance of disclosing this type of information, cl. 18.02 makes reference to disclosing such information pursuant to a confidentiality or licencing agreement.

Despite these restrictions placed on third party transfers, the wording of para. 18.01(d) in the 2007 Procedure provides Parties with greater flexibility to disclose information to third parties than previously allowed under para. 1801(c) of the 1990 Procedure. The third party exception in the 1990 Procedure allowed disclosure "to a third person to which such party has been permitted to assign a portion of its interest hereunder." ${ }^{\text {256 }}$ It has been suggested that the use of the phrase "has been permitted to assign" creates a potential interpretation issue, being that it could either mean: (1) that it applies to a permitted assign under the Procedure who has already been assigned a party's interest; or (2) that it applies to circumstances where a party has been permitted to assign its working interest to a third party, but such assignment has not yet been completed. ${ }^{257}$ Regardless of whether any such ambiguity exists in the 1990 Procedure, the change made to include the language of "prospective assignee" and 
"negotiations" makes it clear that the disclosure of confidential information can occur prior to any transaction or definitive agreement being completed.

Clause 18.03 addresses situations in which a Party is disclosing information for consideration. Notwithstanding cl. 18.01, it requires that any Party that proposes to disclose information (for example, seismic data) to a third party for some form of consideration must notify each other Party of the details of the proposed transaction. Each Party will have 15 days after such notice is received to determine if it approves the proposed disclosure (with any failure to respond being deemed consent). In the event that all Parties consent to the disclosure occurring, each Party shares in the consideration received for that information and any cash consideration received is distributed in proportion to each Party's Working Interest. The changes made to cl. 18.03 in the 2007 Procedure make it clear that a Non-Participating Party with respect to an Operation for which the information proposed for disclosure was obtained will not be regarded as having a proprietary interest in that information and will not be entitled to share in the proceeds of disposition.

Clause 18.04 is new to the 2007 Procedure and corresponds with cl. 18.02 in recognizing that proprietary information does not have to be shared with other Parties. It states that, "[unless] otherwise ... provided in the Head Agreement, nothing [in the Agreement] requires a Party to disclose to any other Party any interpretation developed at its own expense from geological, geophysical or other data held by it.”258 The wording of the first sentence of cl. 1801 in the 1990 Procedure, cl. 18.01 in the 2007 Procedure, and the inclusion of cl. 18.04 in the 2007 Procedure addresses the Court of Queen's Bench ruling in Luscar Ltd. v. Pembina Resources Ltd., ${ }^{259}$ despite the decision being reversed on appeal. In this case, the plaintiffs claimed they were entitled to an equitable remedy because the operator had breached its fiduciary duty when it acquired lands within an area of mutual interest and did not share its proprietary interpretations in respect of that land so that all Parties could pursue the opportunity. The trial judge held that:

\footnotetext{
Pembina never shared Mr. Sluzar's information and geological interpretation with Norcen and/or Luscar even though Mr. Sluzar used information garnered from the operation of the Joint Lands in preparing his interpretation. That information was the property of not only Pembina but also Norcen and Luscar. In my opinion, Pembina had an obligation that was fiduciary in nature to advise Norcen and Luscar fully of the interpretation that had been developed from such information which Pembina, according to evidence, utilized in forming its desire to acquire an interest in the Crown Lands. In my view, Pembina breached this fiduciary duty when it did not inform Norcen and/or Luscar of the interpretation. ${ }^{260}$
}

On appeal, Conrad J.A. stated that the trial judge erred in finding that the geological interpretation was the property of others and that there was a requirement under the contract for the sharing of such information. There was no evidence showing that the sharing of geological information was standard practice or expected. ${ }^{261}$ 
The inclusion of cl. 18.04 in the 2007 Procedure provides greater clarity that Parties do not intend for a fiduciary duty to exist that would require the sharing of geological interpretations developed by an individual Party at its own expense.

Clause 18.06 is also new to the 2007 Procedure. Pursuant to this clause, "[e]ach Party acknowledges that [while the] sharing of information ... is intended to facilitate Joint Operations ... it is not intended to replace or limit independent review or evaluation of that information" received by the Parties. ${ }^{262}$ Absent fraud or deceit, each Party releases the other from any Losses and Liabilities that may be suffered because of the use or reliance on information or materials that were provided to it by another Party, including any evaluations, projections, reports, and interpretive data. As set forth in the Annotations, it is premised on the assumption that Parties will likely have discussions relating to Operations, particularly complex or high-cost projects and notwithstanding the sharing of information, each Party has the ultimate responsibility for its own evaluation of information.

Pursuant to cl. 18.05, a Party will continue to remain bound by this provision and the obligations required of them even after they cease to be a Party, until such time as the information obtained under this Agreement becomes part of the public domain. It is important to note that in addition to the continuing liability for confidentiality, this is the only provision in the 2007 Procedure to which the exclusion of Extraordinary Damages does not apply. As breaches of confidentiality provisions will result largely in indirect losses only, Extraordinary Damages may be claimed for breaches of these contractual provisions. ${ }^{263}$

\section{XiX. Public Announcements}

Article 19.00 is new to the 2007 Procedure and has been included to reflect the increased sensitivity that Parties have to make public releases of information regarding Operations that are conducted under the Procedure. ${ }^{264}$ For the first time, the 2007 Procedure expressly requires that Parties discuss public announcements. It recognizes the need to control the dissemination of information to the public to ensure that public releases made by a Party are not adverse in interest to the other Parties and do not breach the confidentiality requirements of art. 18.00. To facilitate this, subclause 19.01A requires a draft press release or other public announcement be provided by a Party proposing to make such public disclosure at least two Business Days prior to its proposed release, for pre-approval (with approval not to be unreasonably withheld). If a Party objects, it must specify the nature of its objection in reasonable detail and provide suggested modifications to the draft.

Subclause 19.01B creates an additional Operator duty by making it responsible for preparing and releasing all public announcements and releases that are made on behalf of all Working Interest owners. In addition, subclause 19.01B states that an Operator will not be required to obtain pre-approval under subclause 19.01A for public announcements or releases regarding emergencies if it feels that prior approval by Non-Operators is not feasible and it 
limits the release of that confidential information to information that is required to satisfy the regulatory requirements relating to that emergency.

Except as otherwise provided in this provision or in the confidentiality provisions in art. 18.00, subclause 19.01C allows Parties to make public announcements or releases about its involvement in the Agreement or Operations, including disclosure in annual reports or period reports to shareholders and the public. The restrictions on public announcements in subclause 19.01A do not prohibit a Party from making public announcements or releases prior to the expiry of the two-day deadline insofar as they are required by the Regulations, security laws, or stock exchange requirements. The scope of information disclosed in the announcement should be considered carefully by the disclosing Party as only such information as is required by legal or exchange requirements is permitted to be disclosed and any unnecessary disclosure of material, confidential, proprietary, or competitive information may result in liability under arts. 18.00 and 19.00 .

\section{LitigATION}

Article XXV from the 1990 Procedure has been moved to art. 20.00 in the 2007 Procedure. This provision has remained substantially the same insofar as any litigation that affects all of the Parties and is not between the Parties, shall be conducted by the Operator for the Joint Account. In addition, each Party shall notify the other Parties of any process served upon it or that it intends to serve that pertains to any joint matters under the Agreement. The last line pertaining to how a Party may act on its own behalf was revised to provide that "a Party acting on its own behalf may not settle, abandon or otherwise compromise any claim or action being conducted for the Joint Account for its own Working Interest share of that claim or action without the other Parties' written consent, which consent may not be unreasonably withheld.”" 65 This ensures that one Party's individual actions do not detrimentally affect any other Party’s rights with respect to any claim.

\section{Dispute Resolution}

Given the recent trend toward layered dispute resolution mechanisms being included in agreements, the 2007 Procedure has included art. 21.00 as an optional dispute resolution mechanism. The Parties may elect to have the procedure in art. 21.00 apply or not apply; in the latter event, a dispute under paras. 21.03(d)-(i) shall be referred to arbitration under the Arbitration Act. ${ }^{266}$

The first steps in the dispute resolution procedure are negotiation pursuant to subclauses 21.01A and 21.01B and subsequent mediation pursuant to cl. 21.02, subject to an ability to terminate the mediation process. Pursuant to subclause 21.01C, a Party may elect to proceed by notice without engaging in or completing negotiation or mediation to arbitration at any time under cl. 21.03 provided the dispute meets the criteria specified therein. 
Clause 21.03 sets out specific issues for which arbitration may be used as a dispute resolution mechanism. The specific list of issues to be arbitrated under cl. 21.03 does not prevent Parties from agreeing to arbitrate a matter that is not specifically included therein.

\section{NoticE}

Article 22.00 outlines the procedure for how notices are required to be delivered and when notice will be deemed to have been given. The provisions of art. 22.00 of the 2007 Procedure have been revised from the 1990 version to include that notice may not only be delivered personally, but also by private courier to reflect current practices. ${ }^{267}$ In addition, notices may be sent by facsimile or “other electronic medium," if such information is included in a Party's address for service. ${ }^{268}$ This provides the ability to send notices by e-mail if the Parties so choose. The Annotations caution the users to only provide e-mail as a form of acceptable notice where e-mail is checked regularly, including during vacations, to prevent important e-mails being missed. ${ }^{269}$ In addition, if the notices are "important" (for example, right of first refusal (ROFR) notices), personal service or courier should be used to avoid any disputes of proper notice being given. The provision has also been amended to refer to Business Days and the drafting has been improved so that it becomes clearer exactly how a Party should proceed when providing notice. Further, a Party is now under an obligation to notify the other Parties of any address change.

\section{DELinQUent PARTy}

Article XIX of the 1990 Procedure has been moved to art. 23.00 in the 2007 Procedure. The circumstances when a Party will be considered to be a delinquent Party remain the same (not providing notice of address change, not maintaining its legal status, or not responding to communications $)^{270}$ and do not include the failure to make payments, which are dealt with separately under cl. 5.05. Pursuant to cl. 23.02, a delinquent Party is not entitled to any further notices or communications, ${ }^{271}$ is deemed to have elected to not participate in any subsequent proposed Operation, ${ }^{272}$ and is deemed to have elected to participate with the Operator in subsequent farmouts, assignments, surrenders, and Abandonments proposed and effected by the Operator. ${ }^{273}$

Clause 23.02 has been revised to also provide that the Operator is deemed to be the authorized attorney of the delinquent Party for the purpose of executing any documents required to effect the remedies set out in art. 23.00 and the delinquent Party agrees to indemnify the Operator with respect to same. ${ }^{274}$ This Clause also provides the Operator with the ability to commingle the funds it is holding on behalf of the delinquent Party and that has no obligation to provide interest on such funds to the delinquent Party. If a Party remains a 
delinquent Party for 24 months after it receives notice that it is a delinquent Party, the Operator has the ability to assign its interest under the Agreement, any funds, and so on, proportionately to the other Parties under the Agreement. Once such distribution has occurred, the delinquent Party may not restore its status to good standing. Clause 23.03 now requires the Operator to deliver any amounts held by it pursuant to cl. 23.02 to the delinquent Party within 30 days of the delinquent Party restoring its status to good standing. Such revisions should reduce the administrative burden of the Operator and add needed clarity to such processes.

\section{DISPOSITION OF INTEREST}

Similar to the 1990 Procedure, the disposition of interest provision ${ }^{275}$ in the 2007 Procedure seeks to balance the competing objectives of the ability to go to market versus the need for a control on assignments. The changes to this provision were designed to improve the certainty of the provision and structure the "ROFR provision on the assumption that only parties that were serious about attaching the obligation to their interest would include a ROFR.”276

The basic format of the disposition of interest provision also remains the same, as it still provides negotiators with a choice between two optional requirements triggered by a disposition: (1) obtaining the Parties' consent, not to be unreasonably withheld; and (2) granting the ROFR.

The key changes to art. 24.00 in the 2007 Procedure involve the following:

(1) treatment of Earning Agreements;

(2) consent provisions;

(3) limit on the time period of the ROFR;

(4) exceptions to the ROFR; and

(5) incorporation of the Assignment Procedure.

\section{A. Treatment of EARNing AgreEMENTS}

The 2007 Procedure has included a definition of Earning Agreements as follows:

“Earning Agreement” means a farmout or like agreement between a Party and another Party or a third party, the substance of which is that the other Party or third party has the right, obligation or option to acquire a Working Interest in the Joint Lands (and possibly interests in other petroleum and natural gas rights) in return 
for the conduct of certain operations on the Joint Lands or other lands. A transaction for which all or a portion of the consideration for that acquisition is cash (other than for any reimbursement of rentals or other land maintenance costs or a bona fide fee for access to certain proprietary seismic data) or the exchange of another property is not an Earning Agreement. ${ }^{277}$

The execution of an Earning Agreement is now expressly deemed a "disposition" under cl. 24.01 of the 2007 Procedure regardless of if and when a Working Interest is or may be earned. While the 1990 Procedure improved upon the 1981 Procedure by including the undefined concept of "farmout agreements" within the disposition provisions, it did not provide clarification as to whether a disposition pursuant to these provisions occurred at the time of execution of the agreement or at the time of earning. The 2007 Procedure has been amended to make it clear that the disposition occurs at the time of execution for purposes of issuance of any notice required under cl. 24.01 or any determination under cl. 24.02.

The Annotations explain that one of the reasons Earning Agreements are deemed a disposition as of their execution date is that once a farmor enters into these types of agreements, it generally does not control whether the interest will be earned by its farmee. Control has usually been transferred to the farmee during the earning phase. In addition, this treatment forces the other Parties to make their decision to consent to the disposition or exercise their ROFR, as applicable, at the beginning of such process and not after earning with the potential benefit of cost certainty, data resulting from the work (that is, seismic and drilling programs), and knowledge of the success or failure of the work. ${ }^{278}$

The 2007 Alberta Court of Queen's Bench decision in Canadian Natural Resources Ltd. v. Encana Oil \& Gas Partnership ${ }^{279}$ touched upon the issue of whether a ROFR notice needs to be issued when a farmout agreement is executed or whether it can be issued later in the event that the ROFR becomes applicable. In this case, the subject farmout agreement contained joint lands that were subject to the ROFR as well as additional lands that were not subject to the ROFR. The farmee had the option to select where it wanted to drill its earning wells and thus, which lands would be affected. The Court held that the ROFR notice did not need to be issued until such time as the farmee elected to drill a well on the joint lands. The 2007 Procedure would have the effect of changing this requirement and requiring the ROFR notice to be issued at the time of execution of the farmout agreement.

Further, the confusion under the previous Procedures as to when a disposition actually occurs and the possibility it does not occur until an interest is earned by the farmee

potentially places the farmor and farmee at some risk where there is a material delay between expiry of the ROFR period and the time the applicable rights are earned under the farmout, particularly when the 1974 or 1981 document applies or during a period of volatile pricing conditions. 
A prudent farmor should modify its ROFR notice so that the receiving parties are also asked to waive the time periods prescribed in the Operating Procedure for completion of the disposition, to reflect the logistics of the earning cycle. ${ }^{280}$

Negotiating parties should consider whether the 150-day completion period in para. 24.01B(h) should be expressly waived with respect to a disposition by way of an Earning Agreement, provided that earning occurs thereunder in accordance with the earning terms of such Earning Agreement as of the date of such notice (that is, unamended).

\section{B. Consent Provisions - Subclause 24.01A}

Under Alternate A, consent is required for a disposition, but such consent may not be unreasonably withheld. The broad basis under which it is considered reasonable to withhold consent remains that the disposition is likely to have a material adverse effect on the nondisposing Party. Although not restricted to such circumstance, the only specifically referenced example of a reasonable circumstance to withhold consent in the 1990 Procedure is the inability of the proposed assignee to meet financial obligations under the Head Agreement. ${ }^{281}$ The 2007 Procedure also expressly provides that it shall be reasonable to withhold consent if the disposing Party is subject to a bona fide notice of default under the Agreement and the assignment could adversely affect the recovery of amounts owing by such disposing Party.

The 2007 Procedure provides that any notice from which a non-disposing Party is withholding its consent must include the basis for which its consent is being withheld. This requirement should encourage Parties to be cautious when choosing to withhold consent and help ensure there are legitimate reasons for the same.

\section{Right OF FIRST REFUSAL - SUBCLAUSE 24.01B}

As noted, the Annotations indicate that the objective of the revisions to the ROFR provision is to ensure that this option is selected with considered forethought and not merely as a default as may have become the practice of some negotiators:

While some companies still insist on a ROFR as their standard election, most are more selective about when they require a ROFR. Those companies now generally prefer to use them for significant agreements within a core area and potential high-risk, high-reward projects, rather than for minor value properties. ${ }^{282}$

The Annotations explain that the use of the ROFR election has declined since the early 1990s because of the number of acquisitions and divestitures that occur and the practical realization that "each Party is probably a seller at some point during the asset life cycle.”283 $<$ http://www.landman.ca/publications/Negotiator/2007/march/mar07_layout.pdf > [MacLean, "ROFR - Part II"]. 
Even where Alternate B is elected, art. 24.00 is designed to "narrow the potential application of the [ROFR] Alternate when selected,"284 particularly when the disposition is part of a larger deal. Accordingly, many of the revisions contained in the 2007 Procedure are designed to limit the application of ROFRs.

\section{TIME LiMIT ON RIGHT OF FIRST REFUSAL - PARAgRAPH 24.01B(A)}

New to the 2007 Procedure is an expiry date on the duration of the ROFR provision. The addition of an expiry date is a recognition that while the Parties may want the ability to control dispositions and potential assignees during the initial stages of a project that has sensitivities to such ownership changes, they may wish to recognize that such sensitivities will dissipate as the project advances so that eventually a ROFR is no longer needed. ${ }^{285}$ This provision should reduce the number of long-term ROFRs and help to facilitate acquisition and divestiture transactions. If Parties wish the duration of the ROFR to last for an extended period of time, they can choose a time in the distant future for the ROFR expiry period. Upon the expiry of the specified ROFR period, the ROFR option (Alternate B) will no longer apply and the consent option (Alternate A) will apply.

With the use of an expiry date mechanism, additional certainty is required as to when a ROFR is triggered. In the case of Hanen $v$. Cartwright, ${ }^{286}$ one of the parties to an agreement which contained a reciprocal time-limited ROFR entered into an option agreement with a third party with an option exercise date after expiry of the ROFR. The Alberta Court of Queen's Bench held that the triggering event for the ROFR was not completion of the sale, but when the bona fide offer was made that the disposing party was willing to accept. ${ }^{287}$ Alternate $\mathrm{B}(\mathrm{a})$ is clear that the ROFR will apply to any disposition that a party intends to make that is either effective or for which an agreement is completed prior to the specified ROFR expiry date.

\section{E. Purchase And Sale Agreements}

As noted in the Annotations, many commentators encourage the Disposing Party to include a copy of the purchase and sale agreement with the Disposition Notice. ${ }^{288}$ The rationale for this is to ensure that the Offeree can fully evaluate whether it wants to exercise the ROFR on the same terms and thereby minimize the risk of objection due to nondisclosure of such terms and to facilitate the finalization of such agreement if the Offeree does exercise its ROFR. It is recommended practice that the Disposing Party and the proposed assignee ensure that the purchase and sale agreement is final before issuing the

\footnotetext{
284 Ibid.

285 MacLean, “ROFR — Part I,” supra note 276 at 11.

2862007 ABQB 184, 71 Alta. L.R. (4th) 284, aff'd 2007 ABCA 388, 422 A.R. 218.

$287 \quad$ Ibid. at para. 37.

$288 \quad$ Supra note 4 at para. 24.01B(b); Annotations, supra note 6 at 54.
} 
Disposition Notice. Among other concerns, a mere draft form of agreement exposes the notice to challenge and may put completion of the proposed transaction at risk. ${ }^{289}$

\section{F. Non-CASH Consideration - PARAgraPh 24.01B(C)}

Where the consideration for the subject matter of the ROFR is not cash, the 1990 Procedure does not require the disposing party to provide a cash value equivalent in the ROFR notice. Where such estimate is not provided, the Offeree can provide notice requiring the disposing party's bona fide estimate of the cash value of such consideration in which case the response period to the original ROFR notice shall be suspended. Because such failure to provide the estimate of cash value equivalent could result in suspending the notice period for a ROFR notice, it has become recommended practice for a disposing party to include such estimate in its notice. The 2007 Procedure now reflects this practice in non-cash transactions and requires the Disposing Party to provide its bona fide estimate of value, in cash, from the outset. In addition, if the proposed disposition includes assets in addition to the Working Interest, the cash value allocated to such Working Interest must be included in the Disposition Notice.

\section{G. VAlue OF Right OF First Refusal — PARAgraph 24.01B(D)}

Where an Earning Agreement only applies to Joint Lands (and no other lands), "[t]he Disposing Party will offer the Offerees the opportunity to assume the entire obligations of the proposed assignee.”290 The 2007 Procedure has added a provision to deal with the difficult circumstance of an Earning Agreement that pertains to both Joint Lands and other lands. In these circumstances (and assuming none of the cl. 24.02 exceptions apply), the Disposing Party has two options:

(1) Provide a bona fide estimate of value, in cash, attributed solely to the Working Interest in the Joint Lands to be disposed of pursuant to such Earning Agreement; or

(2) Offer to "the Offeree the opportunity to assume the entire obligations of the proposed assignee under [the] Earning Agreement” in respect of all lands subject thereto. ${ }^{291}$

If used, the latter option effectively provides the Offeree the right to "match the deal" in both Joint Lands and other lands. Although contrary to the objective of limiting ROFRs insofar as it expands the application of ROFRs to other lands, this addition allows the

In CNRL, supra note 279, EnCana Oil \& Gas Partnership (EnCana) issued a ROFR notice to Canadian Natural Resources Limited (CNRL) under the terms of the 1990 Procedure and CNRL elected to exercise its ROFR pursuant to such notice. Subsequently, CNRL tried to vary the terms upon which it exercised its ROFR. The Court held that CNRL was obligated to abide by the terms in which it accepted its ROFR because the notice becomes a binding contract once the ROFR is exercised (at para. 53). This decision demonstrates the importance of ensuring that a ROFR notice includes all material terms and that such terms are final, as it can create the basis for the new agreement between the Disposing Party and the Offeree. 
Disposing Party to ensure that it is kept in the same position whether the ROFR is exercised or not. However:

The disposing party should consult with its proposed assignee if it is considering the second option, and it would also need to understand any ROFR issues under other agreements associated with use of that option.

Our expectation is that the proposed assignee will prefer that the broader option only be used if the Joint Lands comprise the most prospective lands included in an Earning Agreement. The less significant the Joint Lands are to the overall transaction, the more likely a farmee would insist that its farmor not offer the broader right to the transaction. ${ }^{292}$

\section{H. VALUE OF Right OF First REFUSAL - PARAgRAPH 24.01B(E)}

Paragraph 24.01B(e) of the 2007 Procedure provides that the Offeree has seven Business Days to object to the Disposing Party's bona fide estimate of the cash value or allocated cash value attributed to the assets subject to the ROFR. A failure to object to the value within this prescribed period precludes the Offeree from challenging the value at a later time. This revision provides greater certainty than the 1990 Procedure by its express application to both allocations of value where the Disposing Party allocates cash consideration between ROFR and non-ROFR assets and to estimates of the cash value of non-cash consideration. This clause should prevent the Offeree from waiting until the ROFR period has almost expired to then decide to challenge values and thereby attempt to frustrate or delay the sale process.

\section{Right OF FiRst REFUSAL EXCEPTIONS TO BE BONA FIDE}

Each of the exceptions contained in cl. 24.02 now expressly require that a disposition, for which an exception is being relied upon, must be bona fide in order for the exception to apply. This specifically incorporates a duty of good faith ${ }^{293}$ and the common law principle that a party cannot do indirectly what it is prevented from doing directly:

Parties that manipulate their transaction to defeat a ROFR held by the other parties should rethink their approach, as they are playing with fire.

The law in Alberta is very clear that there is an implied duty of good faith under ROFR provisions. In GATX Corp. v. Hawker Siddely Canada Inc., [1996] O.J. No. 1462 (Ont. C.J.), the Court stated: "It is well established that the grantor of a right of first refusal must act reasonably and in good faith in relation to that right, and must not act in a fashion designed to eviscerate the very right which has been given.” This implied duty of good faith was also recognized at Trial and the Court of Appeal in Chase Manhattan Bank of Canada v. Sunoma Energy Corp., [2001] A. J. No. 245 (Alta. Q.B.), affirmed [2002] A.J. No. 1550 (Alta., C.A.). The

292 MacLean, “ROFR - Part II,” supra note 280 at 6.

293 Justice Kenny implies that the Parties have a duty of good faith towards each other when dealing with ROFRs in the CNRL case, supra note 279, when she states the following at para. 52: "Encana has done nothing which would breach its obligations of reasonableness and good faith.” However, this case does not directly deal with the concept of whether a duty of good faith is owed by the Parties to each other under the 1990 Procedure. 
Court's endorsement of this principle has major legal implications for the manner in which parties choose to manage their ROFR obligations. ${ }^{294}$

A common example of where a Party may be seen as attempting to do indirectly what it cannot do directly and not complying with the bona fide obligation is structuring an asset transaction as a share transaction by dropping certain assets into an affiliated company and then selling the shares of such company for the primary purpose of avoiding a ROFR. If, however, a Party has as its primary objective a bona fide reason (other than avoiding the ROFR) for structuring its transaction in a certain manner where doing so avoids the triggering of the ROFR, then it should be protected from successful challenge to the disposition on these grounds. However, it is not certain how a court would react if the evidence indicated that one of the reasons for the structure was to avoid the triggering of a ROFR, although such reason may be accompanied by other bona fide reasons:

[I]f the transaction has a legitimate business purpose, and if, in appropriate circumstances, there is at least a meaningful period of time between the effecting of the corporate reorganization and the sale of the shares of the resulting subsidiary whose assets are encumbered by a ROFR, the transaction should not be found to have violated the ROFR provision and may have also satisfied applicable tax requirements. In this context, the "behaviour" of the purchaser of the shares of the resulting subsidiary may also be relevant to the question of the bona fides associated with the particular transaction. ${ }^{295}$

The Annotations caution users that:

A Party that does not comply with a right of first refusal obligation faces the risk that a Court could order specific performance if the acquiring party knew or should have known that there was a ROFR. See, for example, Canadian Long Island Petroleums Ltd. et al. v. Irving Industries (Irving Wire Products Division) Ltd. et al., [1974] 6 W.W.R. 385 (S.C.C.), affirming, [1973] 5 W.W.R. 99 (Alta. S.C., App. Div.), in which it was clear that the assignee was aware of the ROFR. Since that decision, Alberta has amended The Law of Property Act to address a right of first refusal. Section 63 provides that a right of first refusal is an equitable interest in land and may be registered under that Act (application limited to freehold). The common law cases on priority now apply to registrable rights of first refusal in Alberta. The failure to file a caveat protecting a right of first refusal had a negative impact on the offerees in Calcrude Oils Ltd. v. Langevin Resources, [2003] A. J. No. 1575 (Alta. Q.B.). ${ }^{296}$

\section{J. AfFiliate EXCEPTION — PARAgRAPH 24.02(B)}

The 1990 Procedure contains an exception where a Disposing Party is disposing of an interest in return for shares of the receiving corporation or a partnership interest in the receiving partnership. ${ }^{297}$ The 2007 Procedure does not include this exception due to the potential for it to be abused; however, the 2007 Procedure still provides that a disposition to an Affiliate is an exception to the ROFR provision.

MacLean, "ROFR — Part I," supra note 276 at 12.

Clifford D. Johnson \& David J. Stanford, "Rights of First Refusal in Oil and Gas Transactions: A Progressive Analysis” (1999) 37 Alta. L. Rev. 316 at 325.

Annotations, supra note 6 at A-5.

Supra note 3 at para. 2402(b). 


\section{K. All or Substantially All Exception - Paragraph 24.02(C)}

The 2007 Procedure provides further clarification on when the "all or substantially all” exception can be applied. The exception has been revised to provide that it only applies if the disposition is done in a single transaction, although it may apply to multi-party assignees assuming the bona fide test is met (which include an Earning Agreement where multiple parties may earn). Accordingly, this ROFR exception may not be used for multiple transactions to different assignees even if all or substantially all of the assets of the Disposing Party are being sold. The 2007 Procedure does, however, allow the exception to apply where the disposition is to the same proposed assignee under multiple transactions on the same date. This will allow some flexibility for tax or other structuring as part of the transaction without triggering ROFRs. The minimum disposition threshold of 90 percent of the Disposing Party's net hectares of petroleum and natural gas rights for what is considered "all or substantially all” is retained in the 2007 Procedure and this exception still applies on a particular province, territory, or state basis.

\section{Total Net Hectare EXCEPTION - PARAgRAPH 24.02(D)}

The 1981 and 1990 Procedures provide an exception for a disposition in which the net hectares being disposed of in the Joint Lands represent less than 5 percent of total net hectares being disposed of in the transaction. ${ }^{298}$ This 5 percent exception has been increased to 10 percent in the 2007 Procedure in order to decrease the impact of the ROFR provision on larger scale transactions on the rationale that a larger transaction should not be impeded due to a ROFR that applies to a small percentage of the transaction lands. Earning Agreements are specifically excluded from this exception as a new exception has been included that applies specifically to Earning Agreements.

The Annotations explain that the addition of the bona fide requirement should prevent a Party from including unrelated expiring acreage in a transaction for the sole purpose of bringing the transaction within the 10 percent amount. ${ }^{299}$ Nonetheless, it may be very difficult for a Party to prove that the inclusion of lands in a sale was for the purpose of avoiding a ROFR, as such Party will not likely be provided with information from the Disposing Party which would allow it to determine if expiring lands were included in the sale and even with such evidence, it would have to prove that the inclusion of same was intended to defeat the ROFR. However, it should be noted that there is nothing preventing a Party from asking for evidence confirming that the exception properly applies. In the right circumstances, it may be able to win relief from a court allowing it access to such information.

\section{EARning Agreement Hectare EXCEPTION — PARAgraph 24.02(E)}

The 2007 Procedure provides an exception for an arm's-length disposition by a Party pursuant to an Earning Agreement, pursuant to which the net hectares of Joint Lands that can be earned represent less than 35 percent of the total net hectares that can potentially be earned thereunder. The objective of this additional exception is to reduce the potential 
application of ROFRs to larger scale Earning Agreements. This exception should result in fewer Earning Agreements being caught by ROFRs. ${ }^{300}$

\section{N. OPTIONAL EXCEPTION - EARNING AgREEMENTS - PARAgraph 24.02(F)}

The 2007 Procedure provides an additional optional exception to the ROFR. The Parties may simply choose to have ROFRs not apply to a right to earn under an arm's-length Earning Agreement. This provides the ability of a Party to farmout its Working Interest without having to comply with a ROFR ${ }^{301}$ and may have the indirect benefit of encouraging development of Joint Lands by facilitating third party farmouts.

\section{O. NOTICE OF EXCEPTION}

The requirement in the 1990 Procedure that a disposing party relying on a ROFR exception must still notify the other Parties of such disposition has been carried forward in the 2007 Procedure with the additional requirement that the notice must also include the basis by which such Party has determined that the exception applies. ${ }^{302}$

\section{P. Incorporation of Canadian Association of Petroleum LANDMen Assignment Procedure — Clause 24.04}

The 2007 Procedure has incorporated the 1993 CAPL Assignment Procedure ${ }^{303}$ (or its most current replacement), which shall apply to all dispositions under art. 24.00 (subject to permitted dispositions in cl. 24.02). Most industry participants have already agreed to be governed by the 1993 CAPL Assignment Procedure with respect to existing operating agreements and will be familiar with such process. However, subclause 24.04B of the 2007 Procedure provides clarification of how to properly serve a notice of assignment. Where separate agreements are deemed created under cl. 13.01 (Segregation of Joint Lands), notices of assignment may be served only on the Parties holding an interest in the Joint Lands to which the notice of assignment pertains. Alternatively, to avoid a proliferation of assignment documentation, the assigning Party may instead serve a single notice under one or more segregated agreements if: (1) a disposition covers all Joint Lands in which that Party has an interest; or (2) such "Party identifies clearly in the notice of assignment each portion of the Joint Lands covered by those separate agreements to which that notice of assignment pertains and the interest being assigned in each such block." ${ }^{304}$ The Annotations explain that the latter notice of assignment would list all third parties having interests in any of the applicable segregated blocks, even if the third parties or their interests differed between the segregated blocks. ${ }^{305}$ This subclause allows the assigning Party to list in the notice of assignment any third party that holds an interest in any segregated block to which the notice of assignment

MacLean, "ROFR — Part II," supra note 280 at 7.

Annotations, supra note 6 at 56.

Supra note 4, cl. 24.02.

Supra note 24.

Supra note 4, subclause 24.04B.

Annotations, supra note 6 at 56. 
pertains. It is designed to ensure that a Party will not have grounds to reject a notice of assignment because the third parties do not have consistent interests in all of the blocks to which the notice of assignment pertains. ${ }^{306}$

\section{Miscellaneous Provisions}

Articles 1.00 and 25.00 contain numerous important provisions that should not be overlooked by users of the 2007 Procedure and include the following matters.

\section{A. Contra Proferentem}

Subclause 1.02B has been added to the 2007 Procedure and provides that the Agreement will be interpreted as if the Parties participated equally in its drafting and that the rule of contra proferentem shall not apply. ${ }^{307}$

\section{B. NO PARTNERSHIP OR FIDUCIARY RELATIONSHIP}

As discussed under Part V above, cl. 1.05 contains the provision formerly included in cl. 1501 of the 1990 Procedure. Its purpose is to deem that the Parties hold their interests as tenants in common, their obligations and liabilities are separate and not joint or collective or joint and several, and that no partnership, association, partnership duty, obligation, or liability exists or is created thereunder. In addition, cl. 1.05 provides that there is not any trust, trust duty, or fiduciary relationship between them except as provided for: (1) the commingling of funds; (2) the distribution of proceeds of sale of Petroleum Substances; and (3) the obligation to keep information confidential. ${ }^{308}$ Notwithstanding the foregoing, cl. 1.05 contains a statement that the Parties recognize that such agreement may not be effective to prevent a trust, trust duty, or fiduciary relationship from being imposed at law or in equity ${ }^{309}$ and that such statement is not intended to lessen any duty of good faith that may otherwise apply to them at law or in equity. ${ }^{310}$ In addition, subclause $1.05 \mathrm{~B}$ contains a statement to the effect that the Parties are in competition with each other and as such, nothing in the agreement restricts a Party from making elections or decisions in what it perceives to be in its own interest, economic or otherwise, subject to: (1) any trust, trust duty, or fiduciary relationship imposed at law or in equity; (2) any duty of good faith contemplated in subclause 1.05A; and (3) the other provisions of the Procedure. Subclause 1.05C further provides that the Operator will not have any additional obligation in contract, at law, or in equity to either Party thereunder for lands other than the Joint Lands or to apply knowledge or information it otherwise obtains about lands other than the Joint Lands in order to propose any Joint Operation or to take or refrain from taking any action under the Procedure.

$\begin{array}{ll}306 & \text { Ibid. } \\ 307 & \text { Ibid. at 6. } \\ 308 & \text { Supra note 4, subclause 1.05A. } \\ 309 & \text { Ibid. at para. 1.05A(a). } \\ 310 & \text { Ibid. at para. 1.05A(b). }\end{array}$




\section{GOVERNING LAW}

The governing law provision has been moved to cl. 1.06 in the 2007 Procedure and has been revised to state that the laws of Alberta and federal laws of Canada applicable therein shall govern regardless of where the Parties or lands are located. The Annotations state that Alberta was designated as the governing law for two reasons: (1) usually the head offices of the Parties are located in Calgary; and (2) Alberta has more extensive oil and gas case law than any other province. ${ }^{311}$ Nonetheless, the Parties should consider amending the governing law to another jurisdiction if there is no connection to Alberta.

\section{EXTENSiOn OF Alberta Limitations ACT}

Clause 1.07 includes a new provision providing for an extension of the two-year limitation period under s. 3(1)(a) of the Limitations Act: ${ }^{312}$ (1) for claims disclosed by an audit, the limitation period shall be two years after expiry of the time the Procedure permitted such audit to be performed; and (2) for all other claims, the limitation period shall be four years.

\section{E. TERM}

Clause 1.14 clarifies that the term will continue for so long as may be necessary to: "(i) Abandon all wells ... and all Production Facilities; (ii) salvage all equipment relating thereto; and (iii) complete a final settlement of accounts ... whichever last occurs." 313 Notwithstanding the foregoing,

(a) the confidentiality obligations prescribed by Article 18.00 will continue to apply ... until that information is no longer subject to those confidentiality obligations; and

(b) those provisions related ... to audit, liability, indemnity, disposal and salvage of material, Abandonment, responsibility for Environmental Liabilities and enforcement on default will survive ... [for as long as] the Operator ... has rights or obligations with respect to the applicable matter under the Regulations. ${ }^{314}$

\section{F. Modifications to Canadian Association of Petroleum LANDMEN DOCUMENT FORM}

As the 2007 Procedure is expected to be customized more frequently and more extensively than earlier versions of the Procedure, cl. 1.15 should be noted. Clause 1.15 requires that modifications of the Procedure occur by way of completion of the blanks and elections required therein and by those other changes specifically identified therein, in the Head Agreement, or in a Schedule of elections and amendments to the Procedure. Any other modification will be deemed ineffective. 


\title{
G. ENUREMENT
}

The enurement clause (cl. 25.03) has been amended to add that the Agreement will not only enure to the successors and permitted assignees, but that it will also enure to the benefit of the trustees, receivers, and receiver-managers. This will facilitate the sale of assets in receiver situations and hopefully provide for an easier transfer process.

\section{H. HOLDINGS AND OWNERSHIP}

The Regulations governing mineral rights and Spacing Units in Alberta provide that in order to have a "holding," a common ownership requirement must be met. ${ }^{315}$ If there ceases to be common ownership in the Spacing Unit subject to a holding, the Board reserves the discretion to terminate such holding. A new provision, cl. 25.06, addresses this as follows:

\begin{abstract}
If a portion of the Joint Lands is subject to a holding or other similar order under the Regulations that is designed to facilitate production from the same formation(s) in multiple wells within areas of common ownership and the Parties' Working Interests in the Joint Lands become inconsistent within that area of common ownership, the Parties' intention is that such holding or similar order will remaining in full force and effect, subject o any order to the contrary under the Regulations. Each Party holding a Working Interest in the applicable Joint Lands subject to that holding or similar order agrees that it will not use the change of ownership as a basis under the Regulations to file: (i) any objection to that holding or similar order; (ii) any application to terminate it; or (iii) any application to modify the allocation of Petroleum Substances thereunder. $^{316}$
\end{abstract}

This provision is based on the premise "that the Board is unlikely to be concerned as long as the 'well density,' and 'buffer,' and 'interwell' distance requirements under the holding are still being satisfied.”317

\section{CONFLICT OF INTEREST}

A conflict of interest provision has also been added at cl. 25.07, which prevents Parties from conferring or receiving an economic advantage or any benefit from representatives of any other Party, supplier of goods or services, representative of government authority, or any person seeking political office. This provision is intended to prevent conflicts of interest under corporate compliance policies ${ }^{318}$ and ensure compliance with applicable regulations. ${ }^{319}$

\section{CONCLUSION}

The 2007 Procedure represents a significant step forward in the evolution of the CAPL Operating Procedure. Improvements have been made to the document in terms of its organization, drafting, legal certainty, and comprehensiveness. This version of the Procedure

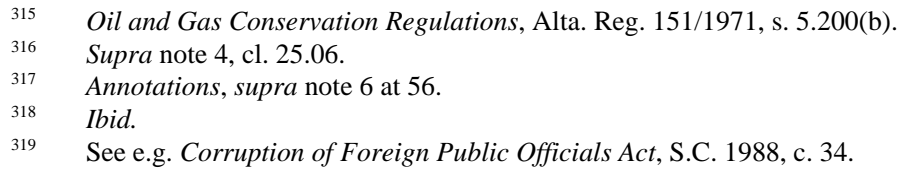


is characterized by the Drafting Committee's desire to move from the "standard-based" approach of earlier versions to a "norm-based" approach. Specifically, while the model form will be suitable in the vast majority of situations, there is recognition that a single standard document with universally applied provisions is no longer feasible or preferable for joint operating arrangements in all circumstances in the WCSB. Accordingly, the Drafting Committee has encouraged users to become familiar with the 2007 Procedure with a view to enlightening them as to the benefits, in the right circumstances, of more frequent and extensive customization and negotiation of such Procedure than has been the case with earlier versions. Industry participants that adopt and utilize the Procedure will find a significantly improved document, albeit a more complex one. Nonetheless, users that take the time to become familiar with the new Procedure and incorporate it in their joint venturing will benefit from working from a superior document and will gain a greater understanding of all versions of the Procedure. 


\section{APPENDix A}

\section{Health, SAfety And The EnVIRonment Common LAw Liability}

There are four common law causes of action most commonly applied for environmental liability: nuisance, strict liability, trespass, and negligence. A Non-Operator could have greater exposure to nuisance, strict liability, and trespass if no action is taken by the NonOperator to stop the environmental contravention despite increased knowledge. A NonOperator could also become directly liable under negligence. Negligence is established if a duty of care is owed to a third party and the defendant's acts or omissions constitute a breach of that duty that results in damages from the breach. Foreseeability and proximity are required to establish a duty of care. Because an audit, inspection, or receipt of information that reveals deficiencies creates foreseeability, a duty would then be owed to all proximate third parties. Accordingly, liability for negligence could be placed on a Non-Operator for having knowledge of hazards and breaching the duty to warn or otherwise take preventative action which then results in damage. Similarly, a negligence action could also be made against the Non-Operator in relation to HSE concerns on the work site if the Non-Operator becomes aware, or should have become aware, of a health and safety concern and breached its duty to take the appropriate care.

The remedy for causes of action in tort is typically damages with the intention of restoring the plaintiff to the same position had the tort not been committed. While not typically granted, if negligent conduct is part of a deliberate course of conduct directed against the plaintiff, the court may grant exemplary damages.

\section{Health, SAFety And The EnVIronment Statutory LIABILITY — ENVIRONMENTAL LEGISLATION}

Environmental matters are regulated in Canada and each province by various statutes, each of which takes a different approach to regulatory offences from express fault requirements to strict liability. The key environmental federal statute is the Canadian Environmental Protection Act, 1999. ${ }^{320}$ Section 274 of the CEPA contains an express fault requirement which states that a person is guilty of an offence and liable to a fine (minimum fines are CDN\$300,000) or to imprisonment of not more than five years if they "(a) intentionally or recklessly [cause] a disaster that results in a loss of the use of the environment; or (b) [show] wanton or reckless disregard for the lives or safety of other persons and thereby [cause] a risk of death or harm to another person." ${ }^{321}$ A person acts recklessly if he or she becomes aware of the risk of prohibited conduct and does not do anything about it. It is possible that a Non-Operator could be considered to be acting "recklessly" and become liable under the CEPA if the Non-Operator either chooses not to investigate a possible HSE issue or becomes aware of such an issue through the audit process or otherwise and does not do anything about it. 
In Alberta, while environmental protection for the oil and gas industry is regulated by the Energy Resources Conservation Act, ${ }^{322}$ the Oil and Gas Conservation Act, ${ }^{323}$ and the Pipeline $A c t,{ }^{324}$ it is mainly regulated by the Environmental Protection and Enhancement Act, ${ }^{325}$ which deals with spills and leaks, contaminated sites, and reclamation. Under the EPEA, offences are strict liability, which means that the Crown must only prove beyond a reasonable doubt that the offence occurred to shift the onus onto the defendant to establish a due diligence defence. Depending upon the offence, a corporation can be subject to fines of up to CDN\$1 million and an individual can be subject to fines of up to $\$ 100,000$ and/or imprisonment for a period of not more than two years. Administrative penalties are also possible. The EPEA imparts liability for contraventions of the Act as well as knowledge of contraventions of the Act and applies the concept of "person responsible” for many sections dealing with contraventions. Pursuant to s. 1 , a person responsible includes every person who has or has had charge, management, or control of the substance or thing. Section 229 provides a due diligence defence: if it is established "on a balance of probabilities that the person took all reasonable steps to prevent [the offence's] commission,"326 then that person will not be convicted of an offence under a number of sections of the EPEA. Arguably, subclause 3.05E of the 2007 Procedure makes a Non-Operator a "person responsible" by increasing the Non-Operator's control over HSE compliance. If a Non-Operator is aware of a deficiency or potential deficiency and does not act, subclause 3.05E could potentially negate the due diligence defence as it can no longer be said that "all reasonable steps were taken to prevent its commission."

Subclause 3.05E could also create personal responsibility for directors and officers of Non-Operators. Under both s. 280 of the CEPA and s. 232 of the EPEA, officers and directors are held responsible for offences committed by the corporation if the officers or directors directed, authorized, assented to, acquiesced in, or participated in the commission of the offence, and can be liable whether or not the corporation has been prosecuted or convicted.

\section{HEALTh, SAFETy AND THE ENVIRONMENT STATUTORY LIABILITY - OCCUPATIONAL HEALTH AND SAFETy LEgisLATION}

Section 2 of the Occupational Health and Safety Act, ${ }^{327}$ makes it an obligation of every employer to ensure the health and safety of “(i) the workers engaged in the work of that employer, and (ii) those workers not engaged in the work of that employer but present at the work site at which that work is being carried out." 328 The OHSA also introduces the concept of a "prime contractor" in s. 3 if there are more than two employers on a work site. It places responsibility for compliance with the OHSA and its regulations at the work site with this party. ${ }^{329}$ The prime contractor is either determined by agreement, or if there is no agreement,

$\begin{array}{ll}322 & \text { R.S.A. 2000, c. E-10. } \\ 323 & \text { R.S.A. 2000, c. O-6. } \\ 324 & \text { R.S.A. 2000, c. P-15. } \\ 325 & \text { R.S.A. 2000, c. E-12 [EPEA]. } \\ 326 & \text { Ibid., s. 229. } \\ 327 & \text { R.S.A. 2000, c. O-2 [OHSA]. } \\ 328 & \text { Ibid., s. 2. } \\ 329 & \text { Ibid., s. 3. }\end{array}$


is the owner of the work site. While not specified, and as both parties are owners, an argument could be made that the Operator would be considered the prime contractor as it is largely responsible for Operations in respect of the project. However, identification of the prime contractor does not absolve the other employers/owners from liability for HSE noncompliance. Each employer still has a duty to ensure the health and safety of workers engaged at the work site, and every owner can still be liable for OHSA compliance. The penalties for contravention of the OHSA include, for a first offence, fines of not more than CDN\$500,000, a further fine of not more than $\$ 30,000$ for each day afterward, and imprisonment for a term not exceeding six months. For a second or subsequent offence, the fines increase to not more than $\$ 1$ million and $\$ 60,000$ each day it continues afterward, and imprisonment for a term not exceeding 12 months.

The OHSA is also a strict liability statute, requiring the Crown to prove commission of the act to shift the onus onto the defendant to establish due diligence. Three factors are considered in a due diligence defence: foreseeability, preventability, and control. Subclause 3.05E increases all three factors for the Non-Operator: greater foreseeability of issues, greater ability to prevent contraventions from commencing and continuing, and greater control over HSE compliance by ensuring the Operator so complies or by replacing a non-compliant Operator. If a Non-Operator does not ensure a deficiency is remedied following an audit or chooses not to undertake an audit when there is some indication of HSE issues, the NonOperator may lose any due diligence defence they may have otherwise had.

Criminal sanctions are also possible under the Criminal Code. ${ }^{330}$ Section 217.1 creates a legal duty for those who direct the work of others to ensure safety in the workplace and liability in negligence if the duty is not satisfied. The Criminal Code requires everyone who undertakes work, or has authority to direct the work of another person, to take reasonable steps to prevent bodily harm that may arise from that work. Section 221 provides that if bodily harm is caused by criminal negligence, the penalty is imprisonment for a term not exceeding ten years. Pursuant to s. 220, criminal negligence causing death carries a possible life sentence. "Everyone is criminally negligent who: (a) in doing anything, or (b) in omitting to do anything that it is his duty to do, shows wanton or reckless disregard for the lives or safety of other persons." ${ }^{331}$ As discussed above, recklessness is becoming aware of a hazardous situation and choosing not to act. The standard required to satisfy the legal duty under s. 217.1 is "reasonable steps" to be taken to prevent bodily harm. Arguably, subclause 3.05E of the 2007 Procedure increases a Non-Operator's responsibility to ensure "reasonable steps" are taken and possibly exposes it to criminal sanctions if someone becomes injured or dies on the work site. 